Gustavo Haralampidou da Costa Vieira

Biólogo

\title{
ANÁLISE FAUNÍSTICA DE ABELHAS (HYMENOPTERA: APOIDEA) E TIPIFICAÇÃO DOS MÉIS PRODUZIDOS POR APIS MELLIFERA L., EM ÁREA DE CERRADO NO MUNICÍPIO DE CASSILÂNDIA/MS.
}

Orientador:

Prof. Dr. LUIS CARLOS MARCHINI

Tese apresentada para obtenção do título de Doutor em Ciências. Área de concentração: Entomologia.

Piracicaba 
Dados Internacionais de Catalogação na Publicação (CIP) DIVISÃO DE BIBLIOTECA E DOCUMENTAÇÃO - ESALQ/USP

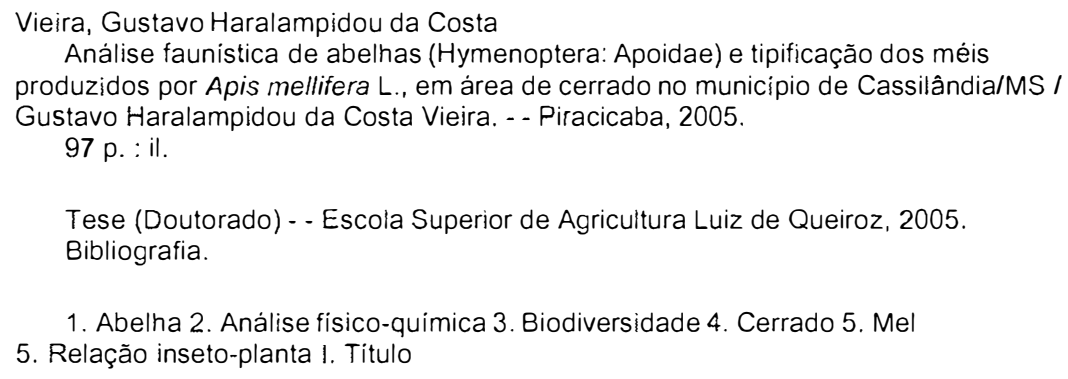

CDD 638.1 


\section{AGRADECIMENTOS}

À Deus, por permitir mais esta conquista em minha vida.

Ao Prof. Dr. Luís Carlos Marchini pela oportunidade, orientação, amizade e confiança.

À Escola Superior de Agricultura "Luiz de Queiroz", pela oportunidade.

Ao Prof. Dr. Nilton Cezar Bellizzi (UEG) pela amizade, incentivo e apoio durante a realização deste Curso.

Aos Professores Dr. Sinval Silveira Neto e Dr. Vinicius Castro Souza, pelo auxílio imprescindível à realização deste trabalho.

Aos companheiros do Laboratório de Insetos Úteis, em especial $\mathrm{Dr}^{\mathrm{a}}$ Augusta Carolina de C.C. Moreti e $\mathrm{Dr}^{\mathrm{a}}$ Geni da Silva Sodré, pela colaboração necessária ao sucesso deste trabalho.

Ao acadêmico Cleiton Dalastra (UEMS), pela dedicação, competência e responsabilidade demonstrada durante a realização dos trabalhos de campo.

Aos professores do Departamento de Entomologia, Fitopatologia e Zoologia Agrícola (ESALQ/USP), pelos ensinamentos necessários à minha formação profissional.

Aos colegas de curso, pelo companherismo e incentivo.

A todos aqueles que de alguma forma contribuíram para realização deste trabalho, meus sinceros agradecimentos. 


\section{SUMÁRIO}

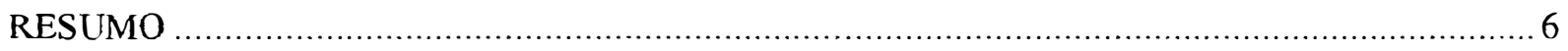

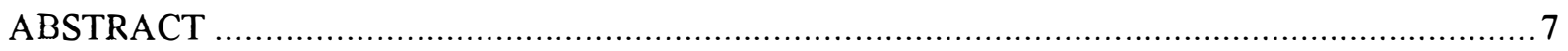

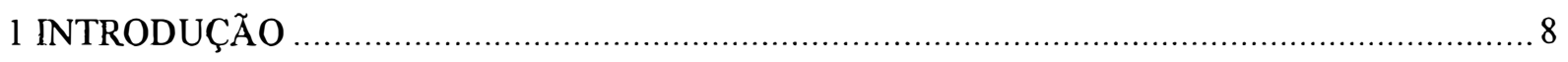

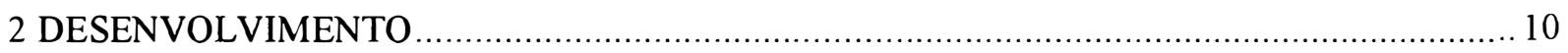

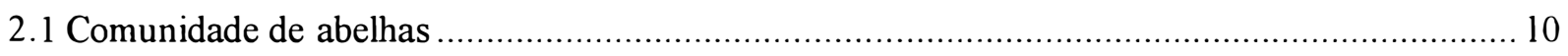

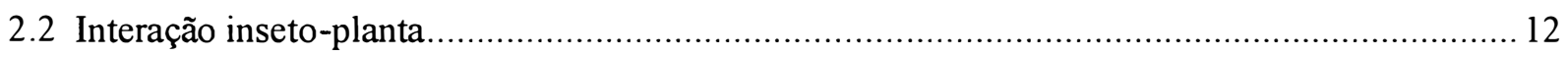

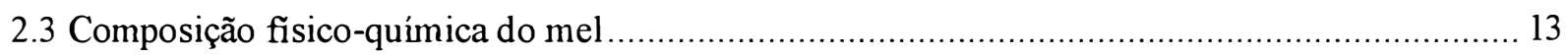

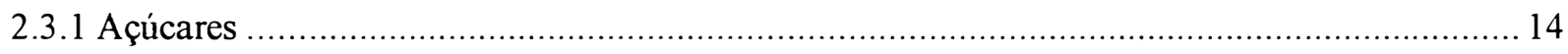

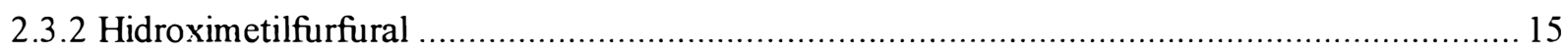

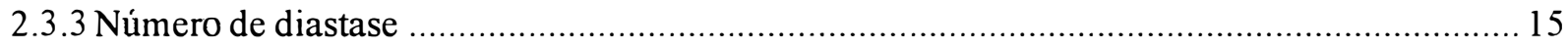

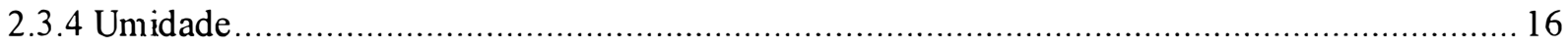

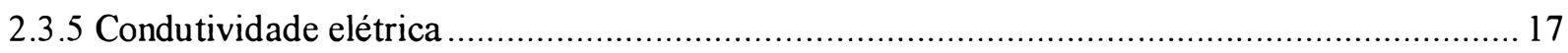

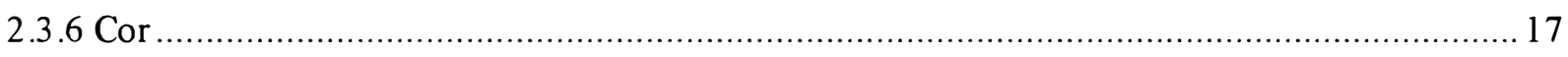

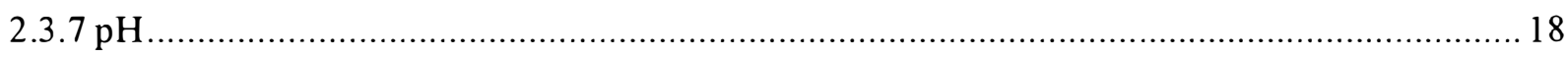

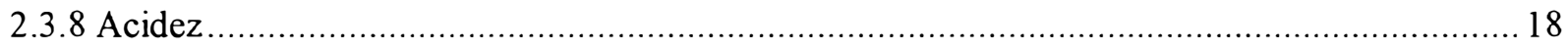

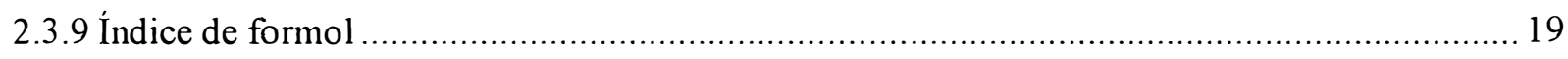

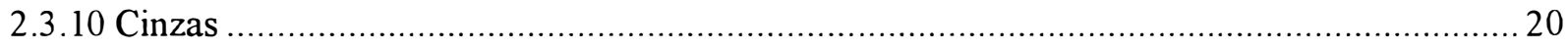

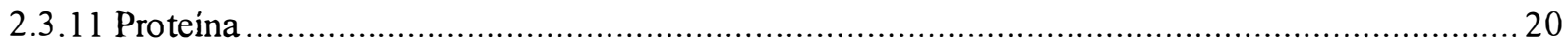

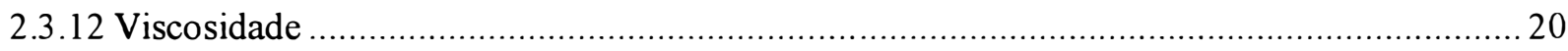

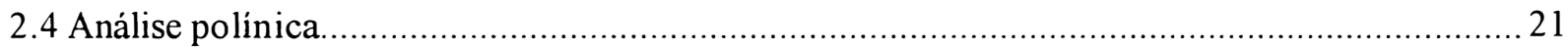

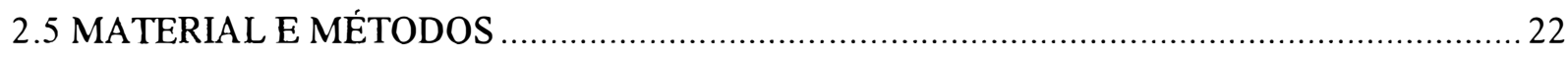

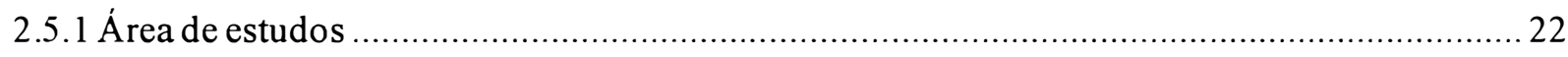

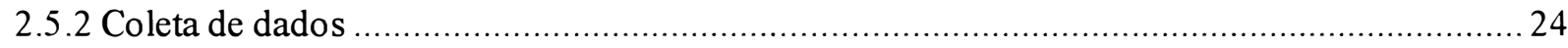

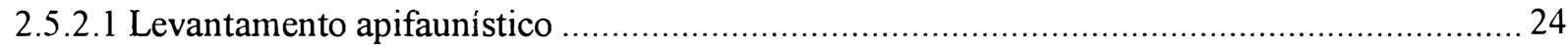

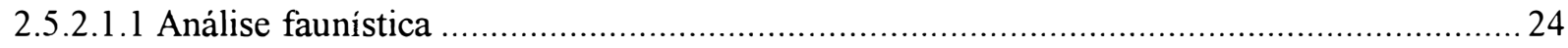

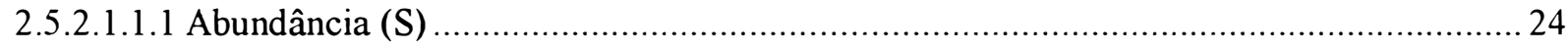

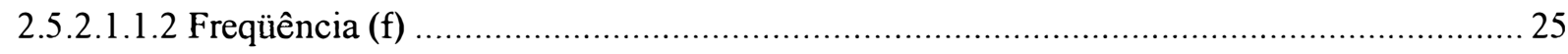

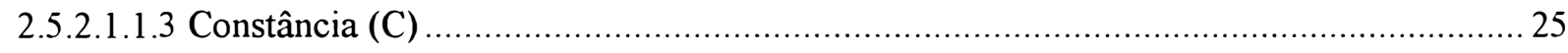

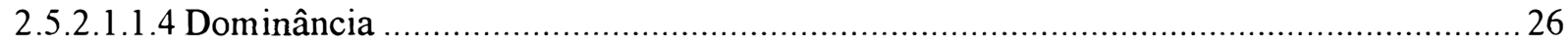

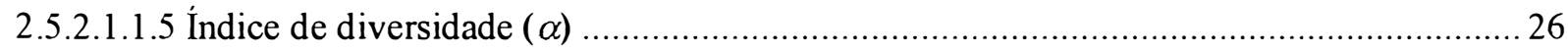

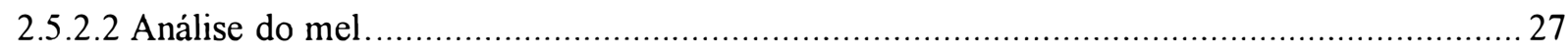

2.5.2.2.1 Açúcares totais, redutores e sacarose (\%) ........................................................ 27 


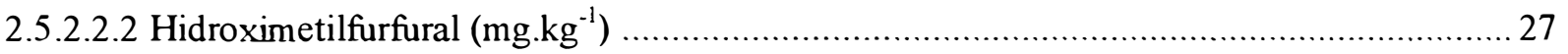

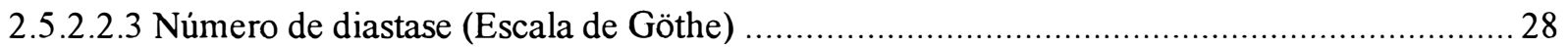

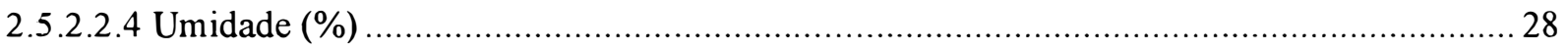

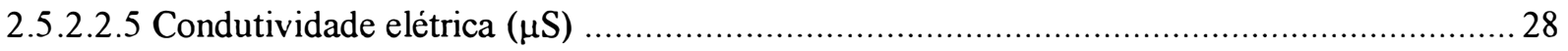

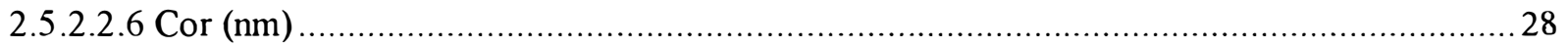

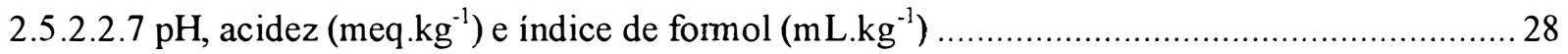

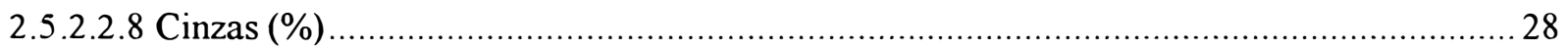

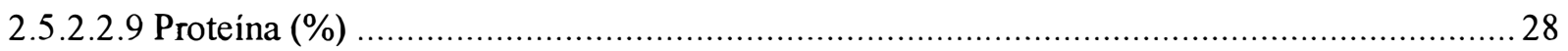

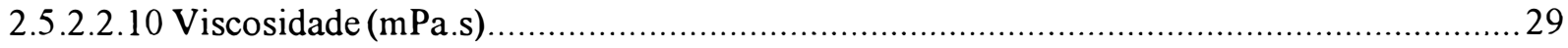

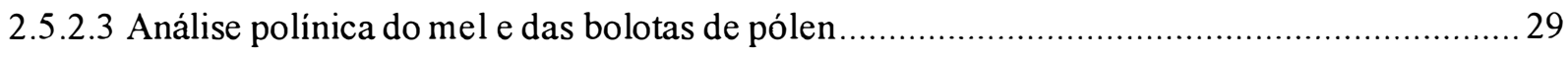

2.5.2.4 Identificação das plantas visitadas por abelhas ........................................................... 30

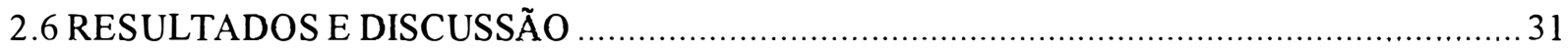

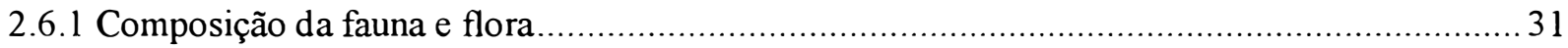

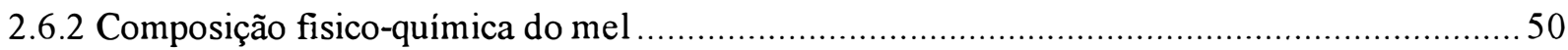

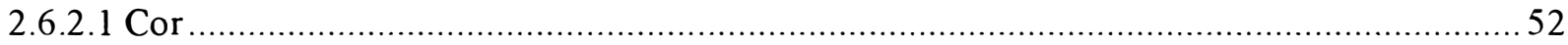

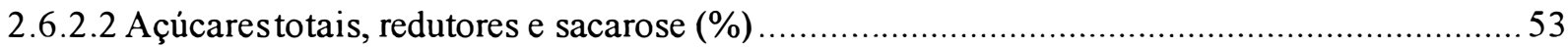

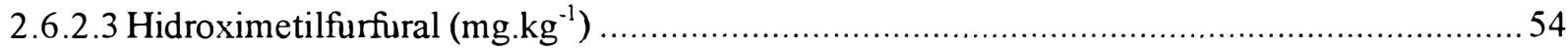

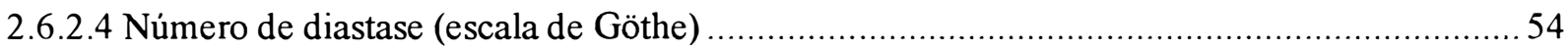

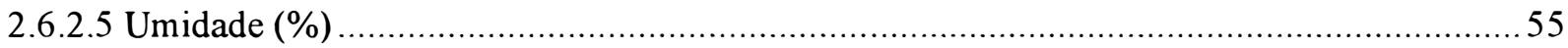

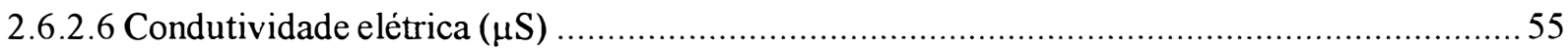

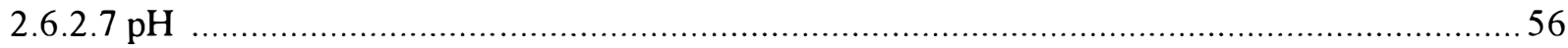

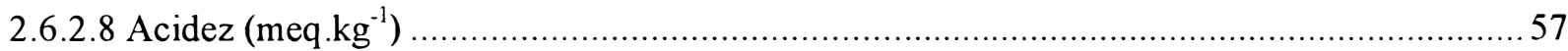

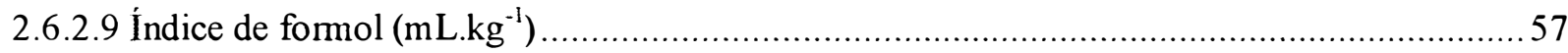

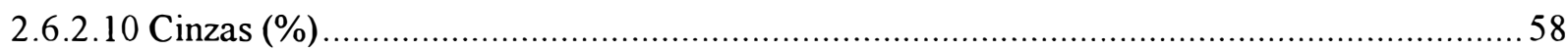

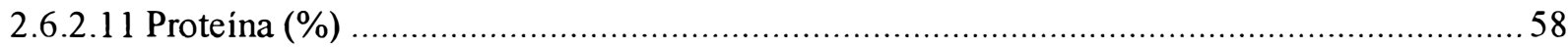

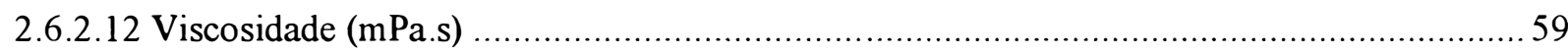

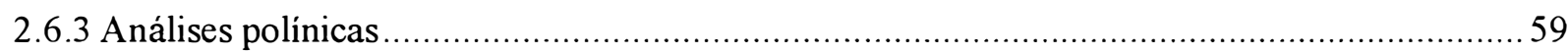

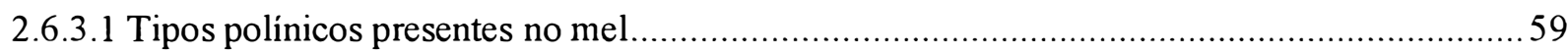

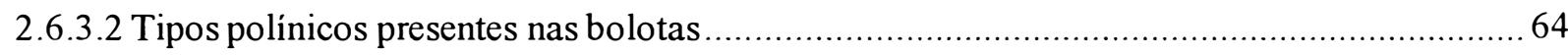

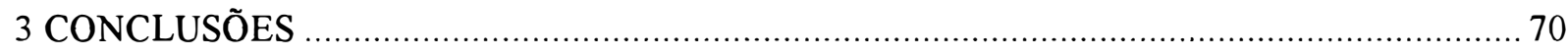

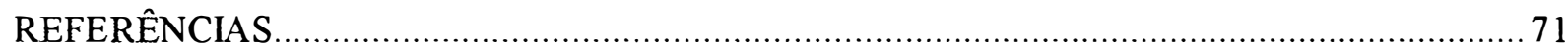




\section{RESUMO}

\section{Análise faunística de abelhas (Hymenoptera: Apoidea) e tipificação dos méis produzidos por Apis mellifera L., em área de cerrado no município de Cassilândia/MS}

Objetivou-se com este trabalho determinar os padrões da comunidade de abelhas e tipificar o mel produzido por Apis mellifera em uma área de cerrado no Campus da Universidade Estadual do Mato Grosso do Sul, município de Cassilândia/MS (1906'48"S; 51 $44^{\circ} 03^{\prime \prime}$ 'W). Os insetos, coletados quinzenalmente de março/2003 a fevereiro/2004, foram obtidos através da captura sistemática nas plantas em florescimento, ao longo de uma trilha com $3 \mathrm{~km}$ de extensão. As amostras de mel foram coletadas mensalmente de junho/2003 a maio/2004, em três colméias de Apis mellifera instaladas na mesma área. A comunidade de abelhas foi representada por 501 indivíduos pertencentes a 04 famílias, 07 subfamílias, 12 tribos, 22 gêneros e 34 espécies. A abundância de espécies seguiu o padrão encontrado nas comunidades neotropicais, caracterizada por apresentar um maior número de espécies raras e poucas espécies abundantes, sendo esta última representada por Apis mellifera e Trigona spinipes. A flora apícola foi representada por 140 indivíduos pertencentes a 49 espécies, 41 gêneros e 25 famílias. A família Malpighiaceae apresentou o maior número de espécies visitadas $(12,2 \%)$ e a família Sapindaceae o maior número de abelhas visitantes (18\%). Com relação ao mel analisado, os valores médios obtidos encontram-se em conformidade com as normas estabelecidas pela legislação nacional. Através das análises polínicas verificou-se que as abelhas utilizaram uma grande diversidade de recursos florais, sendo considerado dominante nas amostras de mel o pólen do tipo Anacardiaceae, Fabaceae, Melastomataceae, Anadenanthera sp. (Mimosaceae), Eucalyptus sp. (Myrtaceae), Bidens sp. (Asteraceae), Chenopodium sp. (Chenopodiaceae), Mimosa scabrella (Mimosaceae) e nas amostras de pólen obtidas nos coletores instalados nas colméias os tipos Schinus sp. (Anacardiaceae), Arecaceae, Vernonia sp. (Asteraceae), Crotalaria incana (Fabaceae), Tibouchina sp. (Melastomataceae), Anadenanthera sp.1 (Mimosaceae), Mimosa scabrella (Mimosaceae), Arecaceae sp.2, Poaceae, Luehea sp. (Tiliaceae), Trema sp. (Ulmaceae), Tipo Myrcia e um tipo polínico não identificado.

Palavras-chave: Análise faunística; Abelhas; Mel; Análise físico-química; Cerrado. 


\begin{abstract}
Faunal Analysis of Bees (Hymenoptera: Apoidea) and Caracterization of the Honey Produced by Apis Mellifera L., in the "Savannah" Area of Cassilandia County, State of Mato Grosso do Sul, Brazil
\end{abstract}

This research aims to determine the bees community standard and the honey characteristic typifing produced by Apis mellifera from the savannah area in the Campus of Mato Grosso do Sul State University, Cassilândia county, State of Mato Grosso do Sul, Brazil. The bees occurring on flowering plants were randomly sampled every other week, from March/2003 to February/2004, along a $3 \mathrm{~km}$ track. The honey samples were collected monthly from June/2003 to May/2004, in three beehive of the africanized bees localized in the same area. The bees community were represented by 501 individuals, 4 families, 7 subfamilies, 22 genera and 34 species. The bee community of the savannah followed the general standard of the neotropical communities, presenting many species with few individuals and few species with many individuals. The most abundant species were Apis mellifera and Trigona spinips. The flora was represented by 140 individuals, 49 species, 41 genera and 25 families. The Malpighiaceae family presented the highest number of visited species (12,2\%) and Sapindaceae family the highest number of bees collecting (18\%). The analysed honey samples are in agreement to the present legislation. Through the pollen analyses was observed that the bees visited a great diversity of flower resources, being considered dominant, in the honey samples, the types Anacardiaceae, Fabaceae, Melastomataceae, Anadenanthera sp. (Mimosaceae), Eucalyptus sp. (Myrtaceae), Bidens sp. (Asteraceae), Chenopodium sp. (Chenopodiaceae); Mimosa scabrella (Mimosaceae) and in the samples of the pollen collector installed in the beehive the types Schinus sp. (Anacardiaceae), Arecaceae, Vernonia sp. (Asteraceae), Crotalaria incana (Fabaceae), Tibouchina sp. (Melastomataceae), Anadenanthera sp.1 (Mimosaceae), Mimosa scabrella (Mimosaceae), Arecaceae sp.2, Poaceae, Luehea sp. (Tiliaceae), Trema sp. (Ulmaceae), Type Myrcia and one pollen type not recognized.

Keywords: Faunal analysis; Bee; Honey; Physical chemistry analysis; Savannah. 


\section{INTRODUÇÃO}

Acredita-se que o surgimento e proliferação das abelhas na Terra tenha ocorrido anteriormente ao aparecimento das angiospermas, há milhões de anos e a partir do aparecimento as plantas e os insetos coevoluíram (PROCTOR; YEO; LACK, 1996). Segundo estes autores, os ancestrais das abelhas atuais seriam insetos que coletavam o néctar como fonte de energia e caçavam pequenos animais que serviam de fonte protéica. Quando estes insetos substituíram a proteína animal pela vegetal, passando então a consumir o pólen das flores, iniciaram uma história de vida própria (WILSON, 1972).

Em contra partida, as angiospermas evoluíram na sua morfologia floral, adaptando suas estruturas e garantindo assim o sucesso na polinização realizada por esses insetos. Este fato explica a grande diversidade de cores, formas e odores observada nas flores (BARTH, 1991).

Atualmente, cerca de 225.000 espécies da flora correspondem às angiospermas, sendo 2/3 dependente das abelhas para polinização (SOUZA et al., 1993). Por outro lado, as abelhas reúnem aproximadamente 20.000 espécies distribuídas por todas as partes do mundo onde há ocorrência desses vegetais (MICHENER, 1979).

A interação entre as abelhas e plantas garantiu aos vegetais o sucesso na polinização cruzada, que constitui importante adaptação evolutiva das plantas, aumentando o vigor das espécies, possibilitando novas combinações dos fatores hereditários e aumentando a produção de frutos e sementes (GIORGINI; GUSMAN, 1972; CAMACHO; MONKS; SILVA, 1999; NOGUEIRACOUTO; COUTO, 2002).

No entanto, nos últimos anos muitas espécies de abelhas foram dizimadas em decorrência de fatores como o desmatamento, queimadas, uso inadequado dos agrotóxicos e até mesmo pela exploração inadequada dos meleiros, que retiram o mel destruindo as colônias (CAMPOS, 1991).

Com relação à eliminação desses insetos, deve-se considerar que a preservação das espécies tanto nativas como introduzidas são de suma importância para a manutenção da biodiversidade, visto que em muitos casos são indispensáveis na polinização das flores (PROCTOR; YEO; LACK, 1996; CAMACHO; MONKS; SILVA, 1999; GIMENES, 2002; RAJU; RAO, 2002), que resultarão em frutos e sementes que constituem a principal fonte de alimento para um grande número de aves e mamíferos (WIESE, 1985; FREE, 1993). 
Além do trabalho de polinização, as abelhas fornecem dentre seus produtos o mel, elemento apreciado no mundo inteiro em função das suas propriedades nutritivas e terapêuticas. No entanto, por ser um produto natural de fornecimento limitado, são comuns os casos de adulterações, que levam à desconfiança dos consumidores tradicionais, criando barreiras para ampliação do seu consumo (AZEREDO; AZEREDO; DAMASCENO, 1999).

Pereira et al. (1983) ressaltaram que é impossível avaliar a qualidade e integridade do mel apenas pelas características organolépticas. Segundo estes autores, alguns parâmetros fisico químicos são constantes dentro de uma faixa nos méis naturais, permitindo a deteç̧ão de fraudes. Este fato tem levado ao desenvolvimento de inúmeros estudos com o intuito de determinar as propriedades físico-químicas deste produto (FELLER-DEMALSY; PARENT; STRACHAN, 1987; OLEK et al., 1987; LOW; NELSON; SPORNS, 1988; JATO et al., 1991; SANCHO et al., 1992).

Considerando a importância das abelhas para a manutenção da biodiversidade no planeta, assim como a grande aplicação dos seus produtos, objetivou-se com este trabalho conhecer a comunidade de abelhas em uma área de cerrado localizada no município de Cassilândia/MS, estabelecendo a relação entre as espécies coletadas e a flora fornecedora de recurso alimentar, além de tipificar através de análises físico-químicas e polínicas os méis produzidos por Apis mellifera no local. 


\section{DESENVOLVIMENTO}

\subsection{Comunidade de abelhas}

Segundo Ricklefs (1996) entende-se por comunidade biótica o conjunto de organismos que habitam o mesmo local interagindo entre si através das suas cadeias alimentares e outras interações. Laroca (1995) e Begon (1996) definiram comunidade biótica como o conjunto de espécies que habitam o mesmo local no mesmo espaço de tempo.

Assim, os ecologistas muitas vezes consideram a comunidade como todos os organismos presentes em uma área. Porém, é comum a ocorrência de trabalhos que restringem a comunidade a um grupo taxômico, como os insetos, aves ou a um grupo com uma atividade particular como os herbívoros ou carnívoros.

A simples contagem ou relação de espécies ocorrentes em um determinado local constitui uma das formas de se caracterizar uma comunidade biótica (BEGON, 1996). No entanto, estudos mais detalhados sobre comunidade abordam outros parâmetros como riqueza, abundância, constância, dominância e diversidade de espécies, podendo ainda comparar diferentes comunidades (LEWIS; TAYLOR, 1976). Além desses aspectos, é notável o número de trabalhos que relacionam o papel de determinadas espécies na comunidade como um todo (CAMACHO; MONKS; SILVA, 1999; BRITO; RÊGO, 2001; GIMENES, 2002; HARTER et al., 2002; RAJU; RAO, 2002).

Com relação à diversidade de espécies em um dado local, deve-se ressaltar que este fator permite avaliar o grau de desgaste dentro de um ecossistema alterado, além de ser um parâmetro relacionado ao equilíbrio dinâmico do ecossistema, por relações estabelecidas entre organismos produtores e consumidores (BROWER; Van LOON, 1984).

O Brasil, em virtude de sua grande extensão territorial e localização geográfica, apresenta características fǐsicas que determinam domínios climato-botânicos, favorecendo a riqueza de insetos, principalmente, de abelhas (MORGADO, 2000). Este grupo de insetos exerce grande importância nos ecossistemas terrestres, devido à sua alta especialização na coleta de pólen, néctar e resinas, sendo excelentes polinizadores, e portanto, indispensáveis à sobrevivência das angiospermas (BAWA et al., 1985; BAWA, 1990; ENDRESS, 1994).

Dentre a composição da flora que necessita das abelhas para polinização merecem destaque as famílias Caesalpiniaceae e Fabaceae, sendo esta última altamente dependente das 
abelhas (PROCTOR; YEO; LACK et al., 1996). Além dessas, muitas espécies das famílias Bignoniaceae, Lamiaceae e Scrophulariaceae podem ter sua sobrevivência comprometida com o desaparecimento das abelhas nos seus locais de ocorrência (NEFF; SIMPSON, 1993).

A grande especialização desse grupo levou ao desenvolvimento de características adaptativas tais como sazonalidade, permitindo a ocorrência somente nos períodos em que as condições são favoráveis, como disponibilidade de alimento e locais de nidificação. Este comportamento constitui uma importante estratégia para minimizar a competição entre as espécies, visto que, em determinadas estações do ano há um grupo de espécies em atividade enquanto outros estão ausentes (BEGON, 1996; MORGADO, 2000).

Outro fator importante encontrado nos estudos sobre comunidades de abelhas são as informações sobre as flores visitadas por elas, indicando assim o recurso floral utilizado (IWAMA; MELHEM, 1979; ENGEL; DINGEMANS-BAKELS, 1980; ABSY et al., 1984; ROUBIK, 1989). Neste contexto muitos trabalhos têm mostrado que nas comunidades de abelhas somente poucos recursos florais são usados intensamente, havendo uma grande divergência entre as espécies quanto a forma de obtenção dos recursos (SOMMEIJER et al., 1983; RAMALHO et al., 1985; ROUBIK et al., 1986; KLEINERT-GIOVANNINI; IMPERATRIZ-FONSECA, 1987; IMPERATRIZ-FONSECA; KLEINERT-GIOVANNINI; RAMALHO, 1989).

Segundo Pinheiro-Machado et al. (2002), a determinação dos padrões da comunidade de abelhas e sua relação com habitats particulares constitui uma importante ferramenta na identificação da vulnerabilidade desses organismos às variações ambientais.

Considerando a importância das abelhas para a manutenção dos ecossistemas e o elevado grau de destruição observado nas áreas de cerrado, decorrente do rápido e devastador processo de ocupação humana nos últimos anos, tem-se elevado a necessidade de estudos que visam a preservação desses insetos (SILVEIRA, 1989).

Dentre os estudos sobre comunidades de abelhas no Brasil pode-se citar Moure (1943, 1944); Sakagami; Laroca e Moure (1967); Sakagami e Laroca (1971); Laroca (1974). Os dados obtidos nestes trabalhos fornecem informações sobre listas de espécies, abundância, sazonalidade, atividade diária e plantas melitófilas (PINHEIRO-MACHADO et al., 2002). Além desses estudos outros trabalhos foram desenvolvidos com o mesmo objetivo (CAMARGO; MAZUCATO, 1984; CAMPOS, 1989; IMPERATRIZ-FONSECA; KLEINERT-GIOVANNINI; RAMALHO, 1989; HOFFMAN, 1990; BARBOSA; LAROCA, 1993; SIHAG, 1993; LAROCA; 
ALMEIDA, 1994; AGUIAR, 1995; OLIVEIRA; CAMPOS, 1995; RAMALHO, 1995; ALBUQUERQUE; MENDONÇA, 1996; FARIA; CAMARGO, 1996; AGUILAR, 1998; ALBUQUERQUE, 1998; CARVALHO; BEGO, 1998; RAW et al. 1998; CARVALHO, 1999; BRITO; RÊGO, 2001; McINTYRE; HOSTETLER, 2001; ALMEIDA, 2002; BANASZAK; WENDZONKA, 2002; KUHLMANN, 2002; KREMEN; WILLIAMS; THORP, 2002; PAWLIKOWSKI; HIRSCH, 2002; WILLIANS; TEPEDINO, 2003).

\subsection{Interação inseto-planta}

$\mathrm{Na}$ literatura existem inúmeros estudos que destacam a importância das abelhas no trabalho de polinização (SCHEREN, 1977; ARAÚJO, 1984; SILVA, 1985; MARTNHO, 1990). Estes autores afirmam que dentre todos os benefícios produzidos pelas abelhas como o mel, cera, própolis e geléia real, sem dúvida a polinização é o mais importante para o homem.

Segundo Carvalho e Silva (2002), a eficiência das abelhas na polinização faz destes insetos um dos principais grupos dentre as espécies da fauna silvestre, possibilitando o equilíbrio na comunidade de animais e plantas. Além disso, as abelhas apresentam maior eficiência entre os agentes polinizadores conhecidos, garantindo assim a boa qualidade dos frutos e sementes produzidos (NOGUEIRA, 1984).

Esta característica levou, já no início do século passado, alguns países a usarem comercialmente as abelhas na polinização. Só nos E.U.A. cerca de um milhão de colméias são alugadas anualmente para este fim (TODD; McGREGOR, 1960).

De acordo com Vansell e Griggs (1952), as abelhas chegam a contribuir com mais de $80 \%$ da polinização nas culturas agrícolas. Andena; Bego e Mechi (2002) afirmaram que proporção semelhante é observada nos ecossistemas tropicais.

Wiese (1984) estima que $60 \%$ dos alimentos vegetais consumidos pelo homem sejam produzidos com o auxílio das abelhas. Outros estudos apresentaram resultados neste sentido (NOGUEIRA NETO, 1953; KERR; AMARAL, 1960; BARROS, 1965; JULIANO, 1972; GIORGINI; GUSMAN, 1972; CAMPOS, 1991).

Proctor; Yeo e Lack (1996) ressaltaram que para a maioria das espécies existentes nas florestas tropicais, a polinização cruzada se faz necessária, visto que em muitos casos as plantas são incapazes de realizar a autopolinização. Neste contexto, os animais contribuem em grande parte para a realização desta tarefa (BAWA 1990; ENDRESS 1994). 
De acordo com Kerr (1994), cerca de 90\% das plantas de nossas florestas necessitam de polinização cruzada, sendo 40 a $90 \%$ das fanerógamas tropicais e subtropicais fecundadas por meliponíneos.

Absy et al. (1984) estudando a polinização em 192 espécies de fanerógamas na floresta amazônica observaram que $42 \%$ delas eram polinizadas por apenas uma espécie de abelha, $12 \%$ por duas espécies e o restante (46\%) por três ou mais espécies da subfamília Meliponinae.

Bawa et al. (1985) realizando estudos de polinização na Costa Rica, observaram que $44 \%$ das espécies tropicais arbóreas eram polinizadas por abelhas de tamanho médio a grande. Segundo estimativa do autor, o mesmo padrão deverá ser encontrado em outras florestas tropicais distribuídas pelo mundo.

Quanto à eficiência de polinização entre as abelhas Apis e nativas, muitos trabalhos divergem nas suas conclusões. Embora tenha ocorrido um grande uso de abelhas do gênero Apis na polinização de culturas agrícolas, muitos estudos têm mostrado que em inúmeros casos as abelhas nativas são mais eficientes (BOYLE-MAKOWSKI, 1988; O'TOOLE, 1993; BARRETT; HELENURM, 1994; NOGUEIRA-COUTO et al. 1992; GROSS; MACKAY, 1998).

Por outro lado, vários autores ressaltam que em um grande número de espécies vegetais as abelhas Apis são mais freqüentes que as nativas, sugerindo portanto, sua utilização como agente polinizador (GARCIA NETO; NOGUEIRA-COUTO; MALHEIROS, 1988; NOGUEIRA-COUTO; PEREIRA; COUTO, 1990; ADEGAS; NOGUEIRA-COUTO, 1992; CHAGNON; GINGRAS; OLIVEIRA, 1993; NOGUEIRA-COUTO; CALMONA, 1993; MALERBO; COUTO, 1994; MOTA; NOGUEIRA-COUTO; MALERBO-SOUZA, 1996; NOGUEIRA-COUTO; PEREIRA; JONG, 1998; MALERBO-SOUZA et al., 2000; RIBEIRO, 2000).

\subsection{Composição físico-química do mel}

Entende-se por mel a substância doce produzida pelas abelhas a partir do néctar das flores ou de exudações de ourras partes vivas das plantas ou presentes nelas (BRASIL, 2000). Quanto à composição, são encontrados no mel diferentes açúcares, predominantemente frutose e glicose, além de proteínas, aminoácidos, enzimas, ácidos orgânicos, minerais, pólen e outras substâncias (MARTINEZ-GOMEZ et al., 1993). 
Por se tratar de um produto alimentício de consumo milenar e universal, inúmeros estudos foram realizados com o intuito de determinar suas propriedades físico-químicas (BONAGA; GIUMANINI, 1986; THRASYVOULOU, 1986; FELLER-DEMALSY; PARENT; STRACHAN, 1987; OLEK et al. 1987; LOW; NELSON; SPORNS, 1988; JATO et al., 1991; SANCHO et al., 1992; RODRIGUES-OTERO et al., 1992; MARTINEZ-GOMEZ et al., 1993; GARCIAALVAREZ et al., 2000). Estes trabalhos visam comparar os resultados obtidos com os padrões estabelecidos internacionalmente ou no próprio país, impondo dificuldades à exploração de produtos de má qualidade ou adulterados, que representam uma grande parcela dos méis encontrados à disposição do consumidor.

No Brasil dentre os estudos físico-químicos do mel, pode-se citar Flechtmann et al. (1963); Barth (1990); Ramalho et al. (1991); Komatsu (1996); Komatsu e Marchini (1996); Rodrigues; Marchini e Haddad (1996); Marchini; Rodrigues e Moreti (1996), Sodré (2000); Cano et al. (2001); Marchini (2001); Almeida (2002); Arruda (2003); Sodré (2005).

\subsubsection{Açúcares}

Os açúcares constituem os compostos em maior porcentagem no mel, sendo sua proporção variável de acordo com a origem do néctar floral (GIL, 1986). Nauta (1983) afirmou que o mel é constituído predominantemente dos monossacarídeos frutose e glicose. Ambos compreendem os açúcares redutores, elementos com capacidade de reduzir íons cobre em solução alcalina (VIDAL; FREGOSI, 1984). Outro açúcar encontrado no mel é a sacarose, que pertence ao grupo não redutor dos oligossacarídeos. Através da ação da enzima invertase a sacarose dá origem à frutose e glicose.

De acordo com a lei brasileira estabelecida, os açúcares redutores não devem apresentar valores inferiores a $65 \%$, enquanto que a sacarose não deve apresentar valores acima de $6 \%$ (BRASIL, 2000).

Autores como Flechtmann et al. (1963); El-Sherbiny et al. (1980); Nauta (1983); Archenti (1984); Moraes e Mantovani (1986); Cornejo (1988); Frias-Tejera e Torre (1991); MartinezGomez et al. (1993); Komatsu (1996); Andrade et al. (1999); Sodré (2000) e Almeida (2002) obtiveram uma variação de 56,2 a $95 \%$ e 0,2 a $11,4 \%$ para açúcares redutores e sacarose, respectivamente. 


\subsubsection{Hidroximetilfurfural}

O hidroximetilfurfural (HMF) constitui um dos parâmetros determinantes da qualidade do mel, principalmente no que se refere ao superaquecimento ou tempo de armanezamento (CORNEJO, 1988). Seu conteúdo pode aumentar com a elevação da temperatura, armazenamento ou adição de açúcar invertido, podendo ser afetado pela acidez, pH, água e minerais presentes no mel (WHITE JÚNIOR, 1978; SEEMANN; NEIRA, 1988; SALINAS et al., 1991).

Sua formação está relacionada à reação de determinados açúcares com ácidos, principalmente, pela decomposição da frutose na presença de ácidos (ARRUDA, 2003).

De acordo com os padrões internacionais "Codex Alimentarius Commission (1969)", méis que apresentam valores superiores a $40 \mathrm{mg} \mathrm{kg}^{-1}$ (escala internacional) ultrapassam o máximo permitido estando, portanto, acima dos padrões de qualidade. No Brasil, considerando o clima tropical, este valor foi estendido para $60 \mathrm{mg} \cdot \mathrm{kg}^{-1}$ (BRASIL, 2000).

Autores como Tabio; Alvarez e Berisiartu (1987); Martinez-Gomez et al. (1993); Komatsu e Marchini (1996); Sodré (2000); Marchini (2001) e Almeida (2002) obtiveram uma variação de 0 a $136 \mathrm{mg} \cdot \mathrm{kg}^{-1}$ para HMF.

\subsubsection{Número de diastase}

A diastase, nome dado a enzima $\alpha$-amilase, constitui um parâmetro indicativo do controle de qualidade do mel que retrata as condições de armazenamento e aquecimento ao qual o produto foi submetido, sendo usada como fator determinante da qualidade do produto para os padrões internacionais (VIT; PULCINI, 1996).

Esta enzima, cuja função é digerir o amido, é originada a partir das secreções salivares das abelhas (STADELMEIER; BERGNER, 1986).

Atualmente, considera-se aceitável méis que apresentam um mínimo de 8 (escala de Göthe) para diastase, exceto para aqueles com baixo conteúdo enzimático, como o mel de citros, onde aceita-se o mínimo de 3 na mesma escala desde que o HMF não exceda $15 \mathrm{mg} \cdot \mathrm{kg}^{-1}$ (BRASIL, 1997).

Takenaka e Echigo (1974) observaram que tanto a diastase como a invertase decrescem durante o armazenamento, podendo apresentar valores maiores em méis com maior conteúdo de água. 
Dentre os trabalhos realizados em outros países com o intuito de determinar o número de diastase pode-se citar: Martinez-Gomez et al. (1993) e Huidobro et al. (1995), que obtiveram valores médios de 20,12 e 19,3 (escala de Göthe), respectivamente, em méis espanhóis; Vit e Pulcini (1996), que obtiveram uma variação de 2,6 a 35,6 (escala de Göthe), em méis venezuelanos; Persano-Oddo; Piazza e Pulcini (1999), que obtiveram valores de 4,3 a 32,9 (escala de Göthe), em méis italianos; Al-Khalifa e Al-Arify (1999), que obtiveram valores de 3,3 e 12,0 (escala de Göthe), em méis da Arábia Saudita e Andrade et al. (1999), que obtiveram uma vairação de 13 a 51,1 (escala de Göthe) em méis portugueses.

No Brasil autores como Bastos e Silva (1994); Komatsu e Marchini (1996); Azeredo; Azeredo e Damasceno (1999) e Sodré (2000) obtiveram para o número de diastase valores de 5,0 a 62,8 (escala de Göthe).

\subsubsection{Umidade}

A água é um componente que chega à colméia em grande abundância integrada ao néctar das flores (GIL, 1986). Este elemento corresponde ao segundo componente em quantidade no mel, apresentando valores de 15 a $20 \%$ do conteúdo total, dependendo do clima, origem floral e colheita antes da completa maturação (SODRÉ, 2000).

$\mathrm{O}$ teor de água presente no mel é de grande importância, por influenciar diretamente sua viscosidade, peso específico, maturidade, cristalização e sabor, condicionando a sua conservação e palatabilidade (SEEMANN; NEIRA, 1988).

Com relação a conservação do mel, o conteúdo de água interfere na sua estabilidade frente à fermentação (WHITE JÚNIOR, 1978). Níveis elevados de umidade provocam a fermentação do mel devido a presença de leveduras que são tolerantes ao açúcar. A fermentação é evitada em condições de alto conteúdo total de açúcar associado a um baixo teor de água (CRANE, 1987). Segundo esta autora, o conteúdo de água mais seguro para que não ocorra a fermentação é de até $19 \%$, considerando que para valores inferiores a este, a fermentação não ocorrerá mesmo se muitas células fermentadas estiverem presentes. No entanto, Cornejo (1988), afirma que o índice ideal de umidade contido no mel não deve ultrapassar $18 \%$.

Autores como Flechtmann et al. (1963); Archenti (1984); Mahajan (1984); Poncini et al. (1984); Martinez-Gomez et al. (1993); Mustafa e Mustafa (2002); Arruda (2003) analisaram diferentes amostras de méis obtendo valores de umidade dentro do permitido. 


\subsubsection{Condutividade elétrica}

A condutividade elétrica é um parâmetro usado para determinar a origem do mel, se é néctar ou melato, ou ainda se o produto está adulterado (CRANE, 1987). Seus valores estão relacionados ao conteúdo de cinzas, $\mathrm{pH}$, acidez, sais minerais e outras substâncias presentes no mel (CRANE, 1990; BOGDANOV et al., 2001).

As normas internacionais consideram aceitáveis valores de condutividade elétrica de 200 a $800 \mu \mathrm{S}$.

Em méis italiano, espanhóis e portugueses, Persano-Oddo et al. (1995); Rendón (1996) e Andrade et al. (1999) encontraram uma variação de 90 a $2110 \mu \mathrm{S}$ para condutividade elétrica.

No Brasil autores como Carvalho et al. (2000); Sodré (2000); Marchini (2001); Almeida (2002); Arruda (2003), Sodré (2005) analisaram méis de diferentes origens florais obtendo valores de condutividade elétrica variando de 90 a $2110 \mu \mathrm{S}$.

\subsubsection{Cor}

Segundo Crane (1987) a cor do mel normalmente apresenta uma tonalidade mais escura que o creme e mais clara que o marrom. Embora esta definição seja puramente arbitrária, deve-se ressaltar que este fator implica no aspecto visual do produto, sendo um dos parâmetros que mais influencia a sua aceitação, afetando diretamente a preferência do consumidor.

Yeboah-Gyan e Marfo (1998) ressaltaram que a cor do mel representa um dos principais entraves para os países produtores que almejam conquistar o mercado internacional. De acordo com os padrões estabelecidos, há uma preferência por méis claros (CRANE, 1975; ITC, 1977), sendo estes mais valorizados que os escuros.

Dentre os fatores que interferem na coloração do mel, pode-se citar a sua origem floral, processamento e armazenamento, variações climáticas durante o fluxo de néctar e a temperatura na qual o mel amadurece na colméia (SEEMANN; NEIRA, 1988).

Olek et al. (1987) compararam a cor de amostras de méis produzidas pelas espécies Apis cerana e Apis laboriosa observando que a primeira produziu mel do tipo âmbar extra claro enquanto a segunda produziu mel âmbar escuro.

Yeboah-Gyan e Marfo (1998) analisaram méis de diferentes origens florais produzidos em Ghana, observando que méis escuros apresentavam maiores concentrações de minerais 
quando comparados com méis claros. Outros autores obtiveram resultados neste sentido (WHITE JÚNIOR, 1961; PETROV, 1970; CAMPOS, 1998).

Em méis paraguaios e espanhóis, Escobar-Martínez; Giménez e Mendoza (1992) e Gomez et al. (1993) encontraram a predominância das cor âmbar claro em relação as demais. Resultado semelhante foi obtido por Baldi Coronel; Dall'Ogllio e Lezcano (1993) e Uñates et al. (1999), em méis argentinos.

No Brasil autores como Sodré (2000); Almeida (2002); Arruda (2003) analisaram a cor de méis de diferentes origens florais observando a predominância da cor clara em relação a escura. Outros estudos apresentaram resultados neste sentido (PAMPLONA, 1989; MARTÍNEZ; MEZA; MENDONZA, 1992; GOMEZ et al., 1993; SERRA-BONVEHÍ; GRANADOSTARRÉS, 1993; PERSANO-ODDO et al., 1995; MARCHINI; MORETI, 2001).

\subsection{7 pH}

$\mathrm{O} \mathrm{pH}$ determinado nas análises do mel refere-se aos íons hidrogênio presentes na solução (VIDAL; FREGOSI, 1984). Segundo Seeman e Neira (1988), todos os méis são ácidos e os valores de $\mathrm{pH}$ encontrados no mel são influenciados pela sua origem botânica e pela concentração de diferentes ácidos e minerais como cálcio, sódio e potássio, além de outros constituintes das cinzas.

Trabalhos como de Crane (1987); Flechtmann et al. (1963); Spettoli; Cecchini e Matcovich (1983); Martinez-Gomez et al. (1993); Sodré (2000); Marchini (2001) Villamiel et al. (2001); Almeida (2002) e Mustafa e Mustafa (2002) apresentaram uma variação de 3,6 a 3,9 para $\mathrm{pH}$.

\subsubsection{Acidez}

A acidez constitui um importante componente do mel contribuindo para sua estabilidade frente ao desenvolvimento de microrganismos (CRANE, 1987; MARCHINI, 2001). Além disso, os ácidos fornecem indícios quanto às condições de armazenamento do mel, pois estão dissolvidos em solução aquosa e produzem íons de hidrogênio que promovem sua acidez ativa (CORNEJO, 1988).

No mel são encontrados os ácidos fórmico, acético, benzóico, butírico, cítrico, isovalérico, láctico, maléico, málico, oxálico, fenilacético, propiônico, piroglutânico, succínico, 
valérico e glucônico, sendo este último o principal (SEEMANN; NEIRA, 1988; DURÁN et al., 1996).

Quanto aos limites estabelecidos pela legislação vigente, são considerados dentro dos padrões méis com valores de acidez de até 50 meq. $\mathrm{kg}^{-1}$ (BRASIL, 2000).

Dentre os trabalhos que determinaram os valores de acidez em méis, pode-se citar Olek et al. (1987), que compararam os valores de acidez para méis produzidos por Apis cerana e $A$. dorsata ocorrentes no Nepal, obtendo valores de 16,07 e 41,48 meq. $\mathrm{kg}^{-1}$; Martinez-Gomez et al. (1993), que analisaram méis produzidos na Espanha, obtendo o valor médio de 28,28 meq. $\mathrm{kg}^{-1}$ para acidez; Marchini (2001), que em méis produzidos no Estado de São Paulo, obteve para acidez valores de 33,8 meq. $\mathrm{kg}^{-1}$ para méis de e ucalipto e 30,11 meq. $\mathrm{kg}^{-1}$ para méis de origem silvestre e Tosi et al. (2003), que caracterizaram o mel produzido na província de Santa Fé (Argentina), obtendo valores de acidez dentro dos níveis aceitáveis ( $<40$ meq. $\left.\mathrm{kg}^{-1}\right)$.

Trabalhos como de Spettoli; Cecchini e Matcovich (1983); Temiz (1983); Faraji-Haremi e Hosseini (1987); Olek et al. (1987); Tabio; Alvarez e Berisiartu (1987); Peréz et al. (1990); Escobar-Martínez; Meza e Mendonza (1992); Martinez-Gomez et al. (1993) apresentaram valores de acidez variando de 10,7 a 45,0 meq. $\mathrm{kg}^{-1}$.

\subsection{9 Índice de formol}

O índice de formol constitui um dos parâmetros usados para avaliar a autenticidade do produto (FRÍAS; HARDISSON, 1992). Valores baixos para o índice de formol podem indicar a adulteração por meio de produtos artificiais, enquanto que valores excessivamente elevados indicam que as abelhas foram tratadas com hidrolisado de proteínas (SIMAL; HUIDOBRO, 1984).

Este parâmetro representa os compostos aminados, permitindo assim determinar o teor de aminoácidos, proteínas e peptídeos presentes no mel (SODRÉ, 2000).

Dentre os estudos que avaliaram o índice de formol em diferentes amostras de méis podese citar Temiz (1983); Komatsu (1996); Sodré (2000); Marchini (2001) e Almeida (2002), que obtiveram valores variando de 1,67 a $29,00 \mathrm{~mL} \cdot \mathrm{kg}^{-1}$. 


\subsubsection{Cinzas}

Através deste parâmetro torna-se possível determinar quais nutrientes minerais estão presentes no mel, assim como avaliar a sua qualidade. De acordo com Bogdanov et al. (2001), o teor de cinzas no mel constitui um critério de qualidade e está relacionado a sua origem botânica.

White Júnior (1984) constatou que os minerais influem diretamente na coloração do mel, estando presente em maior concentração nos méis escuros em comparação aos claros. O mesmo autor identificou no mel os seguintes minerais: potássio, cloro, enxofre, cálcio, sódio, fósforo, magnésio, sílica, silício, ferro, manganês e cobre.

Os valores obtidos para cinzas podem variar de 0,02 a 1,0\% (CRANE, 1987). Dentre os estudos realizados com o objetivo de determinar o teor de cinzas presente no mel pode-se citar Olek et al. (1987); Rodríguez-Otero et al. (1992); Martínez-Gomez et al. (1993); Mendes et al. (1998); Al-Khalifa e Al-Arify (1999) e Terrab et al. (2003), que obtiveram uma variação de 01 a $0,6 \%$.

\subsubsection{Proteína}

As proteínas são encontradas em pequenas quantidades nos méis normais, sendo provenientes mais das abelhas do que das plantas (CRANE, 1987).

De forma geral, as proteínas constituem uma importante fonte alimentar, que ao serem quebradas fornecem os aminoácidos necessários ao organismo. Dentre os aminoácidos encontrados no mel, pode-se citar a lisina, alanina, arginina, cistina, glicina, histidina, isoleucina, metionina, fenilalanina, serina, treonina, triptofano, tirosina, valina e prolina, sendo este último considerado o de maior importância dentre eles (CRANE, 1975).

Com relação aos índices de proteína, autores como Amaral et al. (1986); EscobarMartínez; Meza e Mendoza (1992) e Marchini (2001), obtiveram valores de 0,04 a 2,54\% em méis de diferentes origens florais.

\subsubsection{Viscosidade}

As propriedades reológicas dos alimentos fornecem informações quanto à sua qualidade (CAMPOS, 1998). De acordo com Rao (1977), o comportamento reológico de um fluido depende da sua composição, temperatura e taxa de deformação, levando-se em consideração a duração e a história da taxa. 
Campos (1998) observou que a viscosidade em méis de melato é maior que em méis florais.

Autores como Junzheng e Changying (1998); Al-Khalifa e Al-Arify (1999); Sodré et al. (2002) determinaram os valores de viscosidade para méis de diferentes origens florais obtendo valores de 0,70 a $1607 \mathrm{mPa} . s$.

\subsection{Análise polínica}

O estudo dos grãos de pólen presentes no mel ou melissopalinologia, constitui uma ferramenta de grande importância para o pesquisador que pretende determinar em quais espécies vegetais as abelhas estão encontrando alimento ou quais espécies vegetais são importantes no fornecimento do recurso alimentar às abelhas.

De acordo com Barth (1989), as abelhas ao coletarem o néctar nas flores coletam também, involuntariamente, o pólen que é regurgitando nos alvéolos melíferos. Assim, o pólen presente nas amostras de mel constitui importante indicativo da sua origem botânica e geográfica.

Além disso, a análise quantitativa do grãos de pólen permite determinar o quanto cada planta nectarífera contribui na constituição do mel (IWAMA; MELHEM, 1979).

Trabalhos desenvolvidos por Braga (1961); Santos (1961, 1964); Feller-Demalsy; Parent e Strachan (1987); Imperatriz-Fonseca; Giovannini e Ramalho (1989); Barth (1990); Jato et al. (1991); Herrero e Valencia (2001) e Lazarova e Bozilova (2002) evidenciaram a importância do pólen presente no mel para a determinação da sua origem botânica e geográfica. 


\subsection{MATERIAL E MÉTODOS}

\subsection{1 Área de estudos}

Os estudos foram conduzidos em um fragmento florestal localizado no campus da Universidade Estadual do Mato Grosso do Sul (UEMS), município de Cassilândia/MS (1906’48”S; 51 ${ }^{\circ} 44^{\prime} 03^{\prime \prime} \mathrm{W}-470 \mathrm{~m}$ de altitude) (Figura 1).

O local objeto de estudos apresenta uma área aproximada de 400 ha, caracterizada como floresta semi-decídua, inserida em uma formação vegetal do tipo savana arbórea densa (cerradão), tendendo a savana arbórea aberta (cerrado).

O cerrado apresenta uma extensão superior a dois milhões de $\mathrm{km}^{2}$ em território brasileiro, abrangendo os Estados de Goiás, Mato Grosso do Sul, Mato Grosso, Minas Gerais, ocorrendo ainda em áreas mais restritas nos Estados de São Paulo, Paraná, Maranhão, Piauí e Bahia (TOLEDO FILHO, 1984).

Sua formação vegetal é classificada como xeromórfica, caracterizada por diferentes fisionomias, variando de campos abertos a bosques, porém com a identificação florística reconhecida (PINHEIRO-MACHADO et al., 2002). Sua ocorrência está associada a solos profundos, com grande capacidade de drenagem (EITEN, 1972).

Quanto à disponibilidade de nutrientes são geralmente, pobres em bases e ricos em alumínio, sendo portanto, de grande interesse para o cultivo de soja, leguminosa resistente a este nutriente (NAKANO, com. pessoal).

Nos últimos 50 anos, a vegetação do cerrado tem sido amplamente estudada em sua extensão, diversidade e riqueza de espécies sob o aspecto florístico e ecológico (SILBERBAUERGOTTSBERGER; GOTTSBERGER, 1988). 

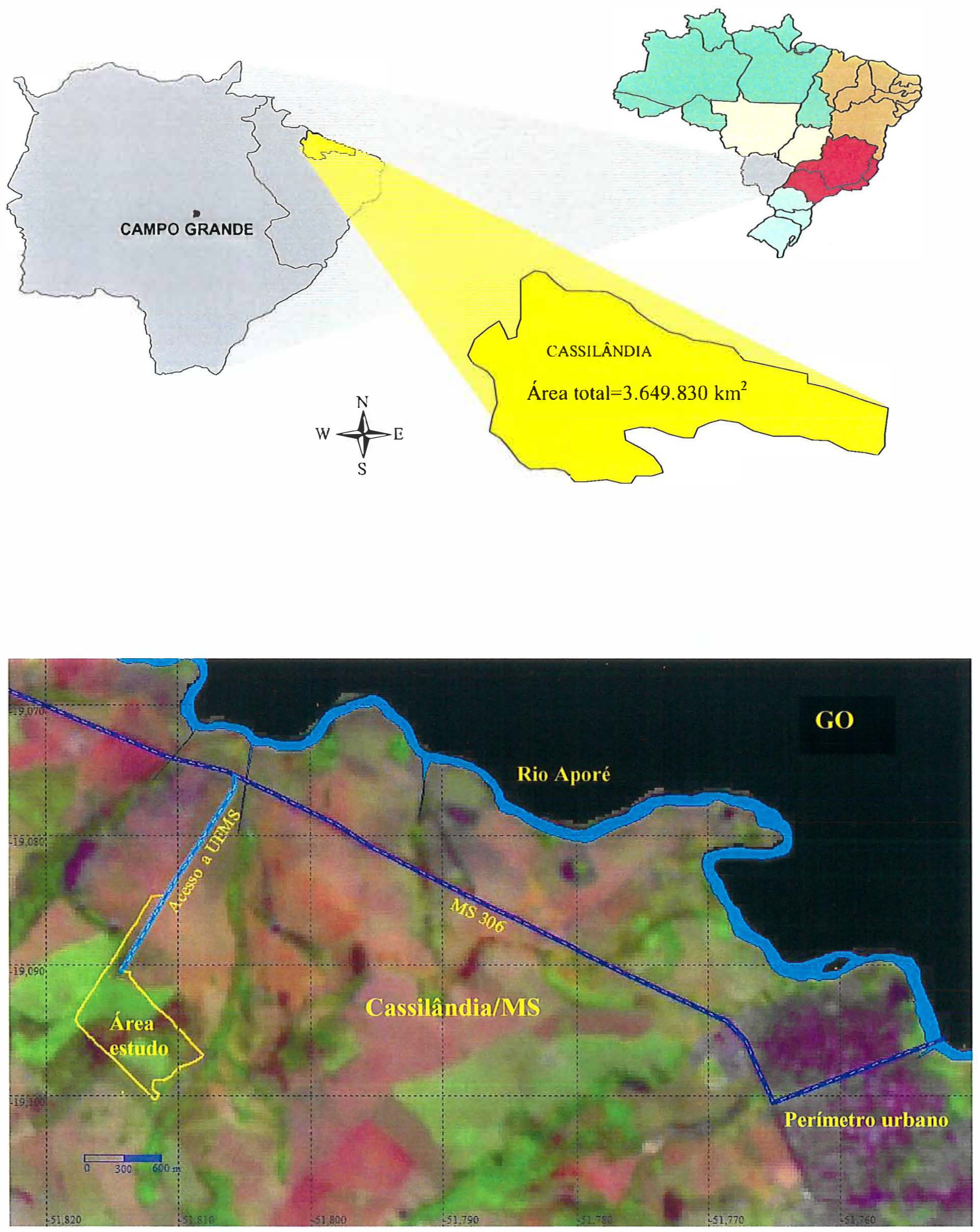

Figura 1 - Localização geográfica do município de Cassilândia/MS (acima) e foto-satélite de parte do município com destaque para área de estudo (abaixo) 


\subsubsection{Coleta de dados}

\subsubsection{Levantamento apifaunístico}

As coletas foram realizadas quinzenalmente durante o período de 12 meses a contar de março de 2003. Os procedimentos de coleta foram os propostos por Sakagami; Laroca e Moure (1967). Este método consiste na captura individual das abelhas em forrageamento ou em vôo, através de uma varredura com redes entomológicas nas plantas em florescimento. Todos os insetos foram capturados em uma trilha com' 3.000 metros de extensão, estabelecida ao longo do fragmento florestal estudado. Durante as coletas a trilha foi percorrida duas vezes (manhã e tarde), nas horas de maior forrageamento das abelhas. Todos os apídeos encontrados, assim como suas respectivas plantas fornecedoras de recurso alimentar foram coletados e identificados.

\subsection{Análise faunística}

Os espécimes coletados foram identificados por comparação com o material disponível na coleção de insetos do museu entomológico do Departamento de Entomologia, Fitopatologia e Zoologia Agrícola da ESALQ/USP. Quando necessário, os espécimes foram encaminhados aos especialistas para identificação.

Para a análise da fauna foram considerados dados de riqueza de espécies, gêneros e famílias das abelhas capturadas.

\subsection{Abundância (S)}

A abundância de indivíduos foi determinada de acordo com o número total de espécies no ambiente. As espécies foram distribuídas em cinco classes, baseada no intervalo de confiança (IC), do número de indivíduos (n) em nível de 5\% e 1\% de significância (BICELLI; SILVEIRA NETO; MENDES, 1989).

Foram considerados os seguintes limites de classes:
a) Raro $(r): n$ menor que o limite inferior do $\mathrm{IC} 1 \%$;
b) Disperso $(d)$ : $n$ entre os limites inferiores dos IC $1 \%$ IC $5 \%$;
c) Comum (c): $n$ situado dentro do IC5\%;
d) Abundante (a): $n$ situado entre os limites superiores dos IC $5 \%$ e IC $1 \%$;
e) Muito abundante $(m)$ : $n$ maior que o limite superior do IC $1 \%$. 


\subsection{Frequiência (f)}

A freqüência $(f)$ foi calculada de acordo com a porcentagem de indivíduos de uma determinada espécie em relação ao total de indivíduos obtidos (SILVEIRA NETO; NAKANO; VILA NOVA, 1976).

$$
f=(\mathrm{ni} / \mathrm{N}) \times 100
$$

sendo:

ni= número de indivíduos da espécie $\mathrm{i}$;

$\mathrm{N}=$ número total de indivíduos.

As espécies obtidas foram enquadradas em três classes de freqüência, baseando-se nos intervalos de confiança (IC a 5\% de probabilidade):

a) Pouco freqüênte $(\mathrm{PF})=f<$ o limite inferior (LI) do IC5\%;

b) Freqüênte $(\mathrm{F})=f$ situado dentro do $\mathrm{IC} 5 \%$;

c) Muito freqüênte $(\mathrm{MF})=f$ o limite superior $(\mathrm{LS})$ do IC $5 \%$.

\subsection{Constância (C)}

Refere-se à porcentagem de espécies presentes nos levantamentos efetuados (SILVEIRA NETO; NAKANO; VILA NOVA, 1976). Os valores de constância foram obtidos através da fórmula:

$$
\mathrm{C}=(\mathrm{Ci} / \mathrm{Nc}) \times 100
$$

sendo:

$\mathrm{C}=$ porcentagem de constância;

$\mathrm{Ci}=$ número de coletas contendo a espécie $\mathrm{i}$;

$\mathrm{Nc}=$ número total de coletas efetuadas.

As espécies obtidas foram classificadas de acordo com os critérios propostos por Bodenheimer segundo Silveira Neto (1976). De acordo com estes autores, considera-se: 
a) Espécies constantes (W): C> o limite superior (LS) do IC5\%;

b) Espécies acessórias (Y): C entre os limites (LI e LS) do IC5\%;

c) Espécies acidentais (Z): C< o limite inferior (LI) do IC5\%.

\subsection{Dominância}

Segundo Silveira Neto; Nakano e Vila Nova (1976), considera-se dominante a espécie que possui a capacidade de receber o impacto do ambiente e transformá-lo em benefício próprio, podendo causar o aparecimento ou desaparecimento de outros organismos. $\mathrm{O}$ nível de dominância de uma espécie é determinado através da fórmula:

$$
\mathrm{LD}=(1 / \mathrm{S}) \times 100
$$

sendo:

$\mathrm{LD}=$ limite de dominância

$\mathrm{S}=$ número total de espécies

Considerou-se dominante a espécie que apresentou o limite inferior ( $\mathrm{Li}$ ) maior que o inverso do número total de espécies multiplicado por 100, de acordo com Sakagami e Matsumura (1967).

\subsection{5 Índice de diversidade $(\alpha)$}

Este índice é obtido através da relação entre a riqueza e uniformidade dos indivíduos em uma comunidade. $\mathrm{O}$ índice de diversidade das comunidades estudadas foi obtido através da fórmula:

$$
\text { Índice } H^{\prime} \text { (Shannon-Wiener): } \quad H=-\sum p_{i}\left(\ln p_{i}\right)
$$

sendo:

$H^{\prime}=$ componente de riqueza de espécies;

$p_{i}=$ frequência relativa da espécie $i$ dada por $n_{i} / \mathrm{N}$;

$n i=$ número de indivíduos da espécie $i$;

$\mathrm{N}=$ número total de indivíduos;

$\ln =$ logaritmo neperiano. 


\subsubsection{Análise do mel}

Os méis produzidos no fragmento estudado foram avaliados quanto às propriedades físico-químicas. Para isso, realizou-se previamente uma inspeção ao longo da trilha com o propósito de levantar os enxames de Apis mellifera existentes no local. Três dos enxames encontrados foram capturados e instalados em colméias tipo Langstroth, sendo responsáveis pela produção do mel destinado às análises. As amostras de méis foram coletadas mensalmente durante o período de 12 meses a contar de junho de 2003.

Para evitar a mistura do mel formado nos diferentes meses de coleta, dois quadros de melgueira foram previamente marcados e colocados ao centro, sendo destinados à coleta do mel durante todo período de realização do experimento.

O procedimento usado na obtenção dos méis foi o habitual, ou seja, os quadros foram centrifugados e o produto filtrado e decantado.

Através das análises físico-químicas determinou-se os teores de açúcares, umidade, HMF, cor, condutividade elétrica, $\mathrm{pH}$, acidez, índice de formol, cinzas, número de diastase, proteínas e viscosidade. As análises polínicas permitiram determinar a origem floral das amostras.

Estes dados possibilitaram tipificar o mel produzido na área estudada, contribuindo para a montagem de um banco de dados correspondente ao padrão dos méis produzidos em áreas de cerrado.

Todas as análises foram realizadas no Laboratório de Insetos Úteis do Departamento de Entomologia, Fitopatologia e Zoologia Agrícola da Escola Superior de Agricultura "Luiz de Queiroz", campus de Piracicaba/USP.

\subsection{Açúcares totais, redutores e sacarose (\%)}

Para determinar os teores de açúcares totais, redutores e porcentagem de sacarose usou-se o método proposto por Coopersucar (1987) com modificações (MARCHINI; SODRÉ; MORETI, 2004).

\subsection{Hidroximetilfurfural (mg. $\left.\mathrm{kg}^{-1}\right)$}

O hidroximetilfurfural foi determinado conforme metodologia de A.O.A.C (1990). 


\subsection{Número de diastase (Escala de Göthe)}

A atividade diastásica foi determinada conforme metodologia de C.A.C. (1990).

\subsection{Umidade (\%)}

A umidade foi determinada logo após a colheita do mel, com o auxílio de um refratômetro manual marca ATAGO (luz natural e temperatura ambiente) específico para mel. Este método baseia-se no fenômeno da refração (variação da velocidade da luz no vácuo e numa substância) que um raio de luz sofre ao incidir sobre uma solução de mel, que apresenta sólidos solúveis.

\subsection{Condutividade elétrica $(\mu S)$}

Para determinação da condutividade elétrica, usou-se um condutivímetro modelo HI8820. O mel usado na determinação da condutividade elétrica apresentou cerca de $20 \%$ de matéria seca a $20^{\circ} \mathrm{C}$, conforme proposto por Réndon (1996).

\subsection{Cor (nm)}

A cor do mel foi determinada pelo Método de Bianchi (1986), com medição espectrofotométrica e posterior transformação por meio da tabela de Pfund.

\subsubsection{7 $\mathrm{pH}$, acidez (meq. $\left.\mathrm{kg}^{-1}\right)$ e índice de formol (mL. $\left.\mathrm{kg}^{-1}\right)$}

$\mathrm{O} \mathrm{pH}$, acidez e índice de formol foram determinados segundo método proposto pelo Laboratório do Centro de Apicultura Tropical do Instituto de Zootecnia de Pindamonhangaba/SP (MORAIS; TELXEIRA, 1998).

\subsection{Cinzas (\%)}

O teor de cinzas foi determinado por meio de calcinação em mufla a $550^{\circ} \mathrm{C}$ até um peso constante (BOGDANOV; MARTIN; LULLMANN, 1997).

\subsection{Proteína (\%)}

A porcentagem de proteína no mel foi determinada segundo as normas analíticas do Instituto Adolfo Lutz (PREGNOLATO, 1985). 


\subsection{Viscosidade (mPa.s)}

A viscosidade foi determinada com o auxílio do viscosímetro Brookfield, modelo $100 \mathrm{~S}$ digital, por meio da medição de torque originado pela resistência que o mel exerce ao movimento rotacional (CAMPOS, 1998).

\subsubsection{Análise polínica do mel e das bolotas de pólen}

A análise polínica do mel e das bolotas de pólen foi determinada através da acetólise (LOUVEAUX; MAURIZIO; VORWOHL, 1970). Este método consiste no tratamento químico do grão de pólen, eliminando a intina, o citoplasma e as substâncias aderentes aos grãos, fossilizando-os artificialmente. Este processo torna a exina mais transparente e, portanto, mais própria para o estudo de seus detalhes.

Para a análise do pólen contido no mel foram preparadas três lâminas de cada amostra de mel analisada. As bolotas de pólen coletadas pelas campeiras foram obtidas com o auxílio de coletores que eram acoplados às colméias durante a coleta do mel. Após a homogeneização das amostras, foi separado $1 \mathrm{~g}$ do material para confecão das lâminas preparadas (com três repetições) também pelo método da acetólise.

A análise qualitativa determinou os tipos polínicos presentes nas amostras. Esta análise fornece informações para caracterização dos méis quanto a sua origem botânica e determinação do mel de origem desconhecida (BARTH, 1970a).

A análise quantitativa foi realizada através da contagem consecutiva de 300 grãos de pólen, sendo consideradas as seguintes classes de freqüência: pólen dominante (PD) mais de $45 \%$ do total; pólen acessório (PA) de 16 a 45\%; pólen isolado (PI) de 3 a 15\% e pólen isolado ocasional (PIO) para pólens com valor inferior a 3\% (BARTH, 1970b; LOUVEAUX; MAURIZIO; VORWOHL, 1978). Esta análise permitiu avaliar o grau de contribuição das espécies na formação do mel estudado.

Os tipos polínicos foram identificados com base no laminário de referência existente no laboratório de Apicultura do Departamento de Entomologia, Fitopatologia e Zoologia Agrícola da ESALQ/USP. O trabalho de identificação foi feito com a colaboração da Dra. Augusta Carolina de C. C. Moreti (Instituto de Zootecnia de Nova Odessa-SP) e da Dra. Ortrud Mônika Barth (Instituto Oswaldo Cruz-RJ). 


\subsubsection{Identificação das plantas visitadas por abelhas}

As plantas coletadas foram montadas em exsicatas e identificadas pela equipe do Prof. Dr.

Vinícius Castro de Souza do Laboratório de Sistemática Vegetal do Departamento de Ciências Biológicas da ESALQ/USP. 


\subsection{RESULTADOS E DISCUSSÃO}

\subsubsection{Composição da fauna e flora}

A comunidade de abelhas foi representada por 501 indivíduos pertencentes a 04 famílias, 07 subfamílias, 12 tribos, 22 gêneros e 34 espécies (Tabela 1).

Quando analisado o número de indivíduos coletados por família, Apidae apresentou maior abundância (91,2\%), seguido por Halictidae (6,8\%), Megachilidae (1,2\%) e Andrenidae (0,8\%).

Distribuição semelhante foi observada com relação ao número de gêneros e espécies por família, havendo maior abundância para Apidae $(68,2 \%)$ seguido por Halictidae (18,2\%), Megachilidae (9,1\%) e Andrenidae (4,5\%). Quanto ao número de gêneros e com relação ao número de espécies, Apidae apresentou (68,6\%), seguido por Halictidae (20,0\%), Megachilidae $(8,6 \%)$ e Andrenidae (2,9\%) (Figura 2).

Mateus (1998) estudando a comunidade de Apoidea em área de cerrado no município de Luiz Antônio/SP, observou que Apidae apresentou maior abundância em relação às demais famílias. Almeida (2002) e Andena (2002) estudando a comunidade de abelhas no cerrado de outros municípios do Estado de São Paulo encontraram a mesma proporção. A família Apidae também apresentou maior abundância em outras formações vegetais, como a caatinga (MARTINS, 1990; CAVALHO, 1999), campos rupestres (FARIA; CAMARGO, 1996) e pastagem abandonada (CURE et al., 1993; SILVEIRA et al., 1993). 


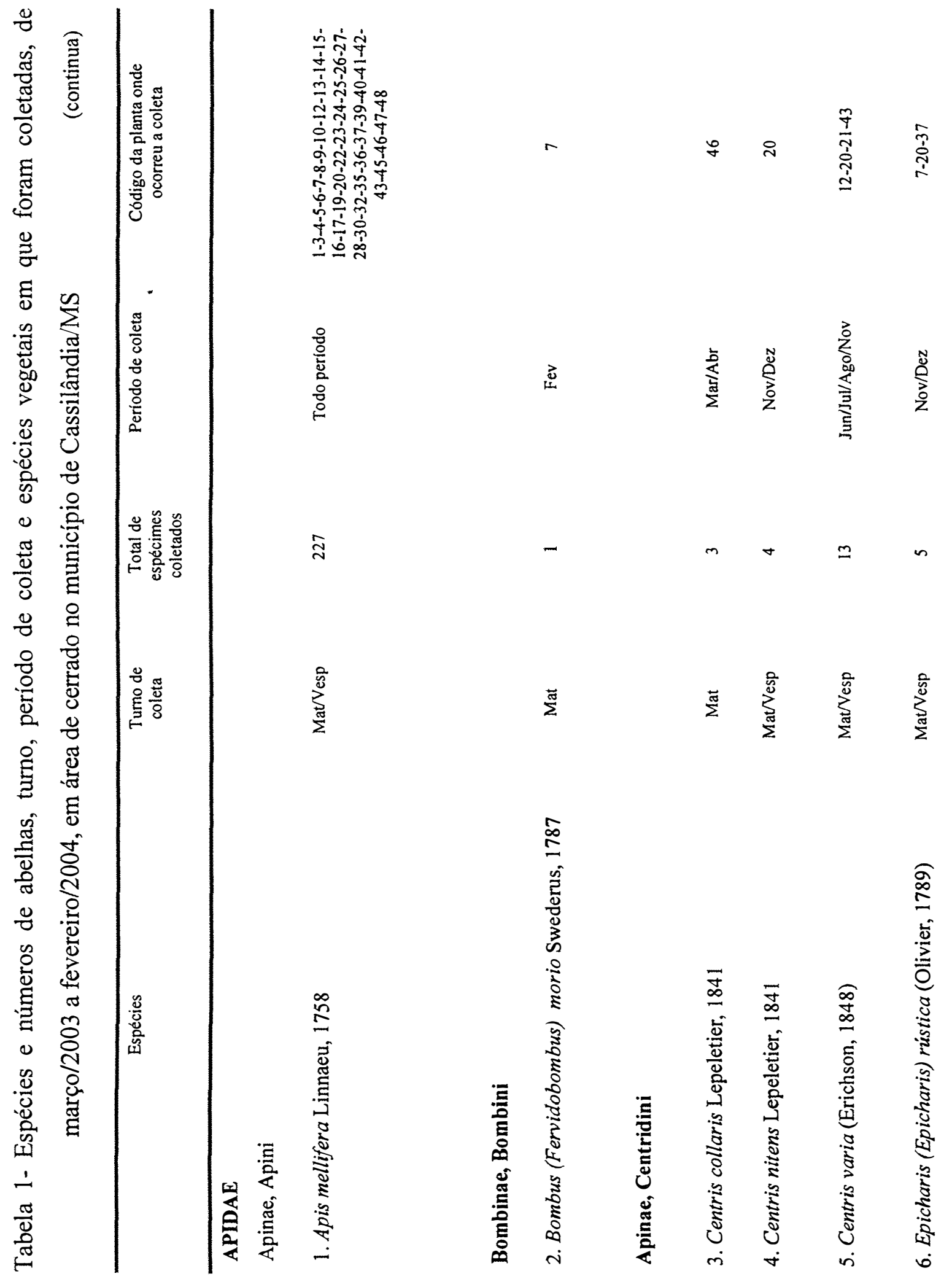




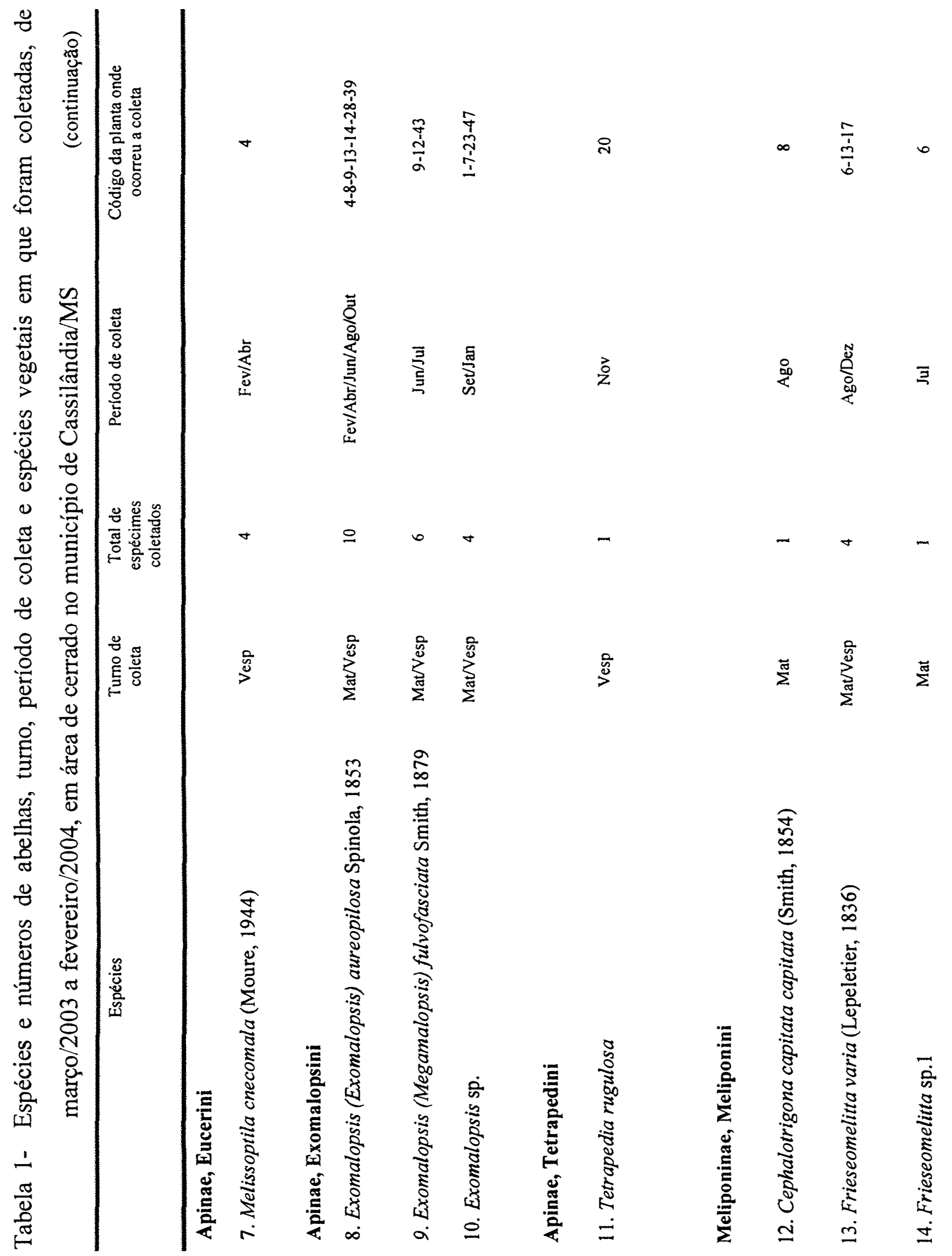




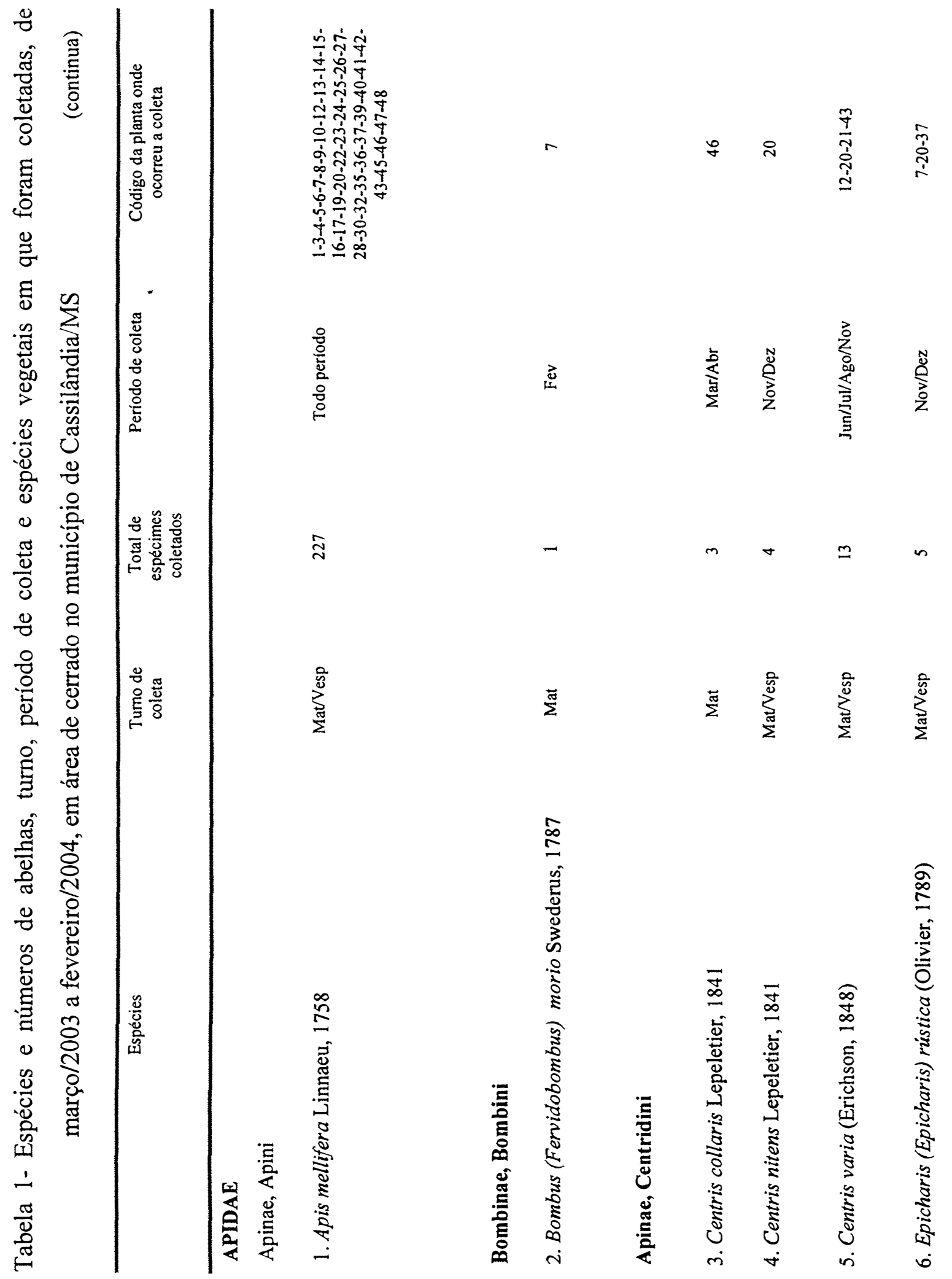




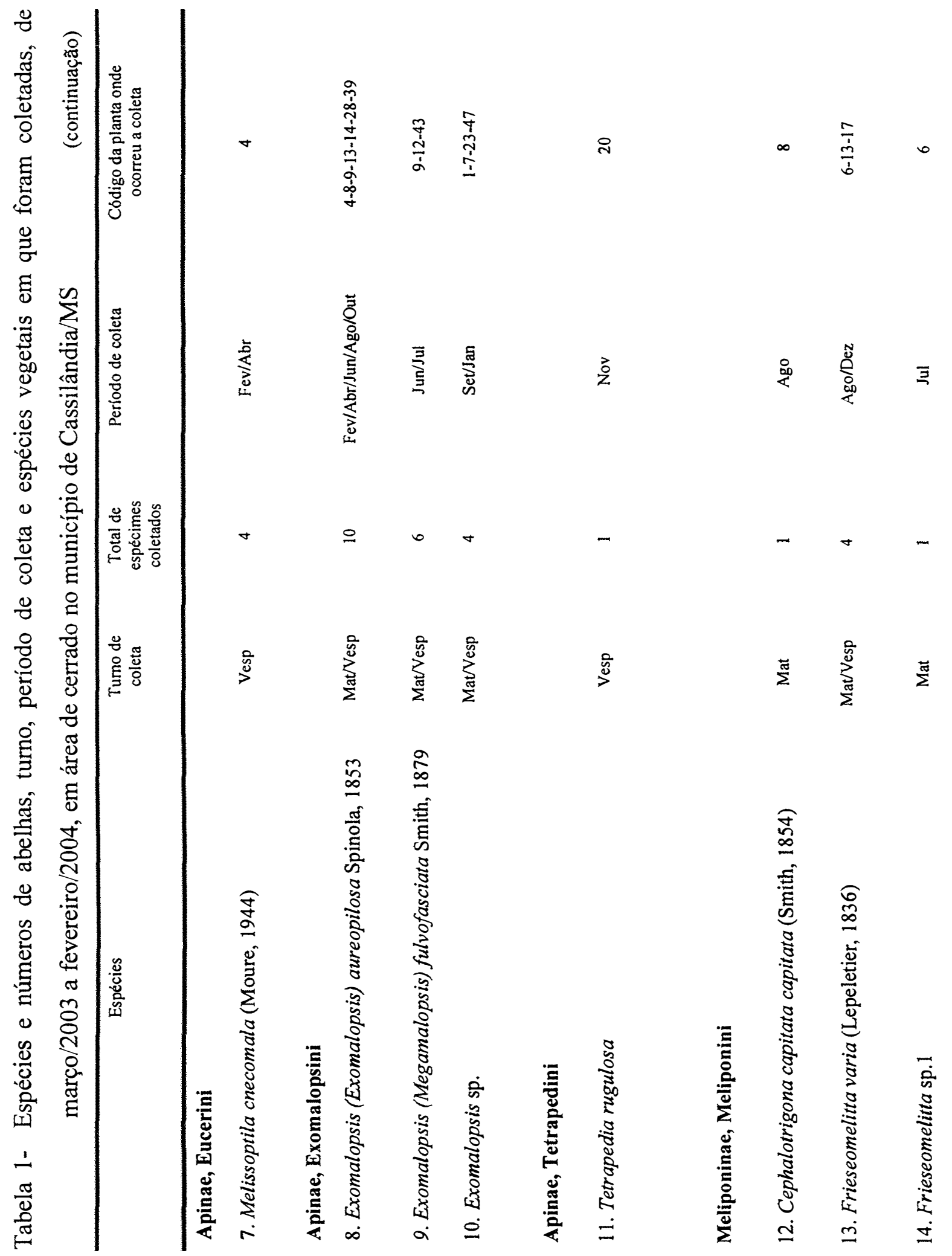




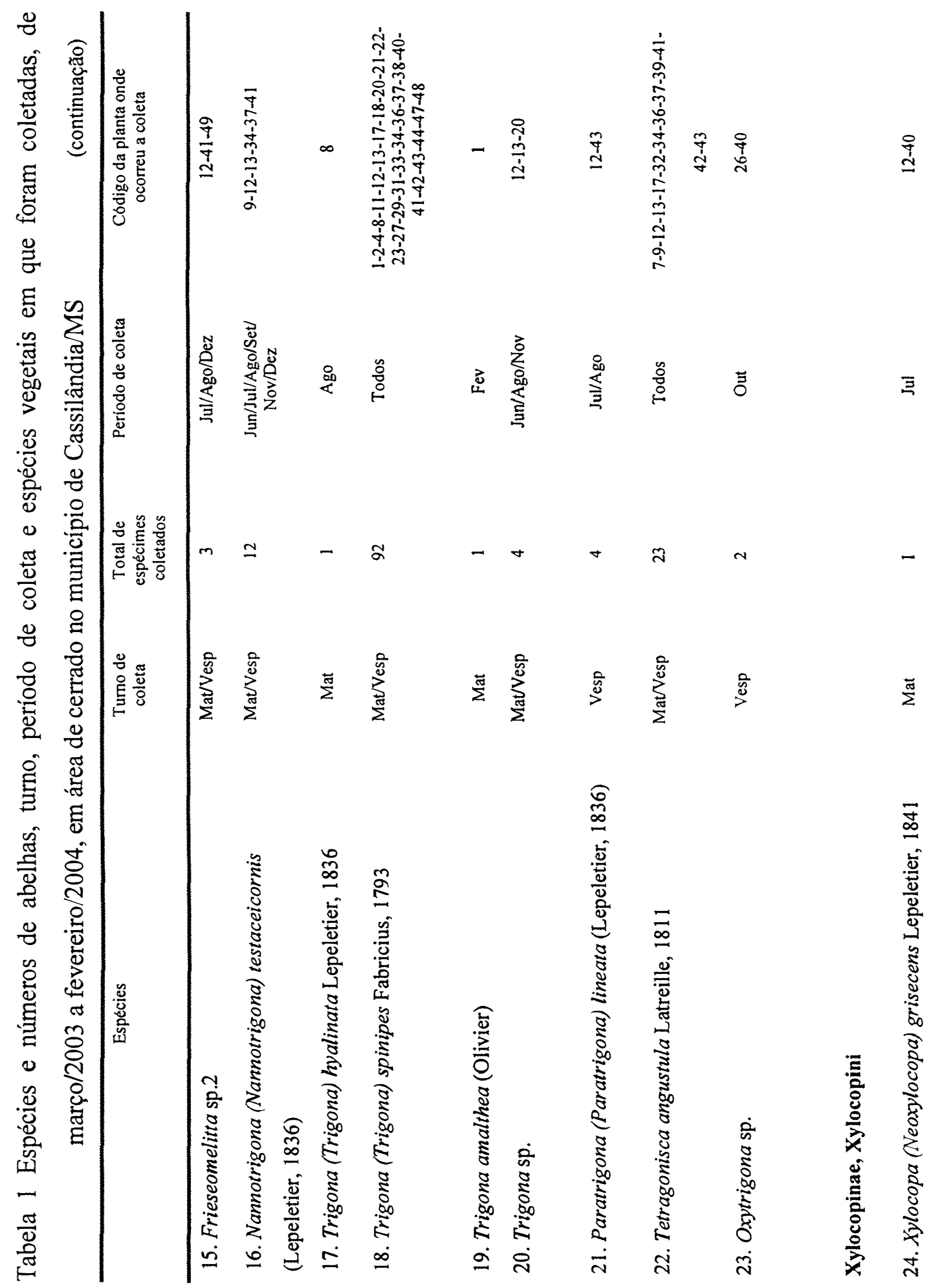




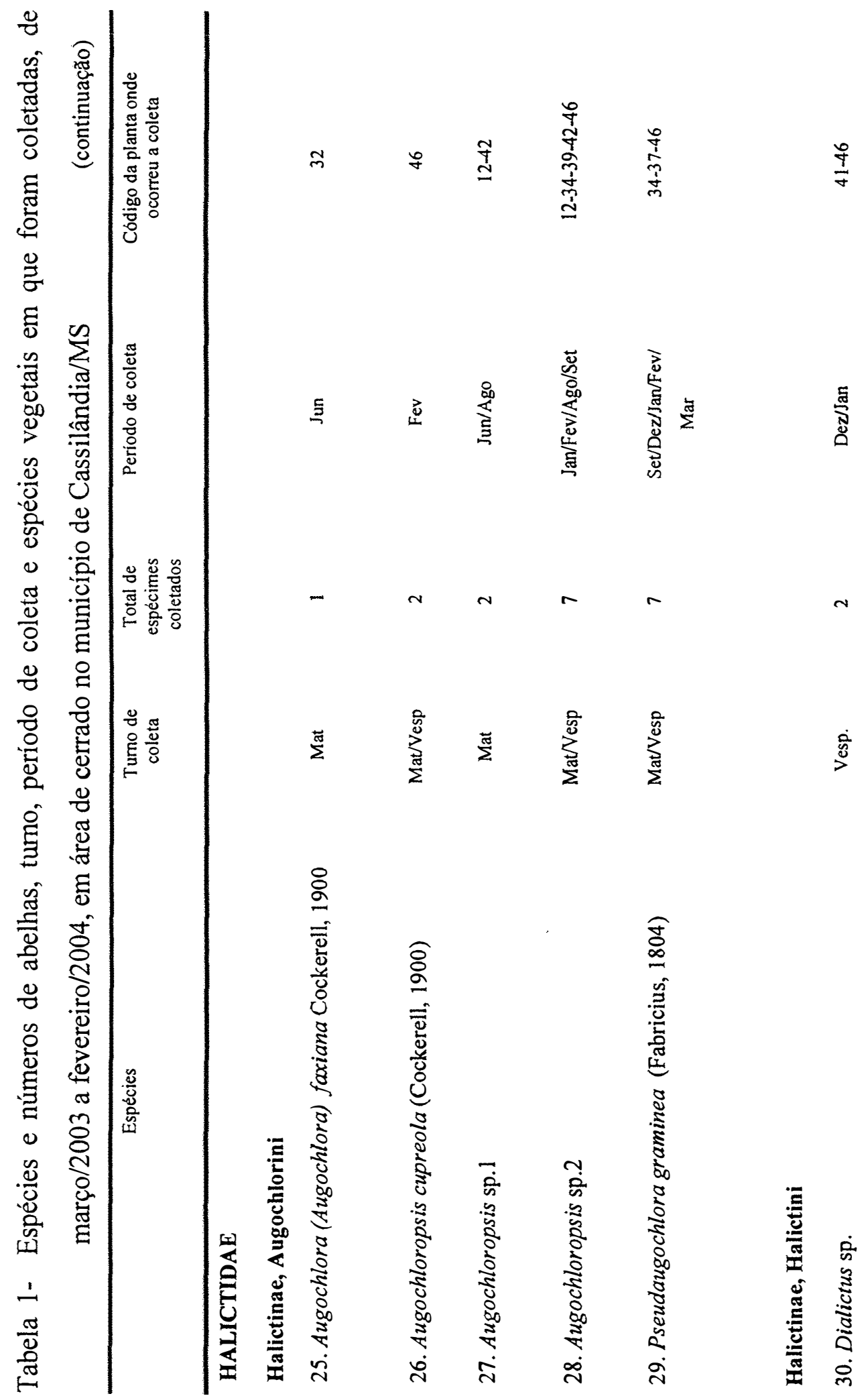


ข

$\frac{8}{8}$

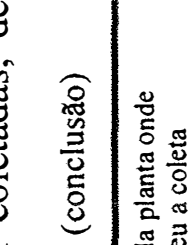

ह

ซ

$\frac{8}{2}$

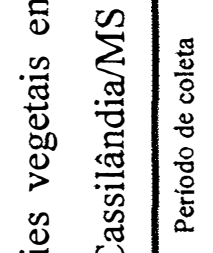

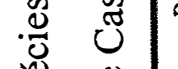

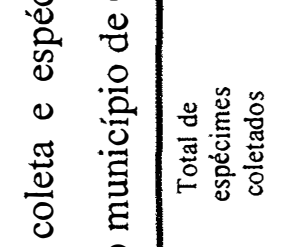

음

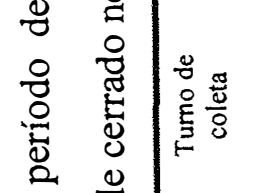

:

คิ

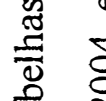

त.

ก

莺

先

분

巧
$\stackrel{\widetilde{N}}{\stackrel{ \pm}{ \pm}}$

密

$\sum_{\substack{\infty \\ \infty}}^{\pi}$

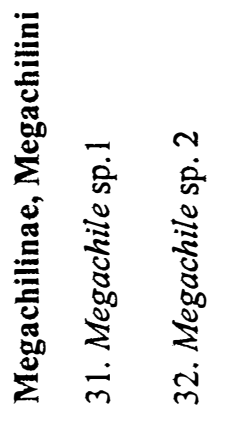

웅

雚

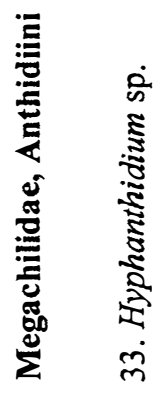

茫

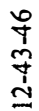

$\Xi$

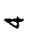

ธิ

这
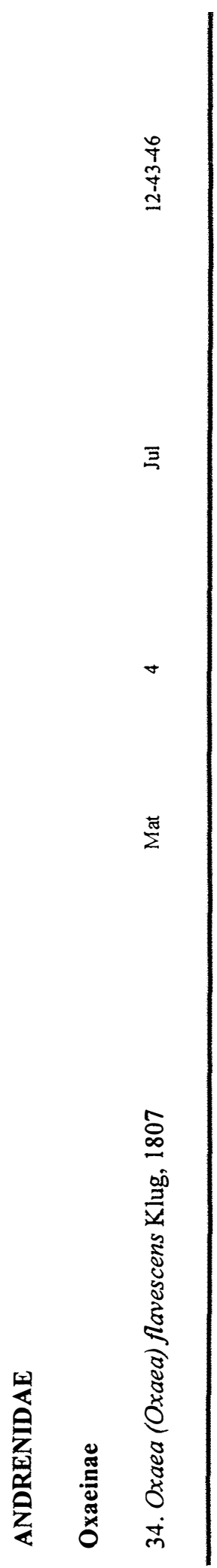


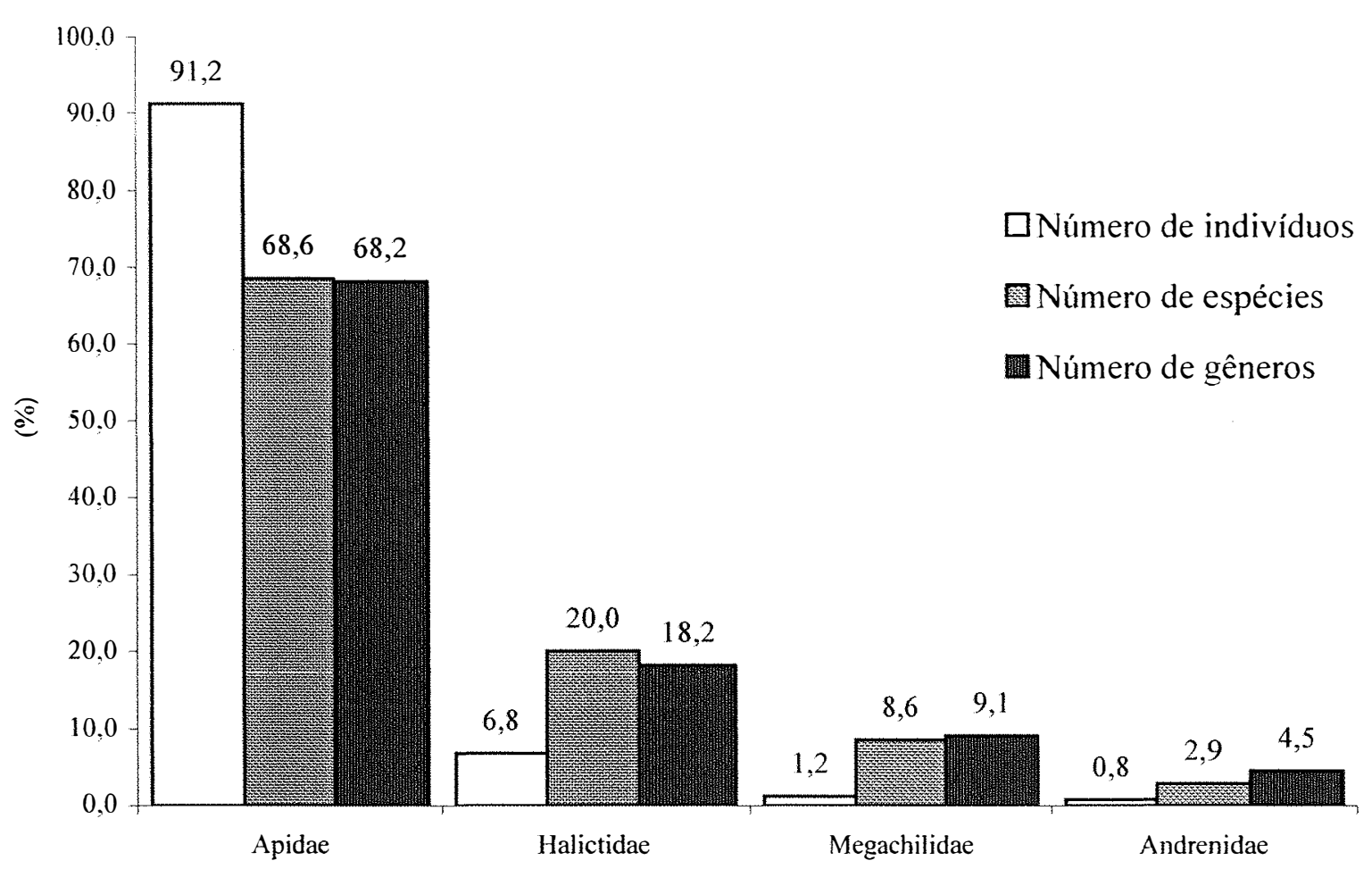

Figura 2 - Índices percentuais obtidos para o número de indivíduos, espécies e gêneros em relação as famílias de abelhas (Apoidea) obtidas de março/2003 a fevereiro/2004, em área de cerrado no município de Cassilândia/MS

O padrão de abundância de espécies observado neste estudo está em conformidade com vários trabalhos sobre comunidades ecológicas, onde observa-se um número pequeno de espécies abundantes sendo a maioria delas rara.

Laroca (1992) analisou diferentes estudos de comunidades de abelhas e concluiu que há uma tendência de se encontrar muitas espécies com poucos indivíduos em diferentes ecossistemas no mundo. Esta hipótese é reforçada por outros estudos (LAROCA , 1974; HEITHAUS, 1979; CURE-HAKIM, 1983; CAMPOS, 1989; SILVEIRA, 1989; BORTOLI; LAROCA, 1990; ZANELLA, 1991; PEDRO, 1992; BARBOSA; LAROCA, 1993; MATEUS, 1998; CARVALHO, 1999). Segundo Andena (2002) este padrão é típico de ecossistemas tropicais. Clássicos da literatura ecológica afirmam que as comunidades ecológicas tendem a apresentar poucas espécies abundantes, sendo a maioria rara (ODUM, 1988; BEGON, 1996). 
Existem vários fatores que podem ser apontados como prováveis causas das variações no número de espécies, de cada família, em diferentes locais (SILVEIRA et al., 1993). Entre eles, destacam-se as condições de nidificação, competição por recursos e a história da distribuição de cada grupo (ROUBIK, 1989).

Autores como Sakagami; Laroca e Moure (1967); Knoll (1985); Campos (1989); Martins (1990); Pedro (1992); Cure et al. (1993); Carvalho e Bego (1995); Sofia (1996) afirmam que a grande abundância da família Apidae se deve à presença de espécies altamente sociais, principalmente Apis mellifera e Trigona spinipes. Esta dominância é explicada pelo modo de vida eussocial dessas abelhas (SAKAGAMI; LAROCA; MOURE, 1967; SAKAGAMI; LAROCA, 1971; SAKAGAMI; FUKUDA, 1973; ALMEIDA; LAROCA, 1988). Os ninhos perenes podem abrigar um número elevado de indivíduos (NOGUEIRA NETO, 1970; MICHENER, 1974; HUBBELL; JOHNSON, 1977; WILLE, 1983), que resulta em um número maior de abelhas forrageando (SAKAGAMI; LAROCA; MOURE, 1967). Além disso, a capacidade de comunicação desses insetos leva um grande número de operárias provenientes de uma mesma colônia a explorar o mesmo recurso.

Essas características têm levado muitos autores a questionar a manutenção dos insetos sociais nas análises faunísticas em estudos de comunidade. Segundo estes autores, a inclusão dessas espécies poderia influenciar a distribuição de outras espécies não sociais nas diferentes classes dos índices faunísticos. No entanto, como elas interagem com outras abelhas e são importantes na distribuição dos recursos na comunidade, Cure et al. (1991) recomendaram tanto a coleta simultânea com as demais abelhas, como sua inclusão nas análises ecológicas.

Dentre as espécies sociais dominantes da família Apidae merece destaque Apis mellifera, cuja abundância é explicada por fatores como hábito generalista, largo período de forrageamento, elevada densidade populacional, sofisticado sistema de comunicação e baixa exigência para locais de nidificação (ROUBIK, 1989). Quanto ao hábito generalista de Apis mellifera e Trigona spinipes, muitos trabalhos apontam a grande diversidade de plantas visitadas por estas abelhas (CAMPOS, 1989; PEDRO, 1992; SOFIA, 1996; MATEUS, 1998; CARVALHO, 1999; ANDENA, 2002), sendo este fato observado também neste trabalho.

Segundo Price (1982) a estratégia generalista de coleta dos recursos é mais adaptada às oscilações na oferta de alimento, possibilitando a adequação das espécies às fontes disponíveis, 
mesmo quando há competição. Sem dúvida, esta é uma das características que explica o grande êxito apresentado por Apis mellifera após sua introdução na América do Sul.

A família Apidae também foi a mais ativa durante todo o período de coleta (Tabela 1), tendo as espécies Apis mellifera e Trigona spinipes sido responsáveis mais uma vez por este resultado. O mesmo comportamento foi observado em outros estudos (SAKAGAMI; LAROCA; MOURE, 1967; SAKAGAMI; LAROCA, 1971; HEITHAUS, 1979; KNOLL, 1985; CAMPOS, 1989; ROUBIK, 1989; MARTINS, 1990; PEDRO; CAMARGO, 1991; COELHOCARVALHO; BEGO, 1995; SILVEIRA; CAMPOS, 1995; AGUIAR; MARTINS, 1997; MATEUS, 1998; ANDENA, 2002). A ausência de um padrão sazonal observado nos Apidae, também é explicada pela sua característica eussocial (SAKAGAMI; LAROCA; MOURE, 1967; SAKAGAMI; LAROCA, 1971).

Halictidae foi a segunda família em abundância de espécies. Outros estudos realizados em área de cerrado apresentaram resultados neste sentido (SILVEIRA, 1989; CARVALHO, 1990; PEDRO, 1992; COELHO-CARVALHO; BEGO, 1996; MATEUS, 1998; CAMPOS, 1989; ALMEIDA, 2002; ANDENA, 2002).

No sul do Brasil a família Halictidae tem apresentado maior abundância de espécies em relação às demais (LAROCA; CURE; BORTOLI, 1982; TAURA, 1990; SOFIA, 1996). O mesmo foi observado por Knoll; Bego e Imperatriz-Fonseca (1987) em estudos realizados na USP campus de São Paulo.

Embora este padrão seja comum em vários trabalhos, não há explicação concreta para o fato. Sabe-se apenas que nos ecossistemas com distúrbio há uma tendência ao aumento na proporção de espécies desta família (SAKAGAMI; LAROCA; MOURE, 1967; SAKAGAMI; FUKUDA, 1973; LAROCA; CURE; BORTOLI, 1982; ROUBIK, 1989) e que a riqueza de espécies tende a aumentar à medida que se afasta do equador (CARVALHO, 1999).

Megachilidae foi a terceira família em abundância, apresentando três espécies. Roubik (1979) estudou a comunidade de abelhas na Guiana Francesa, observando uma baixa diversidade de espécies desta família. Padrão semelhante foi observado em outros estudos realizados em área de cerrado (CAMPOS, 1989; CARVALHO, 1990; MATEUS, 1998; ALMEIDA, 2002; ANDENA, 2002).

Laroca; Cure e Bortoli (1982) atribuíram, em parte, a baixa diversidade de espécies da família Megachilidae aos impactos causados pela ação antrópica, que interferem diretamente na 
disponibilidade dos nutrientes usados na confecção dos ninhos. Roubik (1979) afirma que a baixa freqüência de espécies de Megachilidae observada em alguns estudos, estaria relacionada à restrita distribuição espacial e temporal das espécies, aliada ao hábito especializado de forrageamento.

Andrenidae foi a última família em abundância de espécies, sendo representada apenas por Oxaea flavescens. Dados sobre esta espécie são escassos, mas padrão semelhante foi observado por Campos (1989); Silveira (1989); Pedro (1992); Coelho-Carvalho e Bego (1995); Mateus (1998) e Andena (2002). Segundo Mateus (1998), Andrenidae é normalmente pouco representada em área de cerrado. Este autor ressalta ainda que Oxaea flavescens é a espécie quase exclusiva desta formação vegetal. De acordo com Michener (1979) e Roubik (1989), Andrenidae apresenta maior diversidade nas regiões Paleártica e Neártica. Outros autores reforçam esta hipótese afirmando que esta família é pouco representada na região neotropical (SAKAGAMI; LAROCA; MOURE, 1967; LAROCA; CURE; BORTOLI, 1982; BORTOLI; LAROCA, 1990; SILVEIRA et al. 1993; MARTINS, 1994; SILVEIRA; CAMPOS, 1995).

A Tabela 2 apresenta as classes de freqüência, constância, abundância e dominância das abelhas. Grande parte das espécies foi considerada freqüente nas amostras $(42,86 \%)$, seguida de pouco freqüente $(40 \%)$, muito freqüente $(11,43 \%)$ e super freqüente $(5,71 \%)$. Foram consideradas super freqüente apenas as espécies Apis mellifera e Trigona spinipes.

Com relação à constância nas amostras, $45,71 \%$ das espécies foram consideradas acidentais, $31,43 \%$ acessórias e 22,86\% constantes, representando esta última classe as espécies Apis mellifera, Augochlora graminea, Centris varia, Exomalopsis aureopilosa, Nannotrigona testaceicornis, Tetragonisca angustula, Trigona hyalinata e Trigona spinipes.

Quanto ao padrão de abundância das espécies observado neste trabalho, $42,86 \%$ das espécies foram consideradas comuns, $31,43 \%$ raras, $11,43 \%$ muito abundantes, $8,57 \%$ dispersa e 5,71\% super abundante, sendo esta última classe representada por Apis mellifera e Trigona spinipes. 
Tabela 2 - Classes de freqüência, constância, abundância e dominância de espécies de abelhas coletadas de março/2003 a fevereiro/2004, em área de cerrado no município de Cassilândia/MS

\begin{tabular}{|c|c|c|c|c|}
\hline Espécie & Freqüência & Constância $^{2}$ & Abundância $^{3}$ & Dominância \\
\hline Apis mellifera & SF & W & $\mathrm{sa}$ & SD \\
\hline Augochlora faxiana & PF & $\mathrm{Z}$ & $\mathrm{r}$ & ND \\
\hline Augochloropsis cupreola & $\mathrm{F}$ & Z & c & ND \\
\hline Augochloropsis sp.1 & $\mathrm{PF}$ & $\mathrm{Z}$ & $\mathrm{r}$ & ND \\
\hline Augochloropsis sp.2 & $\mathrm{F}$ & Y & c & ND \\
\hline Augochlora gramínea & $\mathrm{F}$ & W & c & $\mathrm{D}$ \\
\hline Bombus morio & PF & $\mathrm{Z}$ & $\mathrm{r}$ & ND \\
\hline Centris collaris & $\mathrm{PF}$ & $\mathrm{Z}$ & $\mathrm{r}$ & ND \\
\hline Centris nitens & $\mathrm{F}$ & Y & $\mathrm{c}$ & $\mathrm{D}$ \\
\hline Centris varia & MF & W & $\mathrm{ma}$ & $\mathrm{D}$ \\
\hline Cephalotrigona capitata & PF & $\mathrm{Z}$ & $\mathrm{r}$ & ND \\
\hline Dialictus sp. & $\mathrm{F}$ & $\mathrm{Z}$ & c & ND \\
\hline Epicharis rústica & $\mathrm{F}$ & $\mathrm{Y}$ & c & ND \\
\hline Exomalopsis aureopilosa & $\mathrm{F}$ & W & c & $\mathrm{D}$ \\
\hline Exomalopsis fulvofasciata & $\mathrm{F}$ & $\mathrm{Y}$ & c & ND \\
\hline Exomalopsis sp. & PF & Z & $\mathrm{d}$ & ND \\
\hline Frigeomelitta sp.1 & $\mathrm{PF}$ & $\mathrm{Z}$ & $\mathrm{r}$ & ND \\
\hline Frigeomelitta sp.2 & $\mathrm{F}$ & Y & c & ND \\
\hline Frigeomelitta varia & $\mathrm{PF}$ & Y & $d$ & ND \\
\hline Hypanthidium sp. & PF & $\mathrm{Z}$ & $\mathrm{r}$ & ND \\
\hline Megachile sp.1 & $\mathrm{F}$ & Y & c & ND \\
\hline Megachile sp.2 & $\mathrm{PF}$ & Z & $\mathrm{r}$ & ND \\
\hline Melissoptila cnecomala & $\mathrm{F}$ & $\mathrm{Z}$ & $\mathrm{c}$ & ND \\
\hline Nannotrigona testaceicornis & MF & W & $\mathrm{ma}$ & $\mathrm{D}$ \\
\hline Oxaea flavescens & $\mathrm{F}$ & $\mathrm{Y}$ & c & ND \\
\hline Oxytrigonasp. & $\mathrm{PF}$ & $\mathrm{Z}$ & $\mathrm{d}$ & ND \\
\hline Paratrigona lineata & $\mathrm{F}$ & $\mathbf{Y}$ & c & ND \\
\hline Pseudoaugochloropsis graminea & $\mathrm{F}$ & Y & c & $\mathrm{D}$ \\
\hline Tetragonisca angustula & MF & W & $\mathrm{ma}$ & $\mathrm{D}$ \\
\hline Tetrapedia rugulosa & PF & $\mathrm{Z}$ & $\mathrm{r}$ & ND \\
\hline Trigona hyalinata & MF & W & $\mathrm{ma}$ & $\mathrm{D}$ \\
\hline Trigona spinipes & SF & W & sa & SD \\
\hline Xylocopa grisescens & $\mathrm{PF}$ & Z & $\mathrm{r}$ & ND \\
\hline Trigona sp. & $\mathrm{F}$ & $\mathrm{Y}$ & c & $\mathrm{D}$ \\
\hline Trigona amalthea & $\mathrm{PF}$ & $\mathrm{Z}$ & $\mathrm{r}$ & ND \\
\hline
\end{tabular}

Das espécies obtidas neste estudo, 68,57\% foram consideradas não dominantes, $25,71 \%$ dominantes e 5,71\% super dominantes, sendo consideradas super dominantes apenas as espécies Apis mellifera e Trigona spinipes. 
Considerando os resultados apresentados na Tabela 2, classificou-se como predominantes neste trabalho as espécies Apis mellifera e Trigona spinipes.

A predominância de Apis mellifera e Trigona spinipes já foi documentada em outros levantamentos (CARVALHO, 1999; ALMEIDA, 2002; ANDENA, 2002). Carvalho (1999) ressaltou que $A$. mellifera apresenta características favoráveis à dominância, como hábitos generalistas e colônias populosas, o que faz com que esta espécie seja comum nos estudos sobre Apoidea. Com relação a Trigona spinipes, sua abundância estaria relacionada a agressividade das campeiras, instalação de ninhos em locais de difícil acesso, hábito generalista e colônias populosas (ALMEIDA; LAROCA, 1988).

$\mathrm{O}$ índice de diversidade de espécies (Shannon-Wiener) encontrado na área estudada foi de 0,8920; $\mathrm{V}(\mathrm{H})=0,0003$. De acordo com Silveira Neto; Nakano e Vila Nova (1976), o índice de diversidade pode ser comparado entre comunidades, pois não depende do processo de levantamento e tamanho da amostra. Almeida (2002) estudou a comunidade de Apoidea em duas áreas de cerrado, obtendo índice de diversidade (Shannon-Wiener) H=2,3987 para o cerradão e $\mathrm{H}=2,8914$ para o cerrado senso stricto. Outros estudos realizados em área de cerrado apresentaram os seguintes resultados: Silveira (1989), $\mathrm{H}=1,92$; Campos (1989), $\mathrm{H}=1,70$; Andena (2002), H=3,0; Coelho-Carvalho e Bego (1996), $\mathrm{H}=1,51$.

Comparando os índices obtidos por diferentes autores nota-se que a menor diversidade foi observada no presente estudo. Segundo Silveira Neto; Nakano e Vila Nova (1976) ambientes que sofrem forte influência dos fatores limitantes associado a uma forte competição interespecífica tendem a apresentar um baixo índice de diversidade, apresentando um número maior de espécies comuns e menor de espécies raras. O local estudado corresponde a um fragmento florestal circundado por extensas áreas de pastagens, com isso, é muito provável que os fatores mencionados por Silveira Neto; Nakano e Vila Nova (1976) associados a grande dominância de Apis mellifera e Trigona spinipes sejam os grandes responsáveis pelo baixo índice encontrado.

A flora apícola obtida no presente trabalho foi composta por 140 amostras, pertencentes a 49 espécies, 41 gêneros e 26 famílias (Tabela 3). 
Tabela 3 -Relação de espécies de plantas apícolas coletadas em área de cerrado no município de Cassilândia/MS, de março/2003 a fevereiro/2004

(continua)

\begin{tabular}{|c|c|c|c|}
\hline Familia & Espécie & $\begin{array}{l}\text { Código da } \\
\text { amostra }\end{array}$ & Período de coleta \\
\hline Alismataceae & $\begin{array}{l}\text { Echinodorus cf. grandiflorus (Cham. \& } \\
\text { Schltdl.) Micheli }\end{array}$ & 1 & Jan \\
\hline Anacardiaceae & Myracrodruon urundeuva Fr. All. & 2 & Agosto \\
\hline Apocynaceae & Forsterona pubescens Mull. Arg. & 3 & Outubro \\
\hline Asclepiadaceae & Oxypetalum sp. & 4 & Abril/Maio \\
\hline Asteraceae & $\begin{array}{l}\text { Eupatorium sp. } \\
\text { Vernonia ferruginea Less. }\end{array}$ & $\begin{array}{l}5 \\
6\end{array}$ & $\begin{array}{c}\text { Maio } \\
\text { Julho/Agosto }\end{array}$ \\
\hline Bignoniaceae & $\begin{array}{l}\text { Arrabidaea chica (Humb. \& Bonpl.) B. } \\
\text { Verl. } \\
\text { Tabebuia roseo-alba (Ridl.) Sand. }\end{array}$ & 7 & $\begin{array}{l}\text { Janeiro/Fevereiro } \\
\text { Agosto }\end{array}$ \\
\hline Boraginaceae & Cordia trichotoma (Vell.) Amab. ex. & 9 & Junho/Julho \\
\hline $\begin{array}{l}\text { Fabaceae: } \\
\text { Caesalpinioideae }\end{array}$ & $\begin{array}{l}\text { Apuleia leiocarpa (Vogel) Macbride } \\
\text { Bauhinia rufa Steud. } \\
\text { Senna rostrata (Mart.) }\end{array}$ & $\begin{array}{l}10 \\
11 \\
12\end{array}$ & $\begin{array}{c}\text { Setembro } \\
\text { Abril } \\
\text { Junho/Julho/Ago/Set }\end{array}$ \\
\hline Combretaceae & $\begin{array}{l}\text { Terminalia argêntea Mart. et Succ. } \\
\text { Terminalia brasiliensis Camb. }\end{array}$ & $\begin{array}{l}13 \\
14\end{array}$ & $\begin{array}{l}\text { Agosto/Dezembro } \\
\text { Agosto }\end{array}$ \\
\hline Dilleniaceae & Doliocarpus dentatus (Aubl.) Standl. & 15 & Maio \\
\hline Euphorbiaceae & Sgrim glardulatum & 16 & Outubro/Novembro \\
\hline $\begin{array}{l}\text { Fabaceae: } \\
\text { Faboideae }\end{array}$ & Crotalaria incana $\mathrm{L}$. & 17 & Outubro/Dezembro \\
\hline
\end{tabular}


Tabela 3 - Relação de espécies de plantas apícolas coletadas em área de cerrado no município de Cassilândia/MS, de março/2003 a fevereiro/2004

(continuação)

\begin{tabular}{|c|c|c|c|}
\hline Família & Espécie & $\begin{array}{c}\text { Código da } \\
\text { amostra } \\
\end{array}$ & Período de coleta \\
\hline Malpighiaceae & $\begin{array}{l}\text { Banisteriopsis adenopoda (Jun) Gates. } \\
\text { Banisteriopsis sp. } \\
\text { Byrsonima } \mathrm{sp} . \\
\text { Sp.1 } \\
\text { Hiraea cuneata Griseb. } \\
\text { Tetrapterys sp. }\end{array}$ & $\begin{array}{l}18 \\
19 \\
20 \\
21 \\
22 \\
23\end{array}$ & $\begin{array}{c}\text { Março } \\
\text { Setembro } \\
\text { Outubro/Novembro } \\
\text { Agosto } \\
\text { Outubro } \\
\text { Janeiro }\end{array}$ \\
\hline Malvaceae & Peltaea sp. & 24 & Março \\
\hline $\begin{array}{l}\text { Fabaceae: } \\
\text { Mimosoideae }\end{array}$ & $\begin{array}{l}\text { Acacia paniculata Willd. } \\
\text { Anadenanthera colubrina (Vell.) Brenan. } \\
\text { Ingá Vera Willd. } \\
\text { Piptadenia cf. gonoacantha (Mart.) } \\
\text { Macbr. } \\
\text { Mimosa sensitiva L. }\end{array}$ & $\begin{array}{l}25 \\
26 \\
27 \\
28 \\
29\end{array}$ & $\begin{array}{l}\text { Fevereiro } \\
\text { Outubro/Novembro } \\
\text { Setembro } \\
\text { Março/Abril } \\
\text { Abril }\end{array}$ \\
\hline Myrtaceae & $\begin{array}{l}\text { Campomanesia cf. pubescens (DC.) Berg. } \\
\text { Psidium guajava } \mathrm{L} .\end{array}$ & $\begin{array}{l}30 \\
31\end{array}$ & $\begin{array}{l}\text { Setembro } \\
\text { Novembro }\end{array}$ \\
\hline Onagraceae & Ludwigia laruotteana (Canbessi) Hara & 32 & Junho \\
\hline Poaceae & Sp.1 & 33 & Janeiro \\
\hline Polygonaceae & Coccoloba mollis Casar. & 34 & Agosto/Setembro \\
\hline Rhamnaceae & $\begin{array}{l}\text { Govania virgata } \text { Reiss. } \\
\text { Rhamnidium elaeocarpum Reiss. }\end{array}$ & $\begin{array}{l}35 \\
36\end{array}$ & $\begin{array}{c}\text { Março/Abril } \\
\text { Outubro/Novembro }\end{array}$ \\
\hline Rubiaceae & $\begin{array}{l}\text { Coussarea hydrangeifolia (Benth.) Müll. } \\
\text { Arg. } \\
\text { Manettia cordifolia Mart. } \\
\text { Psychotria carthagenensis Jacq. }\end{array}$ & $\begin{array}{l}37 \\
38 \\
39\end{array}$ & $\begin{array}{l}\text { Dezembro/Jan } \\
\text { Maio } \\
\text { Out/Nov/Dez }\end{array}$ \\
\hline Rutaceae & Zanthoxylum rhoifolium Engl. & 40 & Dez/Jan \\
\hline Sapindaceae & $\begin{array}{l}\text { Matayba guianensis Aubl. } \\
\text { Serjania caracasana (Jacq.) Willd. }\end{array}$ & $\begin{array}{l}41 \\
42\end{array}$ & $\begin{array}{c}\text { Nov/Dez } \\
\text { Mar/Mai/Jun/Jul/Ago/ } \\
\text { Set }\end{array}$ \\
\hline
\end{tabular}


Tabela 3 - Relação de espécies de plantas apícolas coletadas em área de cerrado no município de Cassilândia/MS, de março/2003 a fevereiro/2004

(conclusão)

\begin{tabular}{llcc}
\hline Família & \multicolumn{1}{c}{ Espécie } & $\begin{array}{c}\text { Código da } \\
\text { amostra }\end{array}$ & Período de coleta \\
\hline \multirow{2}{*}{ Sapindaceae } & $\begin{array}{l}\text { Serjania communis } \text { Camb. } \\
\text { Serjania } \text { sp. }\end{array}$ & 43 & Maio \\
& & 44 & Maio \\
Sterculiaceae & Guazuma ulmifolia Lam. & 45 & Setembro \\
& & & \\
Tiliaceae & Luehea divaricata Mart. & 46 & Jan/Fev/Mar/Abr \\
& Luehea grandiflora Mart. et Zucc. & 47 & Set/Out/Nov \\
& & 48 & Setembro/Outubro \\
Ulmaceae & Celtis iguanae (Jacq.) Sarg. & 49 & Junho \\
\hline
\end{tabular}

Das 26 famílias catalogadas neste trabalho, 14 foram representadas por apenas uma espécie, sete famílias por duas espécies, duas famílias por três espécies, uma família por quatro espécies e as famílias Mimosaceae e Malpighiaceae que apresentaram cinco e seis espécies, respectivamente (Figura 3 ).

A família Mimosaceae é composta por aproximadamente 60 gêneros representados por 3.000 espécies distribuídas, principalmente, em regiões tropicais e subtropicais, além de algumas espécies que são encontradas em regiões temperadas. Sua importância como fornecedora de recurso alimentar às abelhas é bem conhecida, sendo mencionada em vários estudos (ALMEIDA, 2002; ANDENA, 2002).

Carvalho (1999) estudou a flora apícola do município de Castro Alves/BA, observando que Mimosaceae e Malpighiaceae estavam entre as famílias com maior riqueza de espécies. 


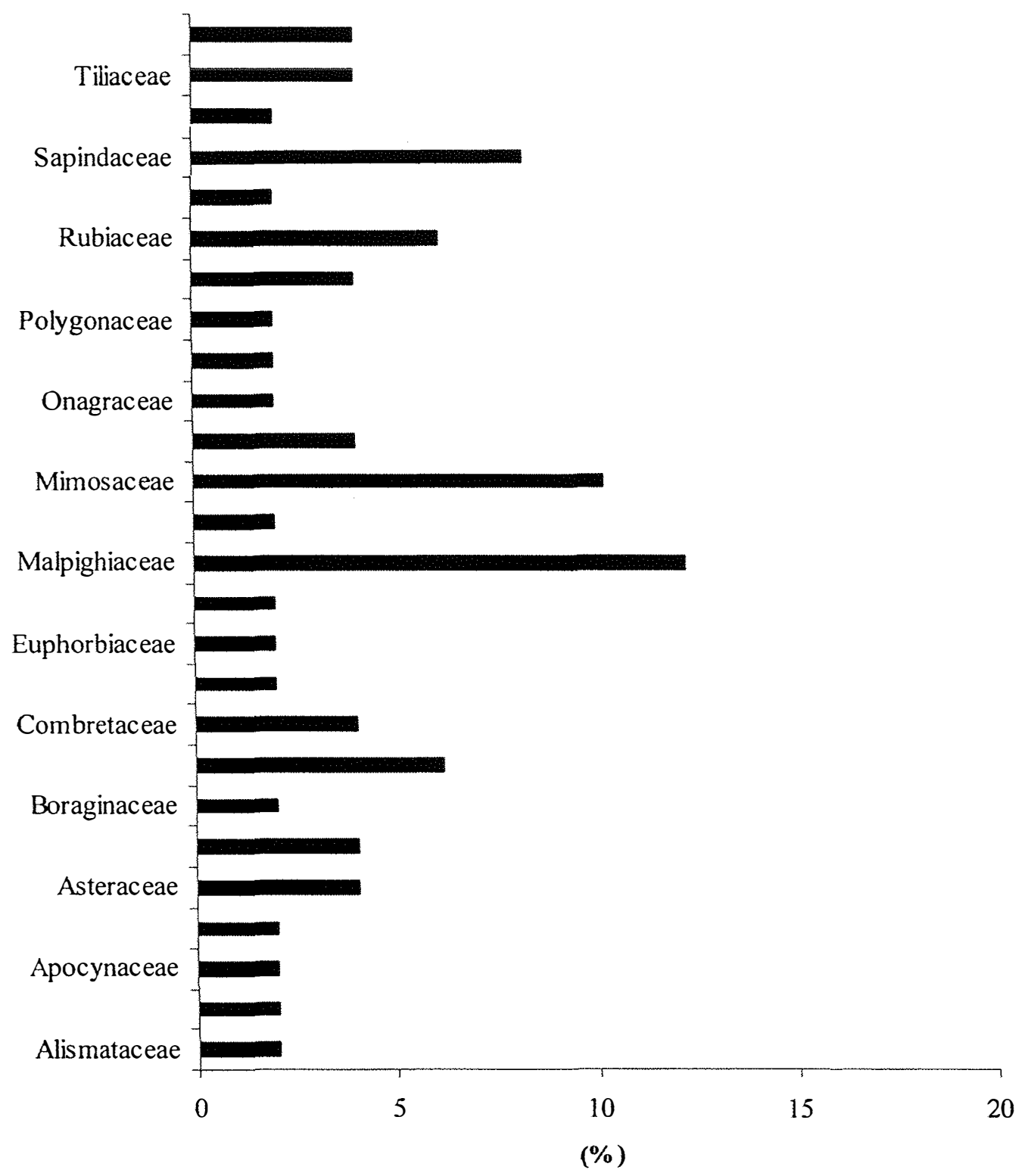

Figura 3 - Porcentagem do número de espécies de plantas apícolas por família encontradas em uma área de cerrado no município de Cassilândia/MS, de março/2003 a fevereiro/2004 
Almeida (2002) estudando a flora apícola no cerrado de Pirassununga/SP, obteve seis representantes da família Mimosaceae, sendo quatro gêneros comuns a este trabalho. Andena (2002) estudou a flora apícola em área de cerrado no município de Corumbataí/SP, obtendo cinco representantes para esta família, sendo dois gêneros comuns a este trabalho.

Ramalho; Kleinert-Giovannini e Imperatriz-Fonseca (1990) consideraram Mimosaceae como uma das principais famílias de importância para o grupo formado por Apis mellifera e Meliponinae na região neotropical.

Com relação a família Malpighiaceae, na literatura existem 63 gêneros e 800 espécies pantropicais catalogadas, sendo encontrados no Brasil 300 espécies pertencentes a 32 gêneros (BARROSO, 1986). Dentre os gêneros desta família que apresentam importância apícola pode-se citar Byrsonima, cujas espécies são freqüentes no cerrado (GOODLAND; FERRI, 1979). Essas plantas são referendadas como importantes produtoras de óleo, que é usado como fonte de alimento por certas abelhas (MECHI, 1996). Dentre as abelhas que utilizam o óleo pode-se citar as dos gêneros Centris, Epicharis e Tetrapedia, além de algumas espécies de Meliponinae (NEFF; SIMPSON, 1981; BUCHMANN, 1987; ALBUQUERQUE; RÊGO, 1989; ALBUQUERQUE; MENDONÇA, 1996).

Silveira (1989) estudou a comunidade de abelhas no cerrado de Paraopeba/MG, observando que 13 espécies da família Malpighiaceae eram visitadas por 40 espécies de abelhas pertencentes aos gêneros Centris, Epicharis, Monoeca, Paratetrapedia e Tetrapedia. Este autor ressaltou ainda a importância de Byrsonima cfr. lancifolia como fonte de pólen a um grande número de abelhas que não coletam óleo.

Carvalho (1999) observou que a família Malpighiaceae foi a mais importante fonte de recursos para a família Anthophoridae.

Campos (1989) estudou a comunidade de abelhas em uma área de cerrado no município de Corumbataí/SP, observando que a família Malpighiaceae ocupava o terceiro lugar em abundância de espécies apícolas, sendo Byrsonima intermedia a principal fonte de alimento das espécies Epicharis affinis, Epicharis bicolor e Arhysoceble huberi. Este autor ressaltou que a importância desta família como fonte de recursos às abelhas já havia sido relatada em outros estudos (LAROCA, 1974; HEITHAUS, 1979; KNOLL, 1985; SILVEIRA, 1989). 
Andena (2002) realizou um trabalho semelhante no mesmo local encontrando oito espécies pertencentes a esta família. Além disso, este autor observou o maior número de visitas para o gênero Byrsonima (Malpighiaceae).

Pedro (1992) estudou a comunidade de abelhas em área de cerrado no município de Cajurú/SP, observando um grande número de Meliponinae e Apis mellifera nas flores de espécies da família Malpighiaceae, concluindo que esta família era a única fonte de óleo no ecossistema.

Mateus (1998) estudou a flora apícola do município de Luiz Antônio/SP, observando que Malpighiaceae estava entre as famílias de maior representatividade em espécies.

Quanto à riqueza de espécies em relação aos gêneros, Serjania apresentou o maior número (três espécies), seguido pelos gêneros Luehea e Terminalia, ambos com duas espécies. Almeida (2002) estudando a flora apícola em área de cerrado encontrou cinco espéciès pertencentes ao gênero Serjania, que apresentou maior riqueza em relação aos demais.

Quanto ao número de visitas das abelhas em relação às famílias de plantas, Sapindaceae foi a mais procurada, seguida por Caesalpiniaceae, Rubiaceae e Rutaceae (Figura 4). O grande número de visitas observado para a família Sapindaceae se deve, principalmente, ao gênero Serjania, que compõe as principais espécies melíferas da região, sendo uma das principais fontes de alimento para Apis mellifera (MATEUS, 1998; ANDENA, 2002).

Nota-se, através deste estudo, que existem diferentes padrões de florescimento. Estes padrões implicam na organização e estrutura das comunidades (FRANKIE; BAKER; OPLER, 1974; FRANKIE, 1975) e no fluxo gênico das plantas (ANDENA, 2002). A diversidade botânica associada ao comportamento fenológico das espécies permitiram a manutenção dos recursos tróficos durante todo o período de coletas. 


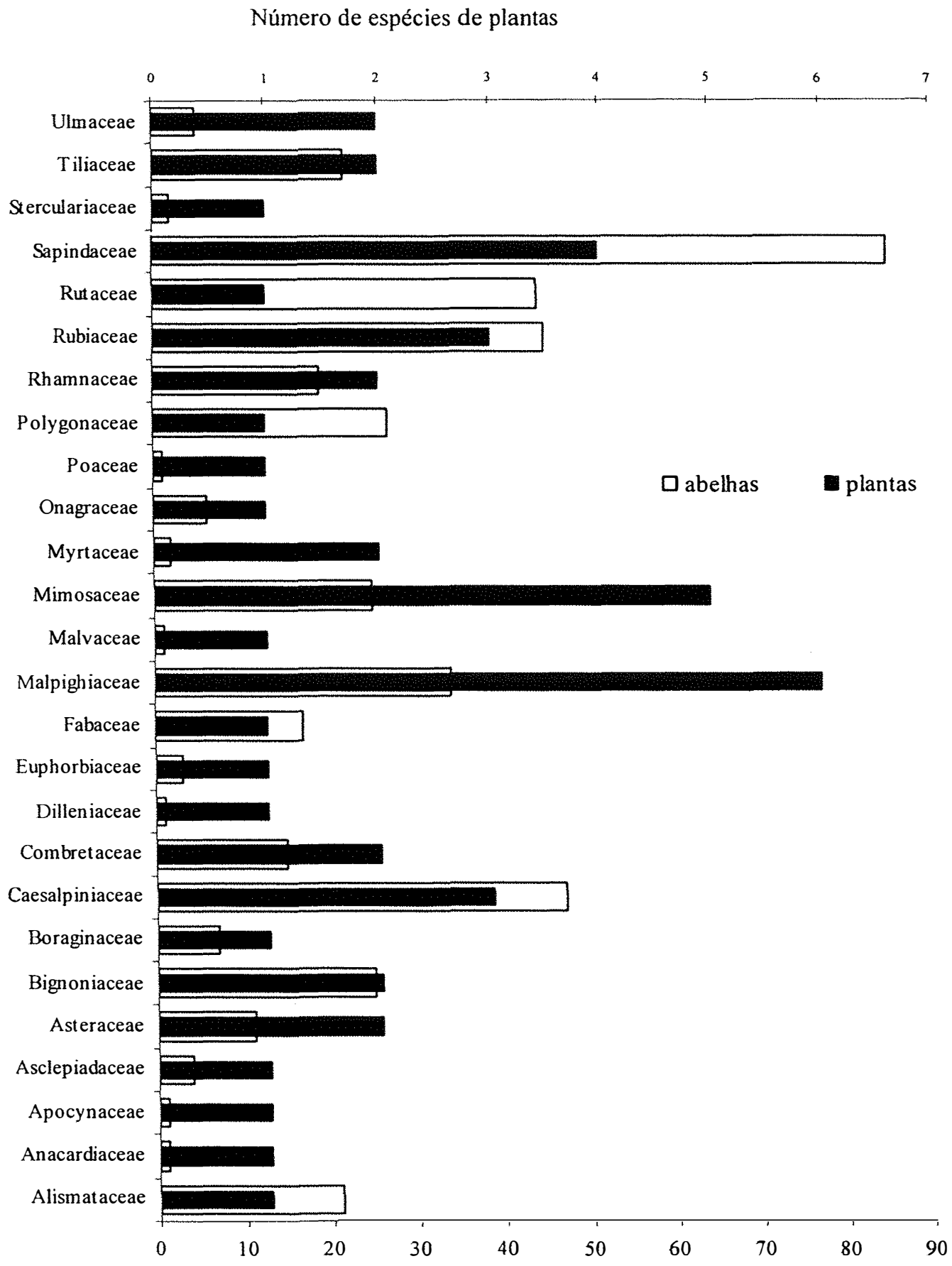

Número coletado de abelhas

Figura 4 - Distribuição do número de espécies vegetais e de abelhas em relação às famílias de plantas visitadas, entre março/2003 a fevereiro/2004, em área de cerrado no município de Cassilândia/MS 


\subsubsection{Composição físico-química do mel}

Os resultados dos parâmetros físico-químicos analisados para as 31 amostras de méis produzidos por $A$. mellifera em Cassilândia/MS, estão nas Tabelas 4 e 5 .

Tabela 4 - Valores de açúcares, hidroximetilfurfural (HMF), diastase e cor de méis produzidos por $A$. mellifera de junho/2003 a maio/2004, em área de cerrado no município de Cassilândia/MS

\begin{tabular}{|c|c|c|c|c|c|c|c|}
\hline Amostra & $\begin{array}{l}\text { Mês } \\
\text { coleta }\end{array}$ & $\begin{array}{c}\text { Cor } \\
(\mathrm{nm})\end{array}$ & $\begin{array}{c}\mathrm{AR}^{* *} \\
(\%) \\
\end{array}$ & $\begin{array}{c}\mathrm{AT}^{* *} \\
(\%)\end{array}$ & $\begin{array}{c}\text { Sacarose } \\
(\%)\end{array}$ & $\begin{array}{c}\text { HMF } \\
\left(\mathrm{mg} \cdot \mathrm{kg}^{-1}\right)\end{array}$ & $\begin{array}{l}\text { Diastase } \\
\text { (Gothe) }\end{array}$ \\
\hline 1 & Jun/03 & Escuro & 77,5 & 82,9 & 5,1 & 1,3 & 27,0 \\
\hline 2 & Jun/03 & Âmbar extra claro & 78,0 & 80,1 & 2,0 & 1,9 & 42,4 \\
\hline 3 & Jun/03 & Âmbar extra claro & 81,4 & 88,1 & 6,4 & 1,0 & 25,3 \\
\hline 4 & $\mathrm{Jul} / 03$ & Âmbar extra claro & 82,0 & 86,9 & 4,7 & 4,2 & 22,6 \\
\hline 5 & $\mathrm{Jul} / 03$ & Âmbar extra claro & 74,4 & 79,9 & 5,2 & 1,4 & 24,0 \\
\hline 6 & Jul/03 & Âmbar claro & 75,0 & 81,0 & 5,7 & 4,5 & 24,1 \\
\hline 7 & Ago/03 & Âmbar claro & 79,0 & 81,5 & 2,4 & 5,0 & 23,9 \\
\hline 8 & Ago/03 & Âmbar extra claro & 76,7 & 77,9 & 1,1 & 4,1 & 9,6 \\
\hline 9 & $\mathrm{Ago} / 03$ & Branco & 82,8 & 85,3 & 2,3 & 0,9 & 22,1 \\
\hline 10 & Set/03 & Branco & 79,4 & 83,0 & 3,4 & 2,8 & 22,1 \\
\hline 11 & Set/03 & Branco & 75,0 & 75,7 & 0,7 & 0,4 & 26,6 \\
\hline 12 & Set/03 & Branco & 75,1 & 88,7 & 12,9 & 1,5 & 31,0 \\
\hline 13 & Out/03 & Âmbar escuro & 77,6 & 81,7 & 3,9 & 0,4 & 32,9 \\
\hline 14 & Out/03 & Âmbar escuro & 79,0 & 81,0 & 1,9 & 1,2 & 31,3 \\
\hline 15 & Out/03 & Âmbar escuro & 79,9 & 82,7 & 2,7 & 2,6 & 31,3 \\
\hline 16 & Nov/03 & Âmbar extra claro & 81,2 & 81,5 & 0,2 & 7,3 & 25,4 \\
\hline 17 & Nov/03 & Âmbar extra claro & 76,5 & 81,9 & 5,1 & 12,4 & 26,0 \\
\hline 18 & Nov/03 & Âmbar claro & 74,3 & 76,4 & 2,0 & 4,6 & 27,6 \\
\hline 19 & Dez/03 & Âmbar extra claro & 73,4 & 79,4 & 5,7 & 1,8 & 37,3 \\
\hline 20 & Dez/03 & Âmbar claro & 74,9 & 80,8 & 5,6 & 3,1 & 36,7 \\
\hline 21 & Dez/03 & Âmbar claro & 80,5 & 86,8 & 5,9 & 1,9 & 42,6 \\
\hline 22 & $\mathrm{Jan} / 04$ & Âmbar extra claro & 84,3 & 89,0 & 4,5 & 1,6 & 22,3 \\
\hline 23 & Fev/04 & Âmbar claro & 85,5 & 91,9 & 6,1 & 0,3 & 16,0 \\
\hline 24 & Fev/04 & Âmbar & 85,8 & 89,5 & 3,5 & 1,1 & 22,1 \\
\hline 25 & Mar/04 & Âmbar claro & 85,5 & 91,9 & 6,1 & 3,4 & 25,7 \\
\hline 26 & $\mathrm{Mar} / 04$ & Âmbar claro & 86,9 & 89,9 & 2,9 & 1,5 & 26,1 \\
\hline 27 & $\mathrm{Abr} / 04$ & Âmbar claro & 81,8 & 84,8 & 2,9 & 1,2 & 9,0 \\
\hline 28 & $\mathrm{Abr} / 04$ & Âmbar claro & 83,4 & 85,2 & 1,7 & 1,2 & 20,1 \\
\hline 29 & Mai/04 & Âmbar claro & 83,5 & 86,0 & 2,4 & 1,9 & 20,9 \\
\hline 30 & Mai/04 & Âmbar claro & 82,9 & 84,5 & 1,6 & 2,5 & 25,1 \\
\hline 31 & Mai/04 & Âmbar claro & 83,1 & 86,8 & 3,5 & 4,3 & 20,6 \\
\hline Média & & & $79,8 \pm 3,9$ & $83,9 \pm 4,3$ & $3,8 \pm 2,4$ & $2,7 \pm 2,4$ & $25,8 \pm 7,6$ \\
\hline Mínimo & & & 73,4 & 75,7 & 0,2 & 0,3 & 9,0 \\
\hline Máximo & & & 86,9 & 91,9 & 12,9 & 12,4 & 42,6 \\
\hline Normas* & & & Mín. 65 & $-\cdots$ & Máx. 6 & Máx. 60 & Mín. 8 \\
\hline
\end{tabular}


Tabela 5 - Valores de umidade, condutividade elétrica, $\mathrm{pH}$, acidez, índice de formol, cinzas, proteína e viscosidade de méis produzidos por $A$. mellifera de junho/2003 a maio/2004, em área de cerrado no município de Cassilândia/MS

\begin{tabular}{|c|c|c|c|c|c|c|c|c|}
\hline Amostra & $\begin{array}{c}\text { Umidade } \\
(\%)\end{array}$ & $\begin{array}{c}\text { Cond. El. } \\
\text { (uS) }\end{array}$ & $\mathrm{pH}$ & $\begin{array}{c}\text { Acidez } \\
\left(\text { meg. } \mathrm{kg}^{-1}\right)\end{array}$ & $\begin{array}{l}\text { Ind. Form. } \\
\left(\mathrm{mL} \cdot \mathrm{kg}^{-1}\right)\end{array}$ & $\begin{array}{c}\text { Cinzas } \\
(\%) \\
\end{array}$ & $\begin{array}{c}\text { Proteína } \\
(\%) \\
\end{array}$ & $\begin{array}{l}\text { Viscos. } \\
\text { (mPa.s) }\end{array}$ \\
\hline 1 & 16,5 & 765,8 & 3,6 & 13,0 & 16,0 & 0,5 & 0,5 & 2270,0 \\
\hline 2 & 20,8 & 287,5 & 3,4 & 7,0 & 13,0 & 0,1 & 0,4 & 820,0 \\
\hline 3 & 19,7 & 368,6 & 3,5 & 15,0 & 12,0 & 0,4 & 0,4 & 1080,0 \\
\hline 4 & 17,5 & 730,9 & 3,9 & 12,0 & 9,0 & 0,1 & 0,3 & 2170,0 \\
\hline 5 & 15,7 & 1774,7 & 4,1 & 5,0 & 14,0 & 0,1 & 0,2 & 5300,0 \\
\hline 6 & 15,7 & 2278,1 & 3,7 & 8,0 & 14,0 & 0,1 & 0,4 & 6810,0 \\
\hline 7 & 16,0 & 1624,8 & 3,9 & 12,0 & 5,0 & 0,3 & 0,2 & 4850,0 \\
\hline 8 & 16,5 & 1716,7 & 4,9 & 12,0 & 7,0 & 0,4 & 0,2 & 5140,0 \\
\hline 9 & 16,0 & 1554,2 & 3,6 & 12,0 & 8,0 & 0,6 & 0,2 & 4640,0 \\
\hline 10 & 17,0 & 1520,8 & 4,0 & 11,0 & 7,0 & 0,2 & 0,3 & 4540,0 \\
\hline 11 & 16,5 & 1679,1 & 4,1 & 8,0 & 6,0 & 0,5 & 0,3 & 5010,0 \\
\hline 12 & 15,8 & 2357,1 & 4,0 & 11,0 & 5,0 & 0,2 & 0,1 & 7040,0 \\
\hline 13 & 18,5 & 771,2 & 3,8 & 11,0 & 7,0 & 0,6 & 0,2 & 2280,0 \\
\hline 14 & 21,8 & 1500,6 & 4,1 & 18,0 & 12,0 & 0,3 & 0,4 & 4470,0 \\
\hline 15 & 19,8 & 733,8 & 4,2 & 15,0 & 11,0 & 0,1 & 0,2 & 2170,0 \\
\hline 16 & 19,4 & 758,6 & 3,7 & 15,0 & 11,0 & 0,2 & 0,3 & 2250,0 \\
\hline 17 & 22,5 & 462,1 & 3,8 & 19,0 & 12,0 & 0,2 & 0,3 & 1360,0 \\
\hline 18 & 22,0 & 499,3 & 3,9 & 13,0 & 15,0 & 0,2 & 0,4 & 1470,0 \\
\hline 19 & 24,3 & 239,3 & 3,5 & 17,0 & 10,0 & 0,4 & 0,3 & 680,0 \\
\hline 20 & 26,0 & 169,0 & 3,5 & 21,0 & 5,0 & 0,1 & 0,3 & 470,0 \\
\hline 21 & 26,0 & 157,7 & 3,5 & 18,0 & 11,0 & 0,3 & 0,4 & 430,0 \\
\hline 22 & 23,3 & 587,0 & 3,5 & 38,3 & 10,0 & 0,1 & 0,2 & 190,0 \\
\hline 23 & 19,5 & 1125,0 & 4,1 & 56,0 & 7,3 & 0,6 & 0,1 & 740,0 \\
\hline 24 & 20,5 & 738,3 & 3,8 & 39,0 & 7,3 & 0,3 & 0,1 & 460,0 \\
\hline 25 & 17,1 & 854,0 & 4,0 & 31,0 & 9,6 & 0,4 & 0,2 & 3110,0 \\
\hline 26 & 19,4 & 1023,0 & 4,0 & 37,6 & 10,6 & 0,4 & 0,2 & 970,0 \\
\hline 27 & 23,2 & 4836,0 & 3,4 & 24,0 & 10,3 & 0,2 & 0,2 & 240,0 \\
\hline 28 & 21,9 & 622,0 & 3,5 & 33,0 & 9,3 & 0,3 & 0,2 & 300,0 \\
\hline 29 & 19,4 & 916,0 & 3,7 & 45,0 & 11,0 & 0,4 & 0,3 & 760,0 \\
\hline 30 & 18,9 & 647,0 & 3,7 & 29,4 & 9,0 & 0,1 & 0,2 & 990,0 \\
\hline 31 & 20,9 & 679,3 & 3,5 & 37,3 & 11,0 & 0,2 & 0,2 & 400,0 \\
\hline Média & $19,6 \pm 3,0$ & $1096,0 \pm 914,4$ & $3,8 \pm 0,3$ & $20,7 \pm 12,8$ & $9,8 \pm 2,9$ & $0,3 \pm 0,1$ & $0,31 \pm 0,1$ & $2368,0 \pm 2099,0$ \\
\hline Mínimo & 15,7 & 157,7 & 3,4 & 5,0 & 5,0 & 0,1 & 0,13 & 190,0 \\
\hline Máximo & 26,0 & 4836,0 & 4,9 & 56,0 & 16,0 & 0,68 & 0,54 & 7040,0 \\
\hline Normas* & Máx. 20 & --- & $\cdots$ & Máx. 50 & $\cdots$ & Máx. 0,6 & --- & --- \\
\hline
\end{tabular}

* Norma nacional (BRASIL, 2000) 


\subsubsection{Cor}

As classes de cores observadas nas amostras analisadas estão na Tabela 4. Observou-se uma predominância da cor âmbar claro (42\%), seguida das cores âmbar extra claro (29\%), branco (13\%), âmbar escuro (10\%), âmbar e escuro, ambas com 3\% (Figura 5).

Segundo Brasil (2000) as cores encontradas no mel podem variar de branco até escuro, portanto, as cores apresentadas neste trabalho estão em conformidade com a legislação.

Dentre os fatores que afetam a cor estão a sua origem floral, clima durante o fluxo do néctar e temperatura da colméia (SEEMANN; NEIRA, 1988). Além destes fatores, a cor é influenciada ainda pelo tempo de estocagem, luz, calor e reações enzimáticas (SMITH, 1967).
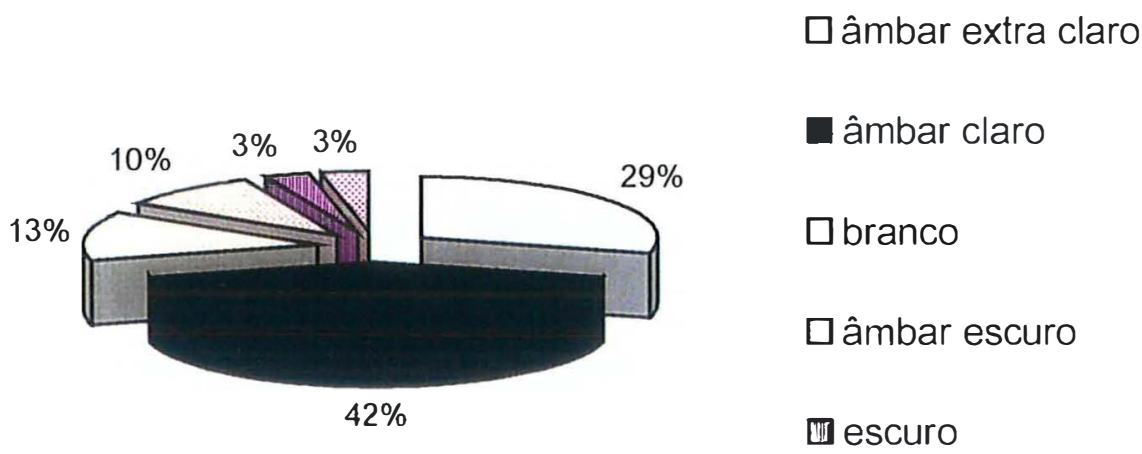

웅 âmbar

Figura 5 - Porcentagem de classes de cor obtidas em amostras de méis produzidos por Apis mellifera de junho/2003 a maio/2004, em área de cerrado no município de Cassilândia/MS

A predominância da cor âmbar claro em relação as demais foi observada em outros trabalhos como de Escobar-Martínez; Meza e Mendoza (1992), em méis paraguaios; Baldi Coronel; Dall'Ogllio e Lezcano (1993) em méis da província de Entre Rios (Argentina); Persano-Oddo et al. (1995) em méis italianos de diferentes origens botânicas; Uñantes et al. (1999) em méis produzidos em San Luis (Argentina); Carvalho et al. (2000) em méis produzidos no Estado da Bahia; Sodré (2000) em méis produzidos no mesmo Estado; Marchini; Sodré e Rodrigues (2001) em méis produzidos no Mato Grosso do Sul. 


\subsubsection{Açúcares totais, redutores e sacarose (\%)}

\section{a. Açúcares totais (AT)}

Os índices de açúcares totais obtidos para as amostras analisadas variaram de 75,7 a $91,9 \%$, com valor médio de $83,9 \pm 4,3 \%$ (Tabela 4). A legislação não estabelece limites para este parâmetro.

Os resultados obtidos neste trabalho estão próximos aos encontrados por Almeida (2002); Komatsu; Marchini e Moreti (2002); Sodré et al. (2002) e Arruda (2003), que obtiveram uma variação de 66,0 a $88,3 \%$ para açúcares totais.

\section{b. Açúcares redutores (AR)}

Os índices obtidos para os açúcares redutores variaram de 73,4 a 86,9\%, com valor médio de 79,8 $\pm 3,9 \%$ (Tabela 4). A legislação considera aceitável méis que apresentem valores mínimos de $65 \%$ para açúcares redutores, portanto, todas as amostras estão em conformidade com os padrões estabelecidos para este parâmetro.

Os resultados observados neste estudo foram semelhantes aos resultados obtidos por ElSherbiny et al. (1980); Moraes e Mantovani (1986); Rodrigues; Marchini e Haddad (1996); Carneiro et al. (2002) e Arruda (2003). Estes autores determinaram os índices de açúcares em méis de diferentes origens florais, obtendo uma variação de 75,3 a 87,3\% para açúcares redutores.

\section{c. Sacarose}

A porcentagem de sacarose encontrada nas amostras analisadas variou de 0,2 e 12,9\%,

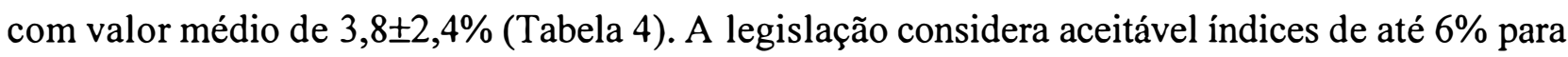
sacarose, com exceção para méis de melato cujo valor pode chegar a $15 \%$. De acordo com a norma vigente $13 \%$ das amostras analisadas estão acima dos valores permitidos.

Outros estudos apresentaram resultados semelhantes aos encontrados neste trabalho, dentre eles pode-se citar: Dozo (1980) que analisou os índices de sacarose em 66 amostras de méis provenientes de Buenos Aires, encontrando uma variação de 0,47 a 8,50\%; Olek et al. (1987) que compararam os índices de sacarose em amostras de méis produzidas por Apis cerana 
e Apis laboriosa, encontrando valores médios de 2,51\% para a primeira e 3,34\% para a segunda. Escobar-Martínez; Meza e Mendoza (1992) que analisaram amostras de méis produzidas por Apis mellifera no Paraguai, encontrando valor médio para sacarose igual a 3,52\%; Almeida (2002) que determinou os índices de sacarose em 34 amostras de méis produzidos em uma área de cerrado no município de Pirassununga/SP, encontrando valores entre 0,2 a 11,4\%; Komatsu; Marchini e Moreti (2002) que analisaram méis de diferentes origens florais obtendo valores de sacarose entre 0,2 a 27,4\% para méis silvestres, 0,1 a 15,2\% para méis de eucalipto e 0,3 a 5,2\% para méis de laranjeira.

\subsubsection{Hidroximetilfurfural (mg.kg-1)}

Os índices obtidos para HMF nas amostras variaram de 0,3 a 12,43 mg.kg-1 com valor médio de 2,7 $\pm 2,4 \mathrm{mg} \cdot \mathrm{kg}^{-1}$ (Tabela 4).

Observa-se com base nesses resultados que todas as amostras estão em conformidade com a legislação, cujo valor máximo permitido é de $60 \mathrm{mg} \cdot \mathrm{kg}^{-1}$ (BRASIL, 2000).

Méis produzidos em países tropicais podem apresentar valores elevados de HMF, em função do clima quente. Tal fato torna fundamental a quantificação deste elemento para determinação da qualidade do produto (DAYRELL; VITAL, 1991; WHITE JÚNIOR, 1992).

Trabalhos como de Pfau e Ruhle (1986); Martinez-Gomez et al. (1993); Serra-Bonvehí e Granados-Tarrés (1993); Persano-Oddo et al. (1995) e Almeida (2002) apresentaram uma variação de 0 e $12,30 \mathrm{mg} \cdot \mathrm{kg}^{-1}$ para HMF.

\subsubsection{Número de diastase (escala de Göthe)}

O número de diastase obtido nas amostras variou de 9,0 a 42,6 (escala de Göthe), com valor médio de 25,8 \pm 7,6 (Tabela 4).

A legislação considera aceitável méis que apresentem um número mínimo de oito (escala de Göthe) para diastase (BRASIL, 2000). Portanto, todas as amostras analisadas estão em conformidade com os padrões estabelecidos para este parâmetro.

Trabalhos como de Persano-Oddo; Baldi e Accorti (1990); Martínez-Gomez et al. (1993); Huidobro et al. (1995); Vit e Pulcini (1996); Andrade et al. (1999) e Sodré (2000) obtiveram uma variação de 2,6 a 51,1 (escala de Göthe) para o número de diastase. 


\subsubsection{Umidade (\%)}

Os valores de umidade obtidos nas amostras variaram de 15,7 a $26 \%$, com valor médio $19,6 \pm 3,0 \%$ (Tabela 5).

As normas nacionais estabelecem o limite de $20 \%$ para a umidade, assim $39 \%$ das amostras analisadas neste trabalho estão acima dos níveis permitidos pela legislação.

Dentre os fatores que afetam a umidade no mel, pode-se citar o clima, origem floral e colheita antes da completa desidratação (SODRÉ, 2000). Neste trabalho, todas as amostras que apresentaram valores acima de $20 \%$ foram colhidas precocemente, ou seja, os favos não estavam operculados, isso deveu-se à metodologia estabelcida para o trabalho, qual seja de coleta mensal do mel produzido.

Valores semelhantes para umidade foram obtidos por vários autores. Natarajan e Yesuvadian (1978) observaram que mais da metade das amostras de méis de Kerala e Tamilnadu, na Índia apresentavam valores mínimos de umidade na ordem de 23\%; Escobar-Martínez; Meza e Mendoza (1992) ao analisar méis produzidos por Apis mellifera no território paraguaio, obtiveram valor médio para umidade igual a 19,4\%; Martínez-Gomez et al. (1993) determinaram os teores de umidade para 25 amostras de eucalipto, obtendo valores entre 16 a 19\%; Carvalho et al. (2000) obtiveram valor médio de umidade igual a $21,58 \%$ para méis produzidos na Bahia; Sodré (2000) analisou amostras de méis provenientes do mesmo Estado obtendo valores de 17,6 a 22,9\%; Marchini; Sodré e Rodrigues (2001) determinaram os teores de umidade em méis produzidos no Mato Grosso do Sul, obtendo valor médio igual a 19,98\%.

\subsubsection{Condutividade elétrica $(\mu \mathrm{S})$}

Os valores de condutividade elétrica obtidos para as amostras analisadas variaram de 157,7 a 4836,0 $\mu \mathrm{S}$, com valor médio de 1096,0 $\pm 914,4 \mu \mathrm{S}$ (Tabela 5). A legislação internacional considera aceitável méis que apresentem valores de condutividade elétrica entre 200 a $800 \mu \mathrm{S}$ (Bogdanov et al., 2001). Estes autores ressaltaram ainda que para méis de eucalipto aceita-se valores de condutividade elétrica acima de $800 \mu \mathrm{S}$.

A Figura 6 apresenta a porcentagem de amostras com valores acima das especificações internacionais. 


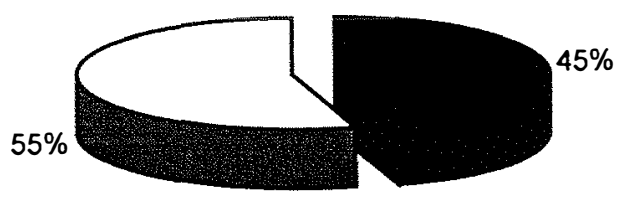

Eão aceitável

Daceitável

Figura 6 - Porcentagem de condutividade elétrica aceitável ou não de acordo com a legislação internacional, para amostras de méis produzidos por Apis mellifera de junho/2003 a maio/2004, em área de cerrado no município de Cassilândia/MS

Resultados semelhantes aos encontrados neste trabalho foram obtidos por Persano-Oddo et al. (1995) que observaram uma variação de 150 a $2060 \mu \mathrm{S}$ em méis italianos; Durán et al. (1996) que obtiveram valores de 100 a $2103 \mu \mathrm{S}$ para méis de diferentes regiões brasileiras; Sodré (2000) que obteve valores de 271,67 a $1634 \mu \mathrm{S}$ para condutividade elétrica em méis provenientes do Estado da Bahia; Almeida (2002) que obteve uma variação de 284 a $2200 \mu \mathrm{S}$ para méis produzidos no cerrado paulista.

\subsubsection{7 pH}

Os valores obtidos para $\mathrm{pH}$ nas amostras analisadas variaram de 3,4 a 4,9 com um valor

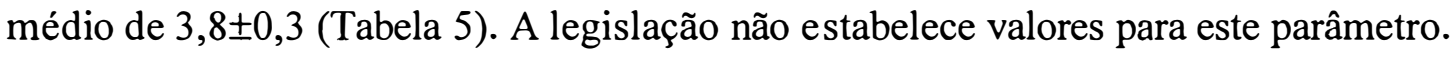

Os valores obtidos neste trabalho estão próximos aos encontrados por Marchini; Sodré e Rodrigues (2001) que obtiveram o valor médio de 4,13 para $\mathrm{pH}$ de méis provenientes do mesmo estado; Pamplona (1989) que obteve uma variação de 3,10 a 5,3 em diferentes amostras de méis brasileiros; Andrade et al. (1999) que analisaram amostras de méis produzidos em Portugal, obtendo valores de $\mathrm{pH}$ entre 3,6 a 4,46. Sodré (2002) que obteve valores de pH com uma variação de 3,37 a 4,46 em méis produzidos no litoral norte da Bahia; Almeida (2002) que obteve os índices de $\mathrm{pH}$ entre 3,27 a 4,45 para méis produzidos no cerrado paulista e Arruda (2003) que obteve valores entre 3,58 a 3,83 em méis produzidos no Estado do Ceará. 


\subsubsection{Acidez (meq. $\left.\mathrm{kg}^{-1}\right)$}

Os valores de acidez obtidos nas amostras variaram de 5,0 a 56,0 meq. $\mathrm{kg}^{-1}$, com valor

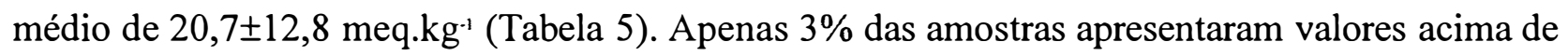
50 meq.kg ${ }^{-1}$, que corresponde ao valor máximo estabelecido pela legislação (Figura 7).

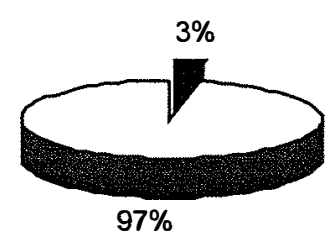

não aceitável

口aceitável

Figura 7 - Porcentagem de acidez aceitável ou não de acordo com a legislação vigente, em amostras de méis produzidos por Apis mellifera de junho/2003 a maio/2004, em área de cerrado no município de Cassilândia/MS

Segundo Pamplona (1989) o ácido glucônico, formado pela ação da enzima glicoseoxidase sobre a glicose, tende a aumentar no mel mesmo durante o armazenamento, pois esta enzima permanece em atividade no mel, mesmo após seu processamento. Assim, a acidez do mel aumenta durante o armazenamento, baixando o $\mathrm{pH}$.

Trabalhos como o de Campos (1998); Carvalho et al. (2000); Marchini (2001) e Almeida (2002) obtiveram uma variação nos valores de acidez de 8,0 a 50,0 meq. $\mathrm{kg}^{-1}$.

\subsubsection{9 Índice de formol $\left(\mathrm{mL} . \mathrm{kg}^{-1}\right)$}

Os valores obtidos para o índice de formol nas amostras analisadas variaram de 5,0 a 16,0 mL. $\mathrm{kg}^{-1}$ com valor médio de 9,85 $\pm 2,93 \mathrm{~mL} \cdot \mathrm{kg}^{-1}$ (Tabela 5). A legislação não estabelece limites para este parâmetro (BRASIL, 2000).

Os valores observados neste trabalho estão próximos aos observados por Komatsu (1996) que obteve o valor médio de $10,1 \mathrm{~mL} \cdot \mathrm{kg}^{-1}$ em méis de diferentes origens florais do Estado de São Paulo; Carvalho et al. (1998) que obtiveram o valor médio de $16,49 \mathrm{~mL} \cdot \mathrm{kg}^{-1}$ em méis da Bahia; Marchini (2001) que comparou índices de formol para méis silvestres e de eucalipto do Estado de 
São Paulo, encontrando uma variação de 5,0 a 20,5 mL. $\mathrm{kg}^{-1}$ e 5,0 a $12,5 \mathrm{~mL} \cdot \mathrm{kg}^{-1}$, respectivamente; Almeida (2002) que encontrou uma variação de 3,5 a 19,0 mL.kg $\mathrm{kg}^{-1}$ para índice de formol em méis produzidos em área de cerrado no Estado de São Paulo.

\subsubsection{Cinzas (\%)}

Os valores de cinzas obtidos para as amostras analisadas variaram de 0,10 a $0,68 \%$, com valor médio de $0,35 \pm 0,16 \%$ (Tabela 5). A legislação considera aceitável méis com valores de cinzas de até 0,6\% (BRASIL, 2000), portanto, todas as amostras analisadas estão em conformidade com os padrões estabelecidos.

De acordo com Bogdanov (1999) o conteúdo de cinzas é influenciado pela origem botânica. Lasceve e Gonnet (1974) complementaram esta afirmativa ressaltando que além da origem botânica, fatores relacionados às abelhas, ao apicultor e ao clima da região podem influenciar este parâmetro.

Dentre os estudos realizados com o intuito de determinar o teor de cinzas em méis brasileiros, pode-se citar: Marchini; Sodré e Rodrigues (2001) que obtiveram valor médio de $0,19 \pm 0,02 \%$ em amostras de méis produzidos no Mato Grosso do Sul; Sodré et al. (2002) que encontraram uma variação de 0,09 a 0,67\% em méis produzidos no Estado da Bahia e Almeida (2002) que observou uma variação de 0,02 a 0,77\% em méis produzidos em uma área de cerrado no município de Pirassununga/SP.

\subsubsection{Proteína (\%)}

Os valores de proteína obtidos para as amostras analisadas variaram de 0,13 a $0,54 \%$, com um valor médio de $0,31 \pm 0,10 \%$ (Tabela 5). A legislação brasileira não estabelece valores para este parâmetro (BRASIL, 2000).

Resultados semelhantes foram encontrados por Baldi Coronel; Dall'Ogllio e Lezcano (1993) que obtiveram valores entre 0,05 a 0,65\% para méis produzidos na Argentina; Carvalho et al. (1998) que obtiveram valor médio de 0,44\% para méis produzidos na Bahia; Bath e Singh (1999) que encontraram valores médios de 0,036 e 0,65\% para flores de Helianthus annuus e Eucalyptus lanceolatus, respectivamente; Marchini (2001) que obteve valores médios de proteína igual a 0,19 e $0,32 \%$, para méis silvestres e de eucalipto, respectivamente e Almeida (2002) que 
obteve valores de proteína variando de 0,07 a $0,49 \%$ em méis produzidos no cerrado de Pirassununga/SP.

\subsubsection{Viscosidade (mPa.s)}

Os valores obtidos para viscosidade nas amostras analisadas variaram de 190,0 a 7040,0 mPa.s, com um valor médio de $2368,06 \pm 2099,01 \mathrm{mPa} . \mathrm{s}$, na temperatura de $25^{\circ} \mathrm{C}$ (Tabela 5). A legislação não estabelece valores para este parâmetro.

Serra-Bonvehí e Granados-Tarrés (1993) em méis de Calluna vulgaris (L.) Hull produzidos na Espanha obtiveram para viscosidade valores de 5198 a $17325 \mathrm{mPa}$.s na temperatura de 20,5 $5^{\circ}$; Marchini e Moreti (2001) determinaram os valores de viscosidade em méis provenientes de diferentes espécies de eucaliptos, encontrando o valor de $9050 \mathrm{mPa}$.s para méis de Eucalyptus citriodora, $10700 \mathrm{mPa}$.s para E. urophylla, $17900 \mathrm{mPa}$.s para E. grandis, $19200 \mathrm{mPa} . \mathrm{s}$ para E. camaldulensis e $11550 \mathrm{mPa} . s$ para E. tereticornis; Sodré et al. (2002) obtiveram valor médio de $1607 \mathrm{mPa}$.s para viscosidade em méis provenientes dos Estados do Ceará, Piauí e Pernambuco; Arruda (2003) analisou 21 amostras de méis provenientes do Estado do Ceará, encontrando valores de viscosidade entre 1620 a $6770 \mathrm{mPa}$.s na temperatura de $25^{\circ} \mathrm{C}$.

\subsubsection{Análises polínicas}

\subsubsection{Tipos polínicos presentes no mel}

As amostras de méis analisadas apresentaram uma grande variedade de tipos polínicos, sendo encontrados 30 tipos diferentes (Tabela 6).

Com relação à porcentagem encontrada nas amostras, foram considerados dominantes os tipos Anacardiaceae, Fabaceae, Melastomataceae, Anadenanthera sp. (Mimosaceae), Eucalyptus sp. (Myrtaceae), Bidens sp. (Asteraceae), Chenopodium sp. (Chenopodiaceae), Mimosa scabrella (Mimosaceae) (Figura 8).

O uso do tipo polínico, segundo Barth (1970a), engloba todas as espécies que possuem grãos de pólen iguais ou muito semelhantes, pertencendo ou não ao mesmo gênero. Este procedimento muitas vezes torna-se necessário devido às dificuldades na identificação das espécies, em função do baixo conhecimento existente sobre a vegetação estudada. Este mesmo autor salienta a importância do pólen dominante e acessório com relação a quantidade de néctar 
fornecido, ao contrário do pólen isolado. No entanto, este último fornece indícios quanto a origem e procedência geográfica do mel analisado.

As espécies mais freqüentes nas amostras foram Eucalyptus sp. (77\%), seguido de uma espécie não identificada da família Melastomataceae $(61,29 \%)$, Anacardiaceae $(54,8 \%)$ e dos tipos Myrcia, Serjania sp. e Anadenanthera sp., todos com (42\%). 


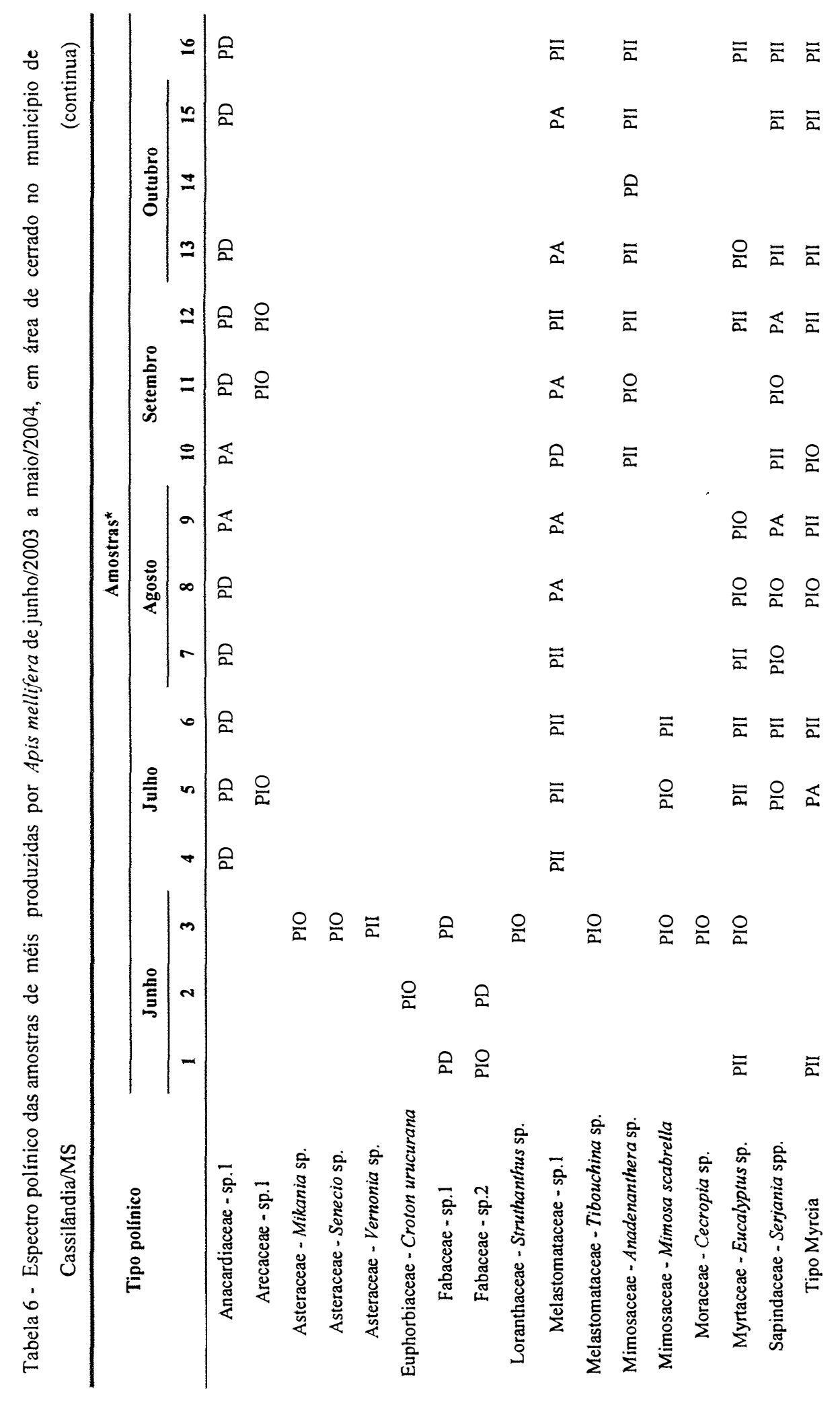




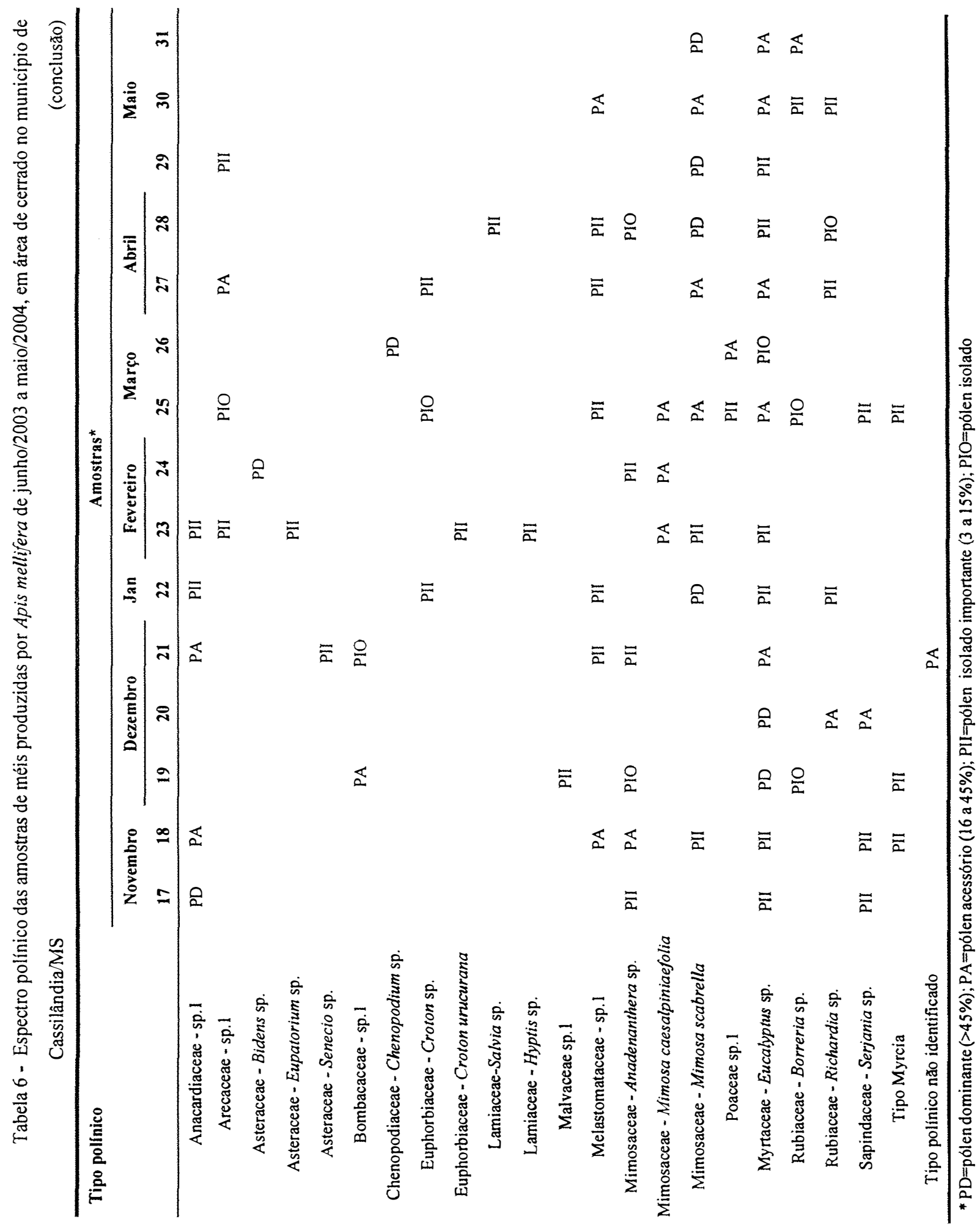




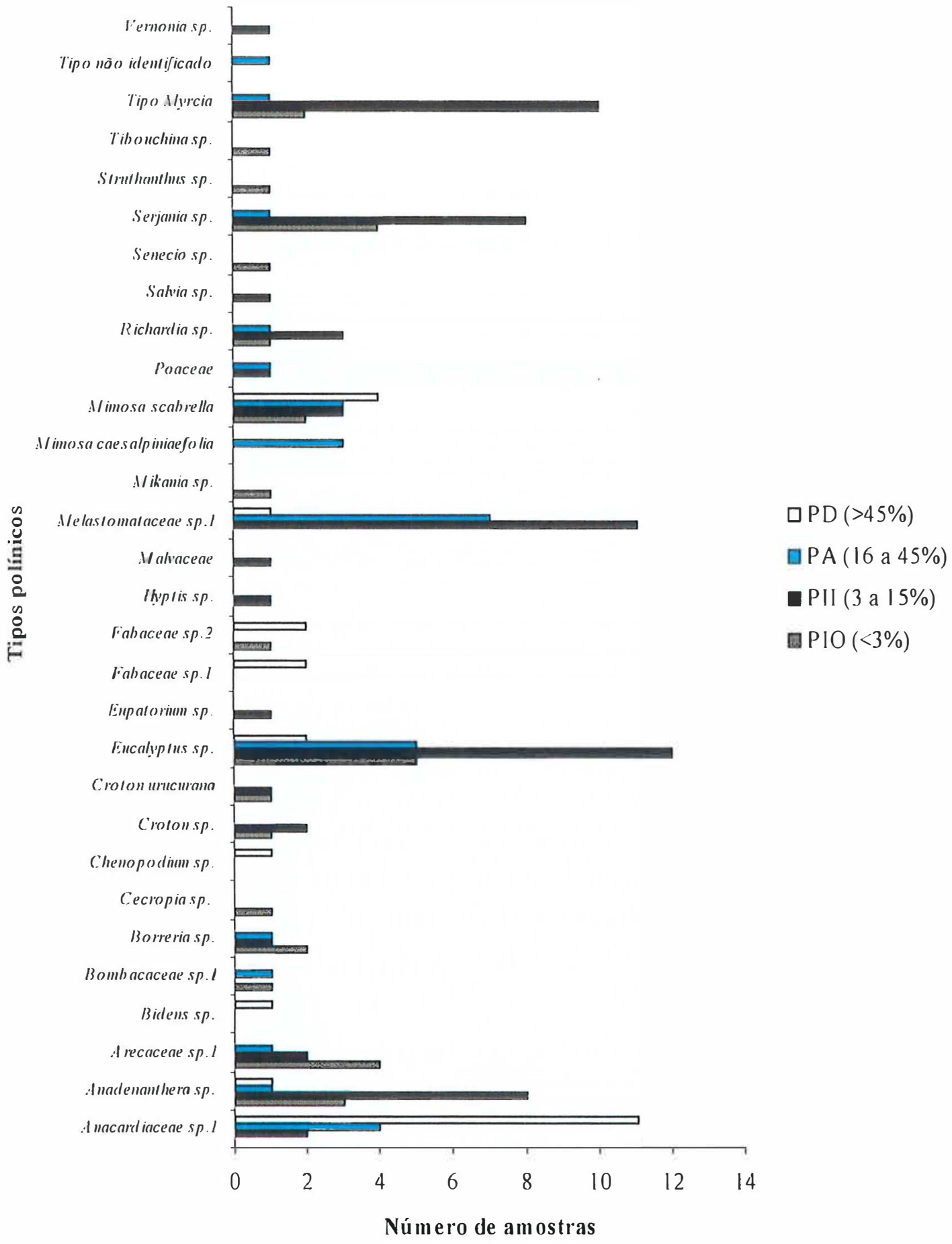

Figura 8 - Número de amostras que continham os diferentes tipos polínicos nas amostras de méis produzidos por Apis mellifera de junho/2003 a maio/2004, em área de cerrado no município de Cassilândia/MS 
Resultados semelhantes foram encontrados por Almeida (2002) em diferentes áreas de cerrado no município de Pirassununga/SP. Esta autora determinou a freqüencia dos grãos de pólen em amostras de méis obtendo maior valor para Eucalyptus sp., Anadenanthera macrocarpa e Didymopanax vinosum no cerradão e Eucalyptus sp., Didymopanax vinosum e Serjania sp. no cerrado "sensu strictu".

Barth e Luz (1998) analisaram o pólen presente no mel produzido por Apis mellifera, encontrando maior freqüência para as espécies Croton sp., Eucalyptus sp., Eupatorium maximilianii, Gochnatia polymorpha, Mimosa bimucronata, Mimosa pudica, Spondias sp. e Sapindaceae.

Bastos; Silveira e Soare (2003) determinaram o espectro polínico do mel produzido em áreas de cerrado no Estado de Minas Gerais, ressaltando a importancia das famílias Anacardiaceae, Amaranthaceae e Sapindaceae para a produção melífera local. À semelhança nestes estudos fica demonstrada a importância dessas famílias para a atividade apícola.

\subsubsection{Tipos polínicos presentes nas bolotas}

As bolotas de pólen encontradas nos coletores apresentaram maior diversidade quando comparado aos tipos polínicos presentes nas amostras de mel, sendo observado um total de 31 tipos (Tabela 7). 


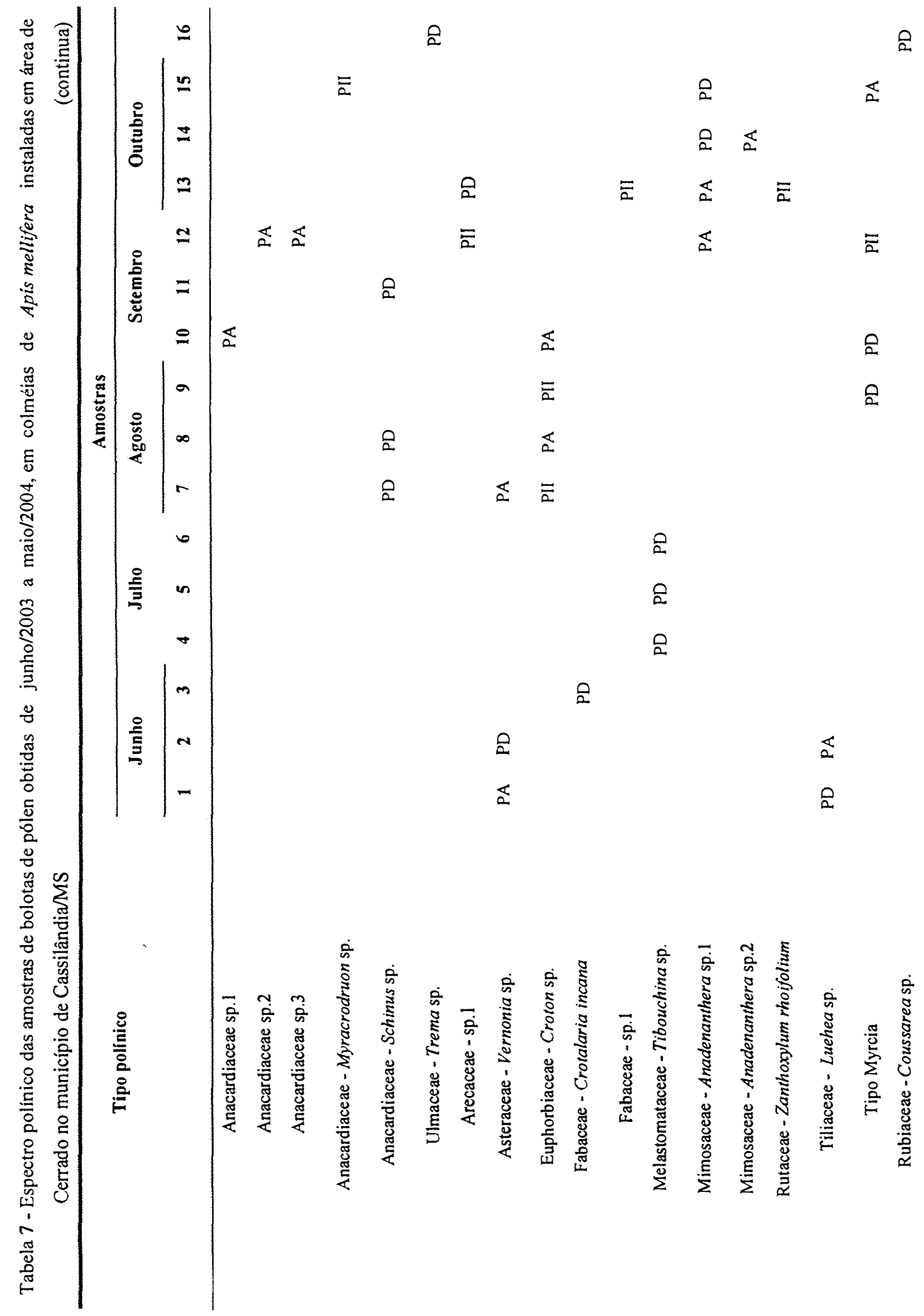




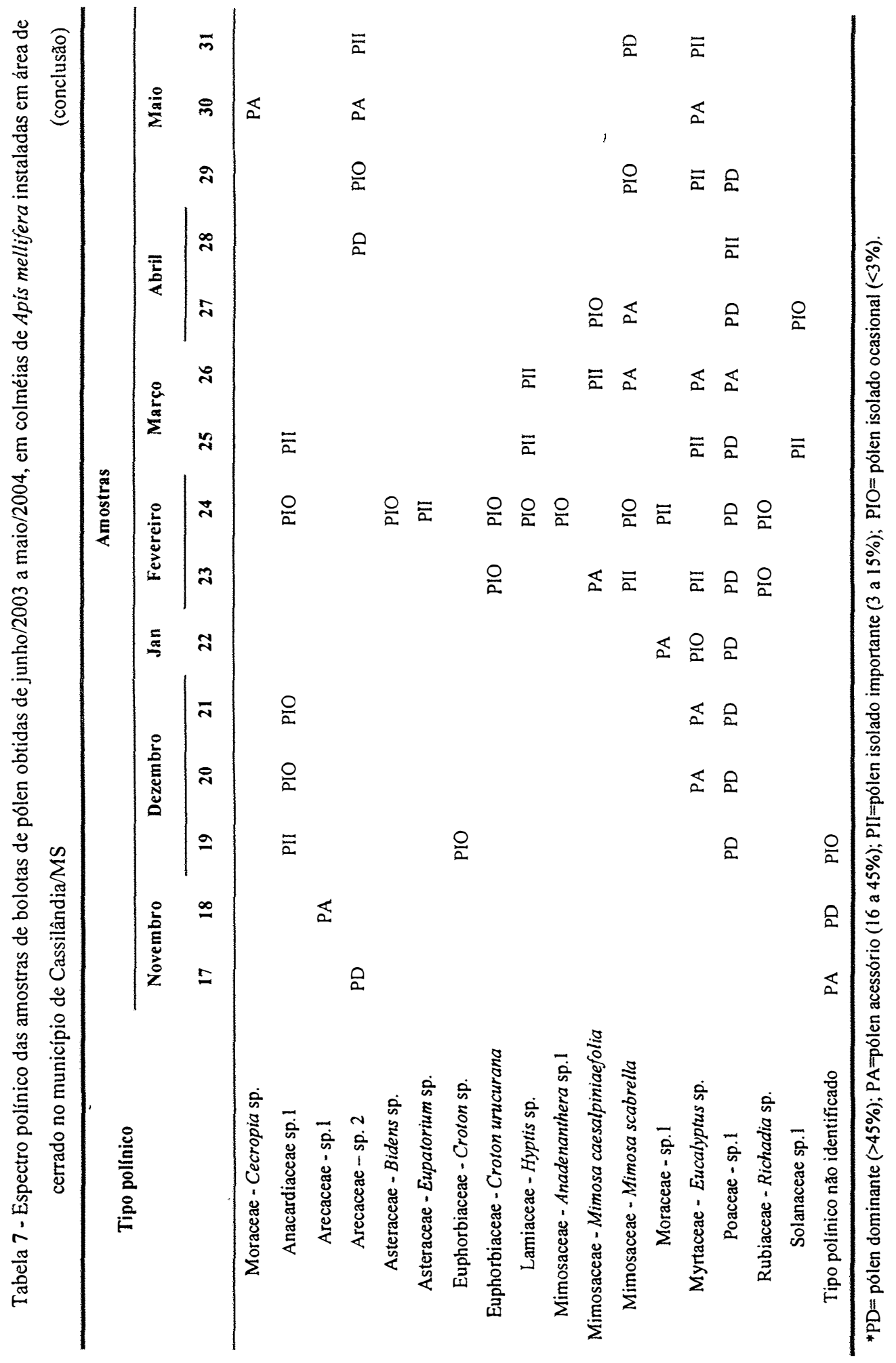

Apresentaram dominância Schinus sp. (Anacardiaceae), Arecaceae, Vernonia sp. (A ste raceae), Crotalaria incana (Fabaceae), Tibouchina sp. (Melastomataceae), Anadenanthera 
sp.1 (Mimosaceae), Mimosa scabrella (Mimosaceae), Arecaceae sp.2, Poaceae, Luehea sp. (Tiliaceae), Coussarea sp. (Rubiaceae), Trema sp. (Ulmaceae), Tipo Myrcia e um tipo polínico não identificado (Figura 9).

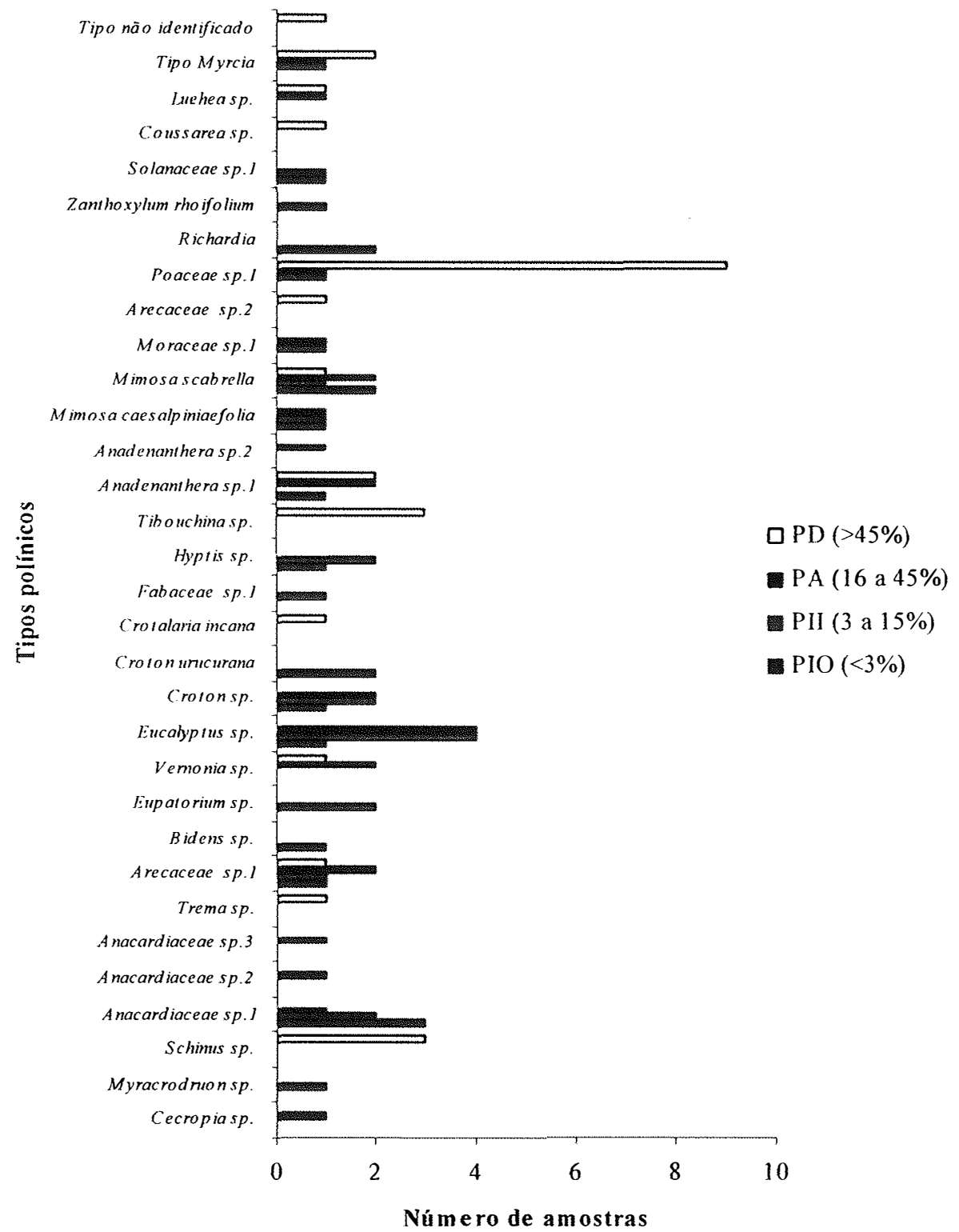

Figura 9 - Número de amostras que continham os diferentes tipos polínicos em amostras de bolotas de pólen coletadas em colméias de Apis mellifera, de junho/2003 a maio/2004, em área de cerrado no município de Cassilândia/MS 
Os tipos polínicos mais freqüentes nas amostras de bolotas de pólen foram Poaceae sp.1 (35,48\%), Eucalyptus sp. (29\%), Mimosa scabrella (Mimosaceae) e Arecaceae sp.1 ambas com $19,35 \%$.

Barth e Luz (1998) analisaram o pólen coletado por Apis mellifera em espécies poliníferas de uma área do Rio de Janeiro, encontrando com maior freqüencia as famílias Asteraceae, Euphorbiaceae, Fabaceae, Myrtaceae, e Arecaceae. Estes autores consideraram como mais freqüente nas amostras de mel e pólen as famílias Mimosaceae e Asteraceae.

Com relação à distribuição dos tipos polínicos por família, Asteraceae e Anacardiaceae apresentaran maior diversidade (11,6\%), seguidas por Mimosaceae (9,3\%) (Figura 10).

Resultados semelhantes foram observados em outros trabalhos, Barth e Luz (1998) encontraram maior diversidade de tipos polínicos para as famílias Mimosaceae, Asteraceae, Myrtaceae e Fabaceae, em estudos realizados no Rio de Janeiro. Almeida (2002) analisando a diversidade de pólen presente nas amostras de mel e pólen coletado em colméias de Apis mellifera no cerrado paulista, observou maior valor para as famílias Asteraceae, Myrtaceae e Mimosaceae. Costa (2002) analisando fontes de pólen utilizadas por Apis mellifera no município de Cruz das Almas-BA, também observou maior diversidade dos tipos polínicos para a família Asteraceae. Bastos; Silveira e Soare (2003) analisando os tipos polínicos em amostras de méis coletadas em área de cerrado no município de Cachoeira da Prata-MG, encontraram maior diversidade para as famílias Asteraceae e Mimosaceae.

Os resultados reforçam a importância de algumas famílias de plantas existentes no cerrado como Asteraceae e Mimosaceae para a atividade apícola. 


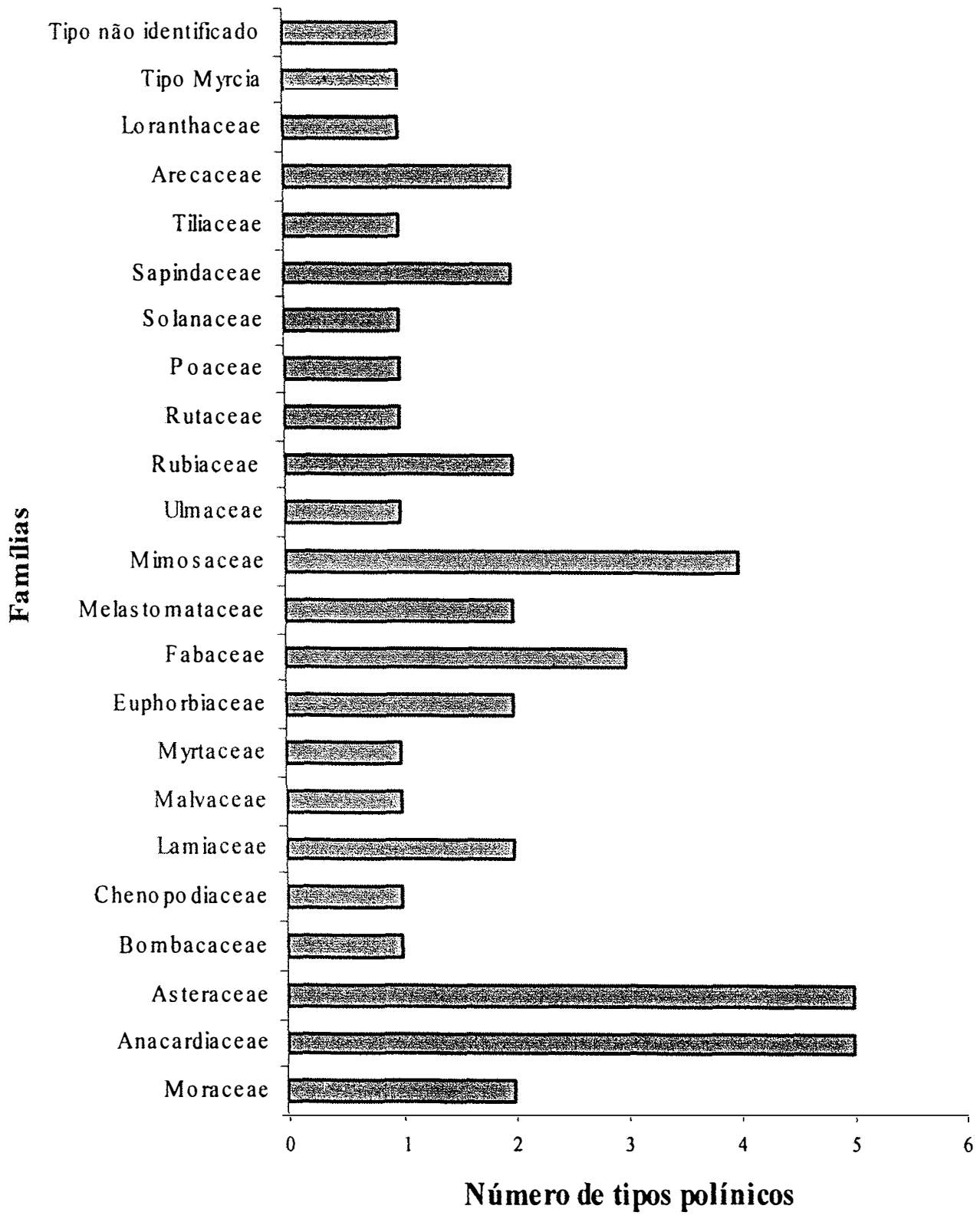

Figuna 0 - Número de tipos polínicos em relação às famílias botânicas coletadas nas amostras de mel e de bolotas de pólen obtidas em colméias de Apis mellifera, de junho/2003 a maio/2004, em área de cerrado no município de Cassilândia/MS 


\section{CONCLUSÕES}

$\checkmark$ O padrão de distribuição das espécies de abelhas neste estudo seguiu o padrão geral encontrado em outras comunidades, no qual se observa um maior número de espécies com poucos indivíduos e poucas espécies abundantes. Neste contexto a família Apidae apresentou maior riqueza e abundância em relação às demais;

$\checkmark$ As famílias botânicas Malpiguiaceae e Mimosaceae apresentaram maior representatividade dentre as espécies da flora apícola estudada;

$\checkmark$ A flora do cerrado possui plantas com diferentes períodos de florescimento, garantindo assim recurso floral em todas as estações do ano;

$\checkmark$ O mel produzido no local está em conformidade com a legislação, sugerindo que a região apresenta condições favoráveis à realização desta atividade e ressaltando a importância do cerrado como alternativa para exploração apícola;

$\checkmark$ Por meio da análise polínica observou-se que as abelhas utilizam uma grande diversidade de recursos florais para produção do mel, sendo em muitos casos classificado como polifloral. 


\section{REFERÊNCIAS}

ABSY, M.L.; CAMARGO, J.M.F.; KERR, W.E.; MIRANDA, I.P.A. Espécies de plantas visitadas por Meliponinae (Hymenoptera, Apoidea) para coleta de pólen na região do médio Amazonas. Revista Brasileira Biologia, São Carlos, v. 44, n. 2, p. 227-237, 1984.

ADEGAS, J.E.B.; NOGUEIRA-COUTO, R.H. Entomophilous pollination in rape (Brassica napus L. Oleifera) in Brazil. Apidologie, Les Ulis, v. 23, p. 203-209, 1992.

AGUIAR, C.M.L. Abundância, diversidade e fenologia de abelhas (Hymenoptera - Apoidea) da caatinga (São João do Cariri, PB) e suas interações com a flor apícola. 1995. 125p.

Dissertação (Mestrado em Entomologia) - Universidade Federal da Paraíba, João Pessoa, 1995.

AGUIAR, C.M.L.; MARTINS, C.F. Abundância relativa, diversidade e fenologia de abelhas (Hymenoptera, Apoidea) na caatinga, São João do Cariri, Paraíba, Brasil. Iheringia. Paraíba. Série Zoologia, n. 83, p. 151-163, 1997.

AGUILAR, J.B.V. A comunidade de abelhas (Hymenoptera: Apoidea) da reserva florestal de Morro Grande, Cotia, São Paulo. 1998. 182p. Tese (Doutorado em Entomologia) Universidade de São Paulo, São Paulo, 1998.

ALBUQUERQUE, P.M.C. Abelhas silvestres (Hymenoptera Apoidea) e suas fontes de alimento em um ecossistema de dunas, na ilha do Maranhão, MA, Brasil; composição, fenologia e interações. 1998. 212p. Tese (Doutorado em Entomologia) - Faculdade de Filosofia, Ciências e Letras de Ribeirão Preto, Universidade de São Paulo, Ribeirão Preto, 1998.

ALBUQUERQUE, P.M.C.; MENDONÇA, J.A. Anthophoridae (Hymenoptera - Apoidea) e flora associada em uma formação de cerrado no município de Barreirinhas, MA. Brasil.

Acta Amazonica, Manaus, v. 26, n. 1/2, p. 45-54, 1996.

ALBUQUERQUE, P.M.C.; RÊGO, M.M.C. Fenologia das abelhas visitantes de Murici (Byrsonima crassifolia, Malpighiaceae). Boletim Musseu Paranaense Emílio Goeldi, série Zoológica, v. 5, n. 2, p. 163-177, 1989.

AL-KHALIFA, A.S.; AL-ARIFY, I.A. Physicochemical characteristics and pollen spectrum of some Saudi honeys. Food Chemistry, Valência, v.67, n.1, p. 21-25, 1999. 
ALMEIDA, D. Espécies de abelhas (Hymenoptera, Apoidea) e tipificação dos méis por elas produzidos em área de cerrado no município de Pirassununga, estado de São Paulo. 2002. 103p. Dissertação (Mestrado em Entomologia) - Escola Superior de Agricultura "Luiz de Queiroz", Universidade de São Paulo, Piracicaba, 2002.

ALMEIDA, M.C.; LAROCA, S. Trigona spinipes (Apidae, Meliponinae): taxonomia, bionomia e relações tróficas em áreas restritas. Acta Biológica Paranaense, Curitiba, v. 17, n. 1, 2, 3, 4, p. 67-108, 1988.

AMARAL, A.D.; IMPERATRIZ-FONSECA, V.L.; GIOVANNINI, A.K.; AZOUBEL, M.L. Estudo comparativo entre amostras de méis com origem floral determinada; análise do teor de proteínas, lipídios e carboidratos totais. In: CONGRESSO BRASILEIRO DE APICULTURA, 7., 1996. Salvador. Programa e resumos. Salvador: Confederação Brasileira de Apicultura, 1986. p.60.

ANDENA, S.R. A comunidade de abelhas (Hymenoptera: Apoidea) de uma área de cerrado (Corumbataí-SP) e suas visitas às flores. 2002. 240p. Dissertação (Mestrado em Entomologia) - Faculdade de Filosofia, Ciências e Letras de Ribeirão Preto, Universidade de São Paulo, Ribeirão Preto, 2002.

ANDENA, S.R.; BEGO, L.R.; MECHI, M.R. Levantamento apifaunístico e utilização dos recursos florais no cerrado de Corumbataí (Corumbataí-SP). In: CONGRESSO BRASILEIRO DE ENTOMOLOGIA, 19, Anais... Manaus: Editora: SEB, 2002. p. 1.

ANDRADE, P. B.; AMARAL, M. T.; ISABEL, P.; CAMARGO, J. C. M. F.; SEABRA, R. M.; CUNHA, A.P. Physicochemical attributes and pollen spectrum of Portuguese heather honeys. Food Chemistry, Valência, v. 66, n. 4, p. 503-510, 1999.

ARAÚJO, N. Ganhe muito dinheiro criando abelhas: a técnica do apiário ao alcance de todos. São Paulo: Nobel, 1984. 210p.

ARCHENTI, A. Chemical composition of honeys from Chubut province (Argentina). Revista de Ciências Agrárias, Santa Maria, v. 5, n. 1/4, p. 12-28, 1984./ Resumo em CAB Abstracts on CDROM, v. 2, 1987-89/. 
ARRUDA, C.M.F. de. Características físico-químicas e polínicas de amostras de méis de $\boldsymbol{A}$ pis mellifera L., 1758 (Hymenoptera, Apidae) da região da Chapada do Araripe, município de Santana do Cariri, Estado do Ceará. 2003. 86 p. Dissertação (Mestrado em Entomologia) Escola Superior de Agricultura "Luiz de Queiroz", Universidade de São Paulo, Piracicaba, 2003.

ASSOCIATION OF OFFICIAL ANALYTICAL COUNCIL (A.O.A.C.). Official methods of analysis. 2. ed. Washington: A.O.A.C, 1990. 1018p.

AZEREDO, M.A.A.; AZEREDO, L.C.; DAMASCENO, J.G. Características físico-químicas dos méis do município de São Fidélis-RJ. Ciência Tecnologia Alimentos, Campinas, v. 19, n. 1, p. 3-7, 1999.

BALDI CORONEL, B.; DALL'OGLLIO, A.M.; LEZCANO, S. Caracterización físico químico de las mieles de la Provincia de Entre Rios. Alimentación Latinoamericana, Buenos Aires, n. 39, p. 39-44, 1993.

BANASZAK, J.; WENDZONKA, J. Bess (Hymenoptera: Apoidea) of the Bory Tucholskie National Park (NW Poland). Polskie Pismo Entomologiczne, Berlin, v. 71, n. 4, p. 327-350, 2002.

BARBOSA, I.; LAROCA, S. A comunidade de Apoidea (Hymenoptera) da Reserva Passa Dois (Lapa, Paraná, Brasil). I Diversidade, abundância relativa e atividade sazonal. Acta Biológica Paranaense, Curitiba, v. 22, n. 1-4, p. 91-113, 1993.

BARRETT, S.C.H.; HELENURM, K. The reproductive biology of boreal forest herbs. I. Breeding systems and pollinatio. Canadian Journal of Botany, Ottawa, v. 65, n. 10, p. 2036-2046, 1994.

BARROS, M.B. Apicultura. Rio de Janeiro, RJ. Serviço de informação Agrícola. 1965. (Série didática, 20). $251 \mathrm{p}$.

BARROSO, O.M. Sistemática de Angiospermas do Brasil. Viçosa-MG. Imprensa Universitária. 1986 , v. 3, 326p.

BARTH, O.M. Análise microscópicas de algumas amostras de mel. 1 - pólen dominante. Anais da Academia Brasileira de Ciência, São Paulo, v. 42, p. 351-366, 1970a. 
BARTH, O.M. Análise microscópicas de algumas amostras de mel. 2 - pólen acessório. Anais da Academia Brasileira de Ciência, São Paulo, v. 42, p. 571-590, 1970b.

BARTH, O.M. O pólen no mel brasileiro. Rio de Janeiro: Gráfica Luxor, 1989. 152p.

BARTH, O. M. Pollen in monofloral honeys from Brazil. Journal of Apicultural Research, Cardiff, v. 29, n. 2, p. 89-94, 1990.

BARTH, F.G. Insects and flowers: the biology of a partnership. Princeton: Princeton University Press, 1991. 408p.

BARTH, O. M.; LUZ, C.F.P. Melissopalynological data obtained from a mangrove area near to Rio de Janeiro, Brazil. Journal of Apicultural Research, Cardiff, v. 37, n. 3, p. 155-163, 1998.

BASTOS, D.H.M.; SILVA, J.R. Análise de méis produzidos na região Bragantina. Lecta, Bragança Paulista, v. 12, n. 2, p. 121-34, 1994.

BASTOS, E.M.A.F.; SILVEIRA, V.M.; SOARE, A.E.E. Pollen spectrum of honey produced in cerrado areas of Minas Gerais State (Brazil). Brazilian Journal Biology, São Carlos, v. 63, n. 4, p. 1-14, 2003.

BATH, P.K.; SINGH, N.A. A comparison between Helianthus annuus and Eucalyptus lanceolatus honey. Food Chemistry, Valência, v. 67, n. 4, p. 389-397, 1999.

BAWA, K.S. Plant-pollination interactions in tropical rain forests. Annual Review of Ecology and Systematics, Palo Alto, v. 21, p. 399-422, 1990.

BAWA, K.S.; BULLOCK, S.H.; PERRY, D.R.; COVILLE, R.E.; GRAYSON, M.H. Reproductive biology of tropical lowland rain forest trees. II. Pollination Systems. American Journal of Botany, St. Louis, v. 72, p. 346-351, 1985.

BEGON, M.; HARPER, J.L.; TOWNSEND, C.R. Ecology: individuals, populations and communities. 3. ed. Oxford: Blackwell Science, 1996. 1068p.

BICELLI, C.R.L.; SILVEIRA NETO, S.; MENDES, A.C.B. Dinâmica populacional de insetos coletados em cultura de cacau na região de Altamir, Pará. II. Análise Faunística. Agrotrópica, Aragua, v. 1, n. 1, p. 29-47, 1989. 
BOGDANOV, S.; MARTIN, P.; LULLMANN, C. Harmonized methods of the european honey commission. Apidologie, Les Ulis, v.2, n.11, p. 1-59, 1997. Extra Issue.

BOGDANOV, S. Honey quality and international regulatory standards: review by the international honey commission. Bee World, Cardiff, v. 80, n. 2, p. 61-69, 1999.

BOGDANOV, S.; LÜLLMANN, C.; MARTIN, P.; Von DER OHE, W.; RUSSMANN, H.; VORWOHL, G.; PERSANO-ODDO, L.; SABATINI, A.G.; MARCAZZAN, A.L.; PIRO, R.; FLAMINI, C.; MORLOT, M.; LHÉRITIER, J.; BORNECK, R.; MARIOLEAS, P.; TSIGOURI, A.; KERKVLIET, J.; ORTIZ, A.; IVANOV, T.; D’ARCY, B.; MOSSEL, B.; VIT, P. Calidad de la mile de abejas y estándares de control: revisión realizada por la comisión internacional de la miel. 2001. http://www.beekeeping.com/articulos/calidad-miel >. Acesso em: 10 jul. 2005.

BONAGA, G.; GIUMANINI, A.G. The volatile fraction of chestnut honey. Journal of Apicultural Research, Cardiff, v. 25, n. 2, p. 113-20, 1986.

BORTOLI, C. de; LAROCA, S. Estudo biocenótico em Apoidea (Hymenoptera) de uma área restrita em São José dos Pinhais (PR, Sul do Brasil), com notas comparativas. Dusenia, Curitiba, v. 15, p. $1-112,1990$.

BOYLE-MAKOWSKI, R.M.D. The importance of native pollinators in cultivated orchards: their abundance and activities in relation to weather conditions. Process Entomology Society, Ontario, v. 118, p. 125-141, 1988.

BRAGA, R. Flora apícola de Curitiba. Boletim da Universidade do Paraná. v. 2, p. 1-11, 1961.

BRASIL. Decreto n. 30.691, de 08 de setembro de 1997. Diário Oficial, de 08 de set. 1997. Seção 1, p. 19696-19697. Aprova as Normas do Regulamento Técnico para Fixação de Identidade e qualidade do mel.

BRASIL. Ministério da Agricultura. Instrução normativa n. 11, de 20 de outubro/2000. Regulamento técnico de identidade e qualidade do mel. Ttp://www.agricultura.gov.Br/das/dipoa/anexo (30 jan 2001).

BRITO, C.M.S.; RÊGO, M.M.C. Community of male Euglossini bees (Hymenoptera: Apidae) in a secondary Forest, Alcântara, MA, Brazil. Brazilian Journal Biology, São Carlos, v. 61, n. 4, p. 631-638, 2001. 
BROWER, J.J.; VAN LOON, A.J. Field and laboratory methods for general ecology. 2 ed. Dubuque: Editora Blackwell Science, 1984. 226p.

BUCHMAN, S.L. The ecology of oil flowers and their bees. Annual Review Ecology System, Palo Alto, v. 18, p. 343-369, 1987.

CAMACHO, J.C.B; MONKS, P.L.; SILVA, J.B. A polinização entomófila na produção e qualidade germinativa de sementes de trevo vesiculoso (Trifolium vesiculosum Savi) cv. EMBRAPA28 "Santa Tecla". Revista Brasileira de Agrociência, Pelotas, v. 5, n. 2, p. 114-119, 1999.

CAMARGO, J.M.F.; MAZUCATO, M. Inventário da apifauna e flora apícola de Ribeirão Preto, SP, Brasil. Dusenia, Curitiba, v. 14, n. 2, p. 55-87, 1984.

CAMPOS, L. A. O. Abelhas indígenas sem ferrão. Informe Técnico. Viçosa, MG: UFV, 1991. $36 \mathrm{p}$.

CAMPOS, M.J.O. Estudo das interações entre a comunidade de Apoidea, na procura de recursos alimentares, e a vegetação de cerrado da Reserva de Corumbataí, SP. 1989. 123 p. Tese (Doutorado em Ecologia) - Universidade Federal de São Carlos, São Carlos, 1989.

CAMPOS, G. Melato no mel e sua determinação através de diferentes metodologias. Belo Horizonte. 1998. 178 p. Tese (Doutorado em Ciência Animal) - Escola de Veterinária, Universidade Federal de Minas Gerais, Belo Horizonte, 1998.

CANO, C.B.; FELSNER, M.L.; MATOS, J.R.; BRUNS, R.E.; WHATANABE, H.M. ALMEIDA-MURADIAN, L.B. Comparation of methods for determining moisture content of citrus and eucalyptus Brazilian honeys by refractometry. Journal of Food Composition and Analysis, Valência, v. 14, n. 1, p. 101-109, 2001.

CARNEIRO, J.G.M.; SOUZA, D.C.; MURATORI, M.C.S; MOURA, S.G. de; MELO, R. de S.; SILVA, E. P. da; REGG, J. G. S. Características físico-químicas de 132 amostras de mel de abelhas da microrregião de Simplício Mendes, PI. In: CONGRESSO BRASILEIRO DE APICULTURA, 2002, Campo Grande. Anais... Campo Grande: Confederação Brasileira de Apicultura, 2002. p. 76. 
CARVALHO, A.M.C. Estudo das interações entre a apifauna e a flora apícola em vegetação de cerrado - reserva ecológica do Panga - Uberlândia-MG. 1990. 182 p. Dissertação (Mestrado em Entomologia) - Faculdade de Filosofia, Ciências e Letras - Ribeirão Preto/SP, Universidade de São Paulo, Ribeirão Preto, 1990.

CARVALHO, A.M.C.; BEGO, L.R. Seasonality of dominant species of bees in the Panga Ecological Reserve, cerrado, Uberlândia, M.G. Annual Society Entomology Brasil, Porto Alegre, v. 24 , n. 2, p. 147-156, 1995.

CARVALHO, A.M.C.; BEGO, L.R. Studies on Apoidea fauna of cerrado vegetation at the Panga Ecological Reserva, Uberlândia, MG, Brazil. Revista Brasileira de Entomologia, Curitiba, v. 40, n. 2, p. 147-156, 1998.

CARVALHO, C. A. L. de ; MARCHINI, L. C. ; TEIXEIRA, G. M. ; OLIVEIRA, P. C. F. ; RUBIA, V. R. Características físico-químicas de amostras de méis da Bahia. In: CONGRESSO BRASILEIRO DE APICULTURA, 1998, Salvador. Anais... Salvador: Confederação Brasileira de Apicultura, 1998. p. 200.

CARVALHO, C.A.L. de. Diversidade de abelhas (Hymenoptera, Apoidea) no Vale do rio Paraguaçu, município de Castro Alves, Estado da Bahia. 1999. 83 p. Tese (Doutorado em Entomologia) - Escola Superior de Agricultura "Luiz de Queiroz", Universidade de São Paulo, Piracicaba, 1999.

CARVALHO, C.A.L.; SILVA, R.F. Abelhas da região do Bico-do-Papagaio, Tocantins, Brasil. In: CONGRESSO BRASILEIRO DE ENTOMOLOGIA, 2000. Manaus, 19, Anais... Manaus: SEB, 2002. p. 183.

CARVALHO, C.A.L. de; MARCHINI, L.C.; SODRÉ, G.S.; ALVES, M.O.; PASSOS, L.R.C. Análises de amostras de méis provenientes do Recôncavo da Bahia. In: ENCONTRO SOBRE ABELHAS, 2000, Ribeirão Preto. Anais... Ribeirão Preto: Faculdade de Filosofia Ciências e Letras, 2000. p. 352.

CHAGNON, M.; GINGRAS, J.; OLIVEIRA, D. Complementary aspects of strawberry pollination by honey and indigenous bees (Hymenoptera). Journal Economical Entomology., Lanham, v. 86, n. 2, p. 416-420, 1993.

CODEX ALIMENTARIUS COMMISSION. Standard for Honey (CAC/RS 12 1969). FAO and WHO. Rome, 1969. p. 59. 
CODEX ALIMENTARIUS COMMISSION (C.A.C.) Official methods of analysis. v 3, Supl 2, p. (s.n.p) Rome, 1990, p. 65.

COELHO-CARVALHO, A.M.; BEGO, L.R. Seasonality of dominant species of bees in the panga Ecological Reserve, Cerrado, Uberlândia, MG. Annual Society Entomology Brasil, Porto Alegre, v. 24, n. 2, p. 329-337, 1995.

COELHO-CARVALHO, A.M.; BEGO, L.R. Studies on apoidea fauna of cerrado vegetation at the Panga Ecological Reserve, Uberlândia, MG, Brazil. Revista Brasileira Entologia, Curitiba, v. 40 , n. 2 , p. $147-156,1996$.

COPERSUCAR (Cooperativa de Produtores de Cana, Açúcar e Álcool do Estado de São Paulo). Métodos Analíticos. In: COPERSUCAR. Manual de Controle Químico da Fabricação de Açúcar. Piracicaba: Copersucar, 1987. p. 1-51.

CORNEJO, L.G. Tecnologia de miel. In: SEEMANN, P.; NEIRA, M. Tecnologia de la produccion apicola. Valdivia: Universidad Austral de Chile, Facultad de Ciencias Agrarias, 1988. p. 145-171.

COSTA, J. B. A. Fontes de pólen utilizadas por operárias de Apis mellifera L. no município de Cruz das Almas, Bahia. 2002. 55p. Dissertação (Mestrado em Produção Animal) - Universidade Federal da Bahia, Cruz das Almas, 2002.

CRANE, E. Honey: a comprehensive survey. London: Neinemann, 1975.608p.

CRANE, E. O livro do mel. 2. ed. São Paulo: Nobel, 1987. 226p.

CRANE, E. Bees and beekeeping-science, practice and world resources. London: Neinemann Newnes, 1990. 614p.

CURE, J.R.; BASTOS FILHO, G.S.; OLIVEIRA, M.J.F.; SOUZA, O.F. Influência do tamanho da amostra na estimativa da riqueza em espécies em levantamentos de abelhas silvestres (Hymenoptera: Apoidea). Revista Brasileira de Zoologia, Curitiba, v. 7, n. 1/2, p. 101-110, 1991.

CURE, J.R.; BASTOS, G.S.; FILHO, M.J.F.O.; SILVEIRA, F.A. Levantamento de abelhas silvestres na Zona da Mata de Minas Gerais. I - Pastagem na região de Viçosa (Hymenoptera, Apoidea). Revista Ceres, Viçosa, v. 40, n. 228, p. 131-161, 1993. 
CURE-HAKIN, J.R. Estudos ecológicos de comunidades de abelhas silvestres (Hymenoptera, Apoidea) do Parque da cidade, comparado ao de outras áreas de Curitiba, Paraná. 1983. 100 p. Dissertação (Mestrado em Zoologia) - Universidade Federal do Paraná, Curitiba, 1983.

DAYRELL, I.O.; VITAL, N.C. Comparação entre dois métodos oficiais para determinação de hidroximetilfurfural (HMF) em mel brasileiro. Ciência e Tecnologia de Alimentos, Campinas, v. 11, n. 1, p. 137-141, 1991 .

DOZO, A.M.M. de. Determinacion de azucares em mieles producidas em la província de Buenos Aires - Republica Argentina. In: CONGRESSO BRASILEIRO DE APICULTURA, 5.; CONGRESSO LATINO-IBERO-AMERICANO DE APICULTURA, 1980, Viçosa. Anais... Viçosa: Universidade Federa de Viçosa, 1980. p. 312-316.

DURÁN, J.E.T.; CORTOPASSI-LAURINO, M.; ISSA, M.R.C. et al. Méis brasileiros: resultados de análises físico-químicas e palinológicas. In: CONGRESSO BRASILEIRO DE APICULTURA, 1996, Teresina. Anais... Teresina: Confederação Brasileira de Apicultura. 1996, p. 403-429.

EITEN, G. The cerrado vegetation of Brazil. The Botanical Review, Washington, v. 38, n. 2, p. 202-341, 1972.

EL-SHERBINY, G.A.; RIZK, S.S.; EL-ASHWAH, F.A.; HEIKAL, H.A. Chemical composition of citrus honey producede in A.R.E. Agricultural Research Review, Oxford, v. 58, n. 3, p. 289-97, 1980. Resumo em CAB Abstracts on CD-ROM, v. 1, 1984-86.

ENDRESS, P.K. Diversity and evolutionary biology of tropical flowers. Cambridge: Cambridge University Press, 1994. (Cambridge Tropical Biology Series). p. 236.

ENGEL, M.S.; DINGEMANS-BAKELS, F. Nectar and pollen resources for stingless bees (Meliponinae, Hymenoptera) in Surinam (South America). Apidologie, Les Ulis, v.11, n. 4, p. 341-350, 1980 .

ESCOBAR-MARTÍNEZ, C.A.; GIMÉNEZ MEZA, G.G.; QUIÑONEZ MENDOZA, M.R. Mieles de abejas de flora paraguaya: composicion, tipificacion y normalizacion. San Lorenzo: Ministério de Agricultura y Ganaderia; Universidad Nacional de Asuncion; Asociacion Suiza para el Desarrollo y la Cooperacion, 1992. $31 \mathrm{p}$. 
FARAJI-HAREMI, R.; HOSSEINI, Z. Chemical composition of honeys from Fars and Kohkiluyeh provinces of Iran. Iran Agricultural Research, Iran, v. 6, n. 2, p. 73-81, 1987. /Resumo em CAB Abstracts on CD-ROM, 1990-91\%.

FARIA, G.M.; CAMARGO, J.M.F. A flora melitófila e a fauna de Apoidea de um ecossistema de campos rupestres, Serra do Cipó - MG, Brasil. In: Encontro sobre Abelhas, 2, 1996. Ribeirão Preto. Anais...1996. p. 217-228.

FELLER-DEMALSY M.J.; PARENT, J.; STRACHAN, A.A. Microscopic analysis of honeys from Alberta, Canada. Journal of Apicultural Research, Cardiff, v. 23, n. 2, p. 123-132, 1987.

FLECHTMANN, C.H.W.; CALDAS FILHO, C.F.; AMARAL, E.; ARZOLLA, J.D.P. Análise de méis do Estado de São Paulo. Boletim de Indústria Animal, Nova Odessa, v. 21, p. 65-73, 1963.

FRANKIE, G.W.; BAKER, H.G.; OPLER, P.A. Tropical plant phenology; applications for studies in community ecology. In: LIETH, H. Phenology and seasonality modeling. Berlin: Springer-Verlag, 1974. P. 287-296.

FRANKIE, G.W. Tropical forest phenology and pollinator plant coevolution. In: GILBERT, L.E.; Raven, P.H. University of Texas. Austin: Coevolution of animals and plants, p. 192-209. 1975.

FREE, J.B. Insect pollination of crops. London: Academic Press, 1993. 684p.

FRIAS-TEJERA, I.; TORRE, A.H. de la. Physico-chemical parameters of honey produced in the province of Santa Cruz in Tenerife. 4. Directly reducing sugars and sucrose. Canarias Apicola, n. 24, p. 4-6, 1991. /Resumo em CAB Abstracts on CD-ROM, v. 4A, 1993-94/.

FRÍAS, I.; HARDISSON, A. Estudio de los parámetros analíticos de interés em la miel. II. Azúcares, cenizas y contenido mineral y color. Alimentaria, Catalunya, v. 28, n. 235, p. 41-43, 1992.

GARCIA-ALVAREZ, M.; HUIDOBRO, J.F.; HERMIDA, M., RODRÍGUEZ-OTERO, J.L. Major components of honey analysis by Near-Infrared transflectance spectroscopy. Journal Agricultural Food. Chemistry, Davis, v. 48, p. 5154-5158, 2000.

GARCIA NETO, M.; NOGUEIRA-COUTO, R.H.; MALHEIROS, E.B. Polinização em Dolichos lab-lab. Ciência Zootécnica. Jaboticabal, v. 3, n. 1, p. 3-4, 1988. 
GIL, J.M.S. Apicultura. 2. ed., Barcelona: Aedos, 1986. 418p.

GIMENES, M. Interactions between bees and Ludwigia elegans (Camb.) Hara (Onagraceae) flowers at different altitudes in São Paulo, Brazil. Revista Brasileira de Zoologia, Curitiba, v. 19, n. 3, p. 681-689, 2002.

GIORGINI, J.F.; GUSMAN, A.B. A importância das abelhas na polinização. In: CAMARGO, J. M.F., Ed. Manual de apicultura. São Paulo: Ceres, 1972. p. 155-214.

GOMEZ, M.E.M.; HERNANDEZ, E.G.; GOMEZ, J.Y.M.; MARIN, J.L.M. Physicochemical analysis of Spanish commercial Eucalyptus honeys. Journal of Apicultural Research, Cardiff, v. 32, n. $3 / 4$, p. $121-126,1993$.

GOODLAND, R.; FERRI, M.G. Ecologia do Cerrado. São Paulo: Ed. Itatiaia, 1979. 193p. (Coleção reconquista do Brasil, 52).

GROSS, C.L.; MACKAY, D. Honeybee reduce fitness in the pioneer shrub Melastoma affine (Melastomataceae). Biology Conservation, Valência, v. 86, p. 169-178, 1998.

HARTER, B.; LEISTIKOW, C.; WILMS, W.; TRUYLIO, B.; ENGELS, W. Bees collecting pollen from flowers with poricidal anthers in a south Brazilian Araucaria forest: a community study. Journal of Apicultural Research, Cardiff, v. 40, n.1/2, p. 9-16, 2002.

HEITHAUS, E.G. Community structure of Neotropical flower visiting bees and wasps: diversity and phenology. Ecology, Washington, v. 60, n. 1, p. 190-202, 1979.

HERRERO, B.; VALENCIA, B.R.M. Palynological analysis of honeys from Palencia Province (Spain). Acta Botanica Croatica, São Paulo, v. 60, n. 1, p. 11-24, 2001.

HOFFMAN, M. Estrutura e importância de uma comunidade de abelhas (Hymenoptera: Apoidea) no Rio Grande do Sul, para a polinização de plantas cultivadas. 1990.162 p. Tese (Doutorado em Entomologia) - Universidade Federal do Paraná, Curitiba, 1990.

HUBBEL, S.P.; JOHNSON, L.K. Competition and nest spacing in a tropical stingless bee community. Ecology, Washington, v. 58, p. 949-963, 1977. 
HUIDOBRO, J.F.; SANTANA, F.J.; SANCHEZ, M.P.; SANCHO, M.T.; MUNIATEGUI, S.; SIMAL-LOZANO, J. Diastase, invertase and $\beta$-glucosidase acitivities in fresh honey from northwest Spain. Journal of Apicultural Research, Cardiff, v. 34, n. 1, p. 39-44, 1995.

IMPERATRIZ-FONSECA, V.L.; KLEINERT-GIOVANNINI, A.; RAMALHO, M. Pollen harvest by eusocial bees in a non-natural community in Brazil. Journal of Tropical Ecology, Cambridge, v. 5, p. 239-242, 1989.

ITC UNCTAD/GATT. Major markets for honey: openings for quality Supplies from Developing Countries. International Trade Centre; Geneva, Switzerland; 1977. 120p.

IWAMA, S.; MELHEM, T.S. The pollen spectrum of the honey of Tretagonisca angustula Latrelle (Apidae, Meliponinae), Apidologie, Les Ulis, v. 10, n. 3, p. 275-295, 1979.

JATO, M.V.; SALA-LLINARES, A.; IGLESIAS, M.I.; SIAREZ-CERVERA, M. Pollens of honeys from north-western Spain. Journal of Apicultural Research, Cardiff, v. 30, n. 2, p. 69-73, 1991.

JULIANO, J.C. Identificação de espécies de interesse apícola da flora do Rio Grande do Sul. In: CONGRESSO BRASILEIRO DE APICULTURA, 1972, Sete Lagoas. Anais...Sete Lagoas: Confederação Brasileira de Apicultura. 1972. p. 85-118.

JUNZHENG, P.; CHANGYING, J. General rheological model for natural honeys in China. Journal of Food Engineering, Auckland, v. 36, p. 165-168, 1998.

KERR, W.E. Progresso na genética de abelhas. In: CONGRESSO BRASILEIRO DE APICULTURA, 1994, Pousada do Rio Quente (GO). Anais...Rio Quente: Confederação Brasileira de Apicultura. 1994. p. 264-277.

KERR, W.E.; AMARAL, E. Apicultura científica e prática. São Paulo, Secretaria de Agricultura. 1960.148 p.

KLEINERT-GIOVANNINI, A.; IMPERATRIZ-FONSECA, V.L. Aspects of the trophic niche of Melipona marginata marginata Lopeletier (Apidae, Meliponinae). Apidologie, Les Ulis, v. 18, n.1, p. 69-100, 1987. 
KNOLL, F.R.N. Abundância relativa de abelhas no campus da Universidade de São Paulo, com especial referência a Tetragonisca angustula. 1985. 78 p. Dissertação (Mestrado em Entomologia) - Universidade de São Paulo, São Paulo, 1985.

KNOLL, F.R.N.; BEGO, L.R.; IMPERATRIZ-FONSECA, V.L. Relative Abundance and phenologyn of bees (Hymenoptera, Apoidea) in São Paulo, Brazil. Proceedomgs Munich: V.J. Pepeny, Congr. Int. IUSSI, Munich.: 1987. p. 702-703.

KOMATSU, S.S. Caracterização fisico-química de méis de Apis mellifera L. 1758 (Hymenoptera: Apidae) de diferentes municípios do estado de São Paulo. 1996. 90 p. Tese (Doutorado em Entomologia) - Escola Superior de Agricultura "Luiz de Queiroz", Universidade de São Paulo, Piracicaba, 1996.

KOMATSU, S.S.; MARCHINI, L.C. Teores de açúcares redutores e sacarose de amostras de méis de flores silvestres produzidos por Apis mellifera no Estado de São Paulo. In: CONGRESSO BRASILEIRO DE APICULTURA, 11, 1996a, Salvador. Anais... Confederação Brasileira de Apicultura, 1996. p 344.

KOMATSU, S.S.; MARCHINI, L.C. Determinação do Índice de Diastase e Hidroximetilfurfural de amostras de méis de flores silvestres produzidos por Apis mellifera no Estado de São Paulo. In: CONGRESSO BRASILEIRO DE APICULTURA, 1996b, Salvador. Anais... Confederação Brasileira de Apicultura, 1996. p 343.

KOMATSU, S.S.; MARCHINI, L.C.; MORETI, A.C.C.C. Análises físico-químicas de amostras de méis de flores silvestres, de eucalipto e de laranjeira, produzidos por Apis mellifera L., 1758 (Hymenoptera: Apidae) no estado de São Paulo. 2. conteúdo de açúcares e de proteína. Ciência Tecnologia de Alimentos, Campinas, v. 22, n. 2, p. 143-146, 2002.

KUHLMANN, M. Struktur der Wildbienen - und Wespenzoenosen ausgewaehlter Waldstandorte im nationalpark Bayerischer Wald (Hymenoptera, Aculeata). Nachrichtenblatt der Bayerischen Entomologen, Berlin, v. 51, n. 3/4, p. 61-74, 2002.

KREMEM, C.; WILLIAMS, N.M.; THORP, R.W. Crop pollination from native bees at risk from agricultural intensification. Proceedings of the national Academy of Sciences of the United States of America, v. 99, n. 26, p. 16812-16816, 2002.

LAROCA, S. Estudo feno-ecológico em Apoidea do litoral e primeiro planalto paranaense. 1974. 102 p. Dissertação (Mestrado em Entomologia) - Universidade Federal do Paraná, Curitiba, 1974. 
LAROCA, S. Community ecology in bees: relative importance of rare and common species in some holartic and neotropical sites. Revista Brasileira de Zoologia, Curitiba, v. 9, n. 1/2, p. 131137, 1992.

LAROCA, S. Ecologia: princípios e métodos. Petrópolis: Vozes, 1995. 197p.

LAROCA, S.; ALMEIDA, M.C. O relicto de cerrado de Jaguariaíva, (Paraná, Brasil): padrões biogeográficos, melissocenosses e flora melissófila. Acta Biologica Paranaense, Curitiba, v. 23, n. 1/4, p. 89-122, 1994.

LAROCA, S.; CURE, J.R.; BORTOLI, C. A associação de abelhas silvestres (Hymenoptera, Apoidea) de uma área restrita no interior da cidade de Curitiba (Brasil): uma abordagem biocenótica. Dusenia, Curitiba, v. 13, n. 3, p. 93-117, 1982.

LASCEVE, G.; GONNET, M. Analyse par radioactivation du contenu mineral d'un mile. Possibilité de préciser son origine géofraphique. Apidologie, Les Ulis, v. 5, n. 3, p. 201-223, 1974.

LAZAROVA, M.; BOZILOVA, E. Pollen and chemical analysis of honey from different floristic regions of South Bulgaria. Phytologia Balcanica, Bulgaria, v. 8, n. 2, p. 145-164, 2002.

LEWIS, T.; TAYLOR, L.R. Introduction to experimental ecology: a student guide to fieldwork and analysis. London: Academic Press, 1976. 41p.

LOUVEAUX, J.; MAURIZIO, A.; VORWOHL, G. Methods of melissopalynology. Bee World, Cardiff, v. 51.p. 125-138, 1970.

LOUVEAUX, J., MAURIZIO, A., VORWOHL, G., Methods of melissopalynology. Bee World, Cardiff, v. 59, p. 139-157, 1978.

LOW, N.H.; NELSON, D.L.; SPORNS, P. Carbohydrate analysis of western Canadian honeys and their nectar sources to determine the origin of honey oligosaccharides. Journal of Apicultural Research, Cardiff, v. 27, n. 4, p. 245-251, 1988.

MAHAJAN, U. Physicochemical analysis of honey of Shimla Hills (Hemachal Pradesh) Índia, 1984. 99p. (Mphil Dissertation Himachal Pradesh University)./Resumo 1360 em Apicultural Abstracts, Valência, v. 36, n. 4, p. 324, 1985/. 
MALERBO, D.T.S.; COUTO, R.H.N. Polinização e uso de atrativos em cultura de laranja ( $\mathrm{Ci}$ trus sinensis L. Osbeck), var. Pêra-Rio. In: ENCONTRO SOBRE ABELHAS DE RIBEIRÃO PRETO, 1994, Ribeirão Preto. Anais...Ribeirão Preto: editora Edusp, 1994. P. 273

MALERBO-SOUZA, D.T.S.; MOTA, M.O.S.; COUTO, R.H.N.; SOUZA, J.C. Insetos associados a inflorescências do manjericão (Ocimum basilicum L.) Revista Brasileira Plantas Medicinais, Botucatu, v. 2, n. 4, p. 27-30, 2000.

MARCHINI, L.C. Caracterização de amostras de méis de Apis mellifera L. 1758 (Hymenoptera: Apidae) do Estado de São Paulo, baseada em aspectos físico-químicos e biológicos. 2001. 83 p. Tese (Livre-Docência) - Escola Superior de Agricultura "Luiz de Queiroz", Universidade de São Paulo, Piracicaba, 2001.

MARCHINI, L.C.; RODRIGUES, A.C.L.; MORETI, A.C. de C.C. Características qualitativas de méis que passaram por diferentes tipos de descristalização. In: CONGRESSO BRASILEIRO DE APICULTURA, 12, 1996, Piauí. Anais... Piauí: Confederação Brasileira de Apicultura. 1996. $348 \mathrm{p}$.

MARCHINI, L.C.; MORETI, A.C.C.C. Características físico-químicas de amostras de mel de cinco diferentes espécies de eucaliptos. In: SIMPÓSIO LATINO AMERICANO DE CIENCIA DE ALIMENTOS, 4., 2001, Campinas. Resumos... Campinas: R. Vieira Gráfica, 2001a. p. 42.

MARCHINI, L.C.; SODRÉ; G.S.; RODRIGUES, S.R. Características físico-químicas de amostras de méis de Apis mellifera (Hymenoptera: Apidae) provenientes do Mato Grosso do Sul. In: SIMPÓSIO LATINO AMERICANO DE CIÊNCIA DE ALIMENTOS, 4., 2001, Campinas. Resumos... Campinas: R. Vieira Gráfica, 2001b. p. 160.

MARCHINI, L.C.; SODRÉ, G. S.; MORETI, A. C. C. C. Mel Brasileiro: composição e normas. Ribeirão Preto: A.S.P., 2004. 131p.

MARTÍNEZ, C.A.E.; MEZA, G.G.G.; MENDONZA, M.R.Q. Mieles de abejas de flora paraguaya: composición, tipificación y normalización. San Lorenzo: Ministerio de Agricultura y Ganaderia, Universidad Nacional de Asunción, Asociación Suiza para el Desarrollo y la Cooperación, 1992.31p.

MARTINEZ-GOMEZ, M.E.; GUERRA HERNANDEZ, E.; MONTILLA GOMEZ, J.Y.; MOLINS MARIN, J.L. Physicochemical analysis of Spanish commercial Eucalyptus honeys. Journal of Apicultural Research, Cardiff, v. 32, n. 3/4, p. 121-126, 1993. 
MARTINHO, M.R. Apicultura. MG: UFV, 1990. 26p. (Informe Técnico).

MARTINS, C.F. Estrutura da comunidade de abelhas (Hymenoptera: Apoidea) na caatinga (Casa Nova, BA) e na Chapada Diamantina (Lençóis, BA). 1990. 159 p. Tese (Doutorado em Ecologia) - Universidade de São Paulo - Instituto de Biociências. São Paulo, 1990.

MARTINS, C.F. Comunidade de abelhas (Hymenoptera, Apoidea) da caatinga e do cerrado com elementos de campo rupestre do estado da Bahia, Brasil. Revista Nordestina Biologia, João Pessoa, v. 9, n. 2, p. 225-257, 1994.

MATEUS, S. Abundância relativa, fenologia e visita as flores pelos Apoidea do cerrado da estação ecológica de Jataí- Luiz Antônio - SP. 1998. 160 p. Dissertação (Mestrado em Entomologia) - Faculdade de Filosofia, Ciências e Letras - Ribeirão Preto/SP, Universidade de São Paulo, Ribeirão Preto, 1998.

McINTYRE, N.E.; HOSTETLER, M.E. Effects of urban land use on pollinator (Hymenoptera: Apoidea) communities in a desert metropolis. Basic and applied Ecology, Washington, v. 2, n. 3, p. 209-218, 2001.

MECHI, M.R. Levantamento da fauna de vespas aculeata na vegetação de duas áreas de cerrado. 1996. 237 p. Tese (Doutorado em Ecologia) - Centro de Ciências Biológicas e da Saúde: Universidade Federal de São Carlos, São Carlos, 1996.

MENDES, E.; PROENÇA, E.B.; FERREIRA, I.M.P.L.V.O.; FERREIRA, M.A.Quality evaluation of portuguese honey. Carbohydrate Polymers, Valência, v.37, n.3, p. 219-223, 1998.

MICHENER, C.D. The social behavior of the bees, a compative study. Cambridge, Massachussetts: Belknap Press of Harvard Univ. Press. 1974. 404p.

MICHENER, C.D. Biogeography of the bees. Annals of the Missouri Botanical Garden, Missouri, v. 66, p. 277-347, 1979.

MORAES, R.M. de; MANTOVANI, D.M.B. Composição química de méis de diferentes fontes florais. In: CONGRESSO BRASILEIRO DE APICULTURA, 7, 1986, Salvador. Programa e Resumos: Salvador: Confederação Brasileira de Apicultura, 1986. p. 58. 
MORAES, R.M.; TEIXEIRA, E.W. Análise do mel. Pindamonhangaba: SN, 1998. 41p. (Manual técnico).

MORGADO, L.N. Fauna de abelhas (Hymenoptera: Apoidea) nas flores de girassol, Helianthus annus Linnaeus, 1753, em Lavras-MG. 2000. 41 p. Dissertação (Mestrado em Entomologia) - Universidade Federal de Lavras, Lavras, 2000.

MOTA, M.O.S.; NOGUEIRA-COUTO, R.H.; MALERBO-SOUZA, D.T.S. Polinização e uso de atrativos para as abelhas Apis mellifera em cultura de morango (Fragaria xananassa D.). In: ENCONTRO SOBRE ABELHAS, 2., 1996. Ribeirão Preto. Anais... Ribeirão Preto: Editora Edusp, 1996. p. 161.

MOURE, J.S. Notas sobre abelhas da coleção. Revista de Entomologia, Curitiba, v. 14, n.3, 447-84, 1943.

MOURE, J.S. Apoidea da coleção do Conde Amadeu A. Barbiellini. Revista de Entomologia, Curitiba, v. 15, n. 1/2, p. 1-18, 1944.

MUSTAFA, T.; MUSTAFA, D. Physicochemical analysis of Tokat region (Turkey) honeys. Advances in Food Sciences, Washington, v.24, n. 3, p. 125-127, 2002.

NATARAJAN, R.; YESUVADIAN, M.S. Project report for a honey concentration equipament. Indian Honey, v. 1, n. 1, p. 15-21, 1978./Resumo em CAB Abstracts on CD-ROM, 1984-86/.

NAUTA, V.S. di. Alcume caratteristiche merceologuche e commerciali del miele. Ind ustrie Alimentari, Pinerolo, v.22, n. 208, p. 624-629. 1983.

NEFF, J.L.; SIMPSON, B.B. Oil-collecting structures in the Anthophoridae (Hymenoptera): morphology, function and use in systematics. Journal Kansas Entomology Society, Kansas, v. 54, n. 1, p. 95-123, 1981.

NEFF, J.L.; SIMPSON, B.B. Bees, pollination systems and plant diversity. In: LASALLE, J., GAULD, I.D. (Ed.). Hymenoptera and biodiversity. Wallingford: CAB International, 1993. p. 143-167.

NOGUEIRA-COUTO, R. H.; CALMONA, R. C. Polinização entomófila em pepino (Cucumis sativus L. var. Aodai melhorada). Naturalia, São Paulo, v. 18, p. 77-82, 1993. 
NOGUEIRA NETO, P. A criação das abelhas in dígenas sem ferrão. São Paulo: Chácaras e Quintais, 1953.268p.

NOGUEIRA NETO, P. A criação de abelhas indígenas. 2. ed. Tecnapis: Chácaras e Quintais, 1970. 365p.

NOGUEIRA-COUTO, R. H.; PEREIRA, J. M. S.; COUTO, L. A. Estudo da polinização em Cucurbita pepo (abóbora italiana). Científica, São Paulo, v. 18, n. 1, p. 21-27, 1990.

NOGUEIRA-COUTO, R. H.; PEREIRA, J. M. S.; DE JONG, D. Pollination of Glycine wightii, a perenial soyabean, by Africanized honey bees. Journal of Apicultural Research, Cardiff, v. 37, n. 4, p. 289-291, 1998.

NOGUEIRA-COUTO, R. H. ; COSTA, J. A.; SILVEIRA, R. C. ; COUTO, L. A Polinização de Crotalaria juncea por abelhas nativas. Ecossistema, Campo Grande, v. 17, p. 12-16, 1992.

NOGUEIRA-COUTO, R. H.; COUTO, L. A. Polinização com abelhas Apis mellifera e abelhas sem ferrão. In: XIV CONGRESSO BRASILEIRO DE APICULTURA. Campo Grande, MS. 2002. Anais... Campo Grande. p. 251-256.

NOGUEIRA, R.H.F. Polinização. In: SIMPÓSIO SOBRE APICULTURA, 1984, Jaboticabal. Anais... Jaboticabal: Editora Edusp, 1984. p. 231.

ODUM, E.P. Ecologia. Rio de Janeiro: Guanabara Koogan, 1988. 434p.

OLEK, A.; STEINKRAUS, K.H.; MATTICHK, L.R.; MUEGO, K.; UNDERWOOD, B.A.; MORSE, R.A. Carbohydrate composition of two Nepalese honeys produced by Apis laboriosa and Apis cerana. Journal of Apicultural Research, Cardiff, v. 26, n.3, p. 203-204, 1987.

OLIVEIRA M.L.; CAMPOS, L.A. Abundância, riqueza e diversidade de abelhas Euglossinae em florestas contínuas de terra firme na Amazônia Central. Revista Brasileira de Zoologia, Curitiba, v. 12 , p. 546-56, 1995.

O'TOOLE, C. Diversity of native bees and agroecosystems. In: LASALLE, J.; GAULD, ID. (Eds.). Hymenoptera and Biodversity. Wallingford, England: CAB International. 1993. p. 431. 
PAMPLONA, B.C. Exame dos elementos químicos inorgânicos encontrados em méis brasileiros de Apis mellifera e suas relações fisico-biológicas. 1989. 131 p. Dissertação (Mestrado em Entomologia) - Instituto de Biociências, Universidade de São Paulo, São Paulo, 1989.

PAWLIKOWSKI, T.; HIRSCH, J. Bees (Hymenoptera: Apoidea) as indicators of xerisation processes in the lower Vistula Valley. Acta Zoologica, Cracoviensia, v. 45, n. 4, p. 321-336, 2002.

PEDRO, S.R.M. Sobre as abelhas (Hymenoptera: Apoidea) em um ecossistema de cerrado (Cajuru, NE do estado de São Paulo): Composição, fenologia e visita às flores. 1992. 164 p. Dissertação (Mestrado em Entomologia) - Faculdade de Filosofia, Ciências e Letras - Ribeirão Preto, Universidade de São Paulo, Ribeirão Preto, 1992.

PEDRO, S.R.M.; CAMARGO, J.M.F. Interactions on floral resources between the africanized honey bee Apis mellifera L. and native bee community (Hymenoptera: Apoidea) in a natural "cerrado" ecosystem, in southeast Brazil. Apidologie, Les Ulis, v. 22, n. 4, p. 397-415, 1991.

PEREIRA, J.G.; DENADAI, J.M.; HIANE, P.A.; ARÃO, A.; RAMOS Fº, M.M.; RAMOS, M.I.L. DENADAI, S.M.S. Mel de abelhas - análises de amostras comercializadas no município de Campo Grande-MS. Higiene alimentar, São Paulo, v. 2, n. 4, p. 213-216, 1983.

PERSANO-ODDO, L.P.; BALDI, E.; ACCORTI, M. Diastatic activity in some unifloral honey. Apidologie, Les Ulis, v. 21, p. 17-24, 1990.

PERSANO-ODDO, L.P.; PIAZZA, M.G.; SABATINI, A.G.; ACCORTI, M. Characterization of uniflora honeys. Apidologie, Les Ulis, v. 26, p. 453-465, 1995.

PERSANO-ODDO, L.P.; PIAZZA, M.G.; PULCINI, P. Invertase activity in Money. Apidologie, Les Ulis, v. 30, p. 57-65, 1999.

PEREZ-ARQUILLUÉ, C.; CONCHELLO, P.; ARIÑO, A.; JUAN, T. Estudio de algunos parametros fisico-quimicos en mieles monoflorales de Zaragoza. Alimentaria, Catalunia, v. $27, \mathrm{n}$. 213, p. 59-61, 1990.

PETROV, V. Mineral constituents of some Australian honeys as determined by atomic absorption spectrophotometry. Journal of Apicultural Research, Cardiff, v.9, n.2, p. 95-101, 1970. 
PFAU, L.A.; RUHLE, E.R. Concurso de mel: método de avaliar a qualidade do mel. In: CONGRESSO BRASILEIRO DE APICULTURA, 7., 1986, Salvador. Programa e Resumos: Salvador: Confederação Brasileira de Apicultura, 1986. p. 58-59.

PINHEIRO-MACHADO, C.; ALVES-DOS-SANTOS, I.; IMPERATRIZ-FONSECA, V.L.; KLEINERT, A. de M. P.; SILVEIRA, F.A. Brazilian bee surveys: State of knowledge, conservation and sustainable use. In: KEVAN, P.G. \& IMPERATRIZ-FONSECA, V.L. Pollinating bees: the conservation link between agriculture and nature. Brasilia: Ministry of Enviroment, 2002. $313 \mathrm{p}$.

PONCINI, L.; PRASAD, B.; SINGH, S.K. WIMMER, F.L. A survey of some Fijian honeys. New Zealand Journal of Science, Nova Zelândia, v. 27, n.2, p. 141-144, 1984./ Resumo em CAB Abstracts on CD-ROM, v.1, 1984-86/.

PREGNOLATO, W. Normas analíticas do Instituto Adolfo Lutz, v. 1. Métodos químicos e físicos para análise de alimentos. In: PREGNOLATO, W.; PREGNOLATO, N.P. (Coord.) 3 ed. São Paulo: Instituto Adolfo Lutz, 1985. 533p.

PRICE, P.W. Hypotheses on organization and evolution in herbivorous insec communities. In: DENNO, R.F.; McCLURE, M.S. (Ed.) Variable plants and herbivores in natural and managed systems. New York: Academic Press, 1982. p. 559-596.

PROCTOR, M.; YEO, P.; LACK, A. The natural history of pollination. London: Harper Collins Publishers, 1996. 479p.

RAJU, A.J.S.; RAO, S.P. Pollination ecology and fruiting behaviour in Acacia sinuata (Lour) Merr. (Mimosaceae), a valuable non-timber forest plant species. Current Science, Bangalore, v. 82 , n. 12, p. 1466-1471, 2002.

RAMALHO, M. A diversidade de abelhas (Apoidea- Hymenoptera) em um remanescente de floresta Atlântica, em São Paulo. 1995. 235 p. Tese (Doutorado em Entomologia) - Universidade de São Paulo, São Paulo, 1995.

RAMALHO, M.; KLEINERT-GIOVANNINI, A.; IMPERATRIZ-FONSECA, V.L. Important bee plants for stingless bees (Melipona e Trigonini) and africanized honeybess (Apis mellifera) in neotropical habitats: a review. Apidologie, Les Ulis, v. 21, p. 469-488, 1990. 
RAMALHO, M.; IMPERATRIZ-FONSECA, V.L.; KLEINERT-GIVANNINI, A.; CORTOPASSI-LAURINO, M. Exploration of floral resources by Plebeia remota Holmberg (Apidae, Meliponinae), Apidologie, Les Ulis, v.16, n.3, p.307-333, 1985.

RAMALHO, M.; GUIBU, L.S.; GIANNINI, T.C.; KLEINERT-GIOVANNINI, A.; IMPERATRIZ-FONSECA, V.L. Characterization of some southern Brazilian honey and bee plants through pollen análisis. Journal of Apicultural Research, Cardiff, v. 30, n. 2, p. 81-86, 1991.

RAO, M.A. Rheology of liquid foods - a review. Journal of Texture Studies, Les Ulis, v. 8, n. 2, p. 135-168, 1977.

RAW, A.; FREITAS, R.I.P.; FREITAS, G.S.; BOAVENTURA, M.C.; Hábelas silvestres do Distrito Federal; 1998. Available from: URL: http://www//unb.br/ib/zoo/publicacoes/raw2.htm. (23 jun 2005).

RENDÓN, S.R. Estudio de la composicion fisico-química de las mieles extremenas Y extranjeras. In: CONGRESSO IBERO LATINO AMERICANO DE APICULTURA, 5, 1996, Uruguai. Anais.., Mercedes: Intendência Municipal de Soriano. p. 174-183. 1996.

RIBEIRO, A.M.F. Polinização e uso de atrativos e repelentes para Apis mellifera L. em acerola (Malpighia emarginata D.C.), girassol (Helianthus annuus L.), maracujá (Passiflora edulis Sims) e soja (Glycine max Merrill). 2000.63 p. Dissertação (Mestrado em Entomologia) FCAV-UNESP, Jaboticabal, 2000.

RICKLEFS, R.E. A Economia da natureza. 3. ed. Rio de Janeiro: Editora Guanabara Koogan. 1996. 470p.

RODRIGUES, A.G.L.; MARCHINI, L.C.; HADDAD, M. de L. Índice de diastase e HMF de mel extraído de colméias expostas diretamente ao Sol e sombra. In: CONGRESSO BRASILEIRO DE APICULTURA, 11., 1996, Salvador. Anais... Confederação Brasileira de Apicultura, 1996. p. 342 .

RODRIGUEZ-OTERO, J.L.; PASEIRO, P.; SIMAL, J.; TERRADILLOS, L.; CEPEDA, A. Determination of $\mathrm{Na}, \mathrm{K}, \mathrm{Ca}, \mathrm{Mg}, \mathrm{Cu}, \mathrm{Fe}, \mathrm{Mn}$ and total cationic milliequivalents in Spanish comercial honeys. Journal of Apicultural Research, Cardiff, v. 31, n. 2, p. 65-69, 1992. 
ROUBIK, D.W. Africanized honey bees, stingless bees and structure of tropical plant-pollinator communities. INT. SYMP. POLL. MARYLAND AGRIC. EXP. STA. SPEC. MISC. PUBLI., 4, 1979. Maryland. Proceedings Maryland: Editora, Oxford, 1979. v. 1, p. 403-417.

ROUBIK, D.W.; MORENO, J.E.; VERGARA, C.; WITTMANN, D. Sporadic food competition with the African honey bees: projected impacto $\mathrm{n}$ neotropical social bees. Journal of Tropical Ecology, Cambridge, v. 2, p. 97-111, 1986.

ROUBIK, D.W. Ecology and natural history of tropical bees. Cambridge: Cambridge University Press, 1989.514p.

SAKAGAMI, S.F.; FUKUDA, H. Wild bee survey at the campus of Hokkaido University. Journal of the Faculty of Science, Hokkaido, v. 15, p. 190-250, 1973.

SAKAGAMI, S.F.; LAROCA, S. Relative abundance, phenology and flower visits of Apid bees in Eastern Paraná, South Brazil (Hym., Apidae). Kontyii, Otsu, v. 39, n. 3, p. 213-230, 1971.

SAKAGAMI, S.F.; LAROCA, S.; MOURE, J.S. Wild bees biocenotics in São José dos Pinhais (PR), South Brazil - preliminary report. Journal of the Faculty of Science, Hokkaido, v. 6, p. 253-291, 1967.

SAKAGAMI, S.F.; MATSUMURA, T. Relative abundance, phenology and flower preference of andrenid bees in Sapporo, north Japan (Hym., A poidae) Japanese Journal of Ecology, Otsu, v. 17 , n. 6 , p.237-250, 1967.

SALINAS, F.; ESOINOSA-MANSILLA, A.; BERZAS-VEVADO, J.J. Flor-injection determination of HMF in Money by Winkler method. Journal of Analytical Chemistry, Fresenius, v. 340, n. 4, p. 250-252, 1991.

SANCHO, M.T.; MUNIATEGUI, S.; HUIDOBRO, J.F. et al. Aging of Money. Journal of Agricultural and Food Chemistry, Ourense, v. 40, p. 134-138, 1992.

SANTOS, C.F.O. Principais tipos de pólen encontrados em algumas amostras de mel. Nota Prévia. Revista Agricultura, Cuiabá, v. 36, p. 93-96, 1961.

SANTOS, C.F.O. Avaliação do período de florescimento das plantas apícolas no ano de 1960, através do pólen contido nos méis e dos coletados pelas abelhas Apis mellifera L. Anais da Escola Superior de Agricultura Luiz de Queiroz, Piracicaba, v. 21, p. 253-264, 1964. 
SCHEREN, O.J. Apicultura Racional. 3. ed. São Paulo: Nobel, 1977. 110p.

SEEMANN, P.; NEIRA, M. Tecnologia de la producción apícola. Valdivia: Universidad Austral de Chile Facultad de Ciencias Agrarias Empaste, 1988. 202p.

SERRA-BONVEHI, J.; GRANADOS-TARRÉS, E. Physicochemical properties composition and pollen spectrum of ling heather (Calluna vulgaris (L) Hull) honey produced in Spain. Apidologie, Les Ulis, v. 24, p. 586-596, 1993.

SIHAG, R.C. Behaviour and ecology of the subtropical acarpenter bee, Xylocopa fenestrata F. 6. Foraging dynamics, crop hosts and pollination potential. Journal of Apicultural Research, Cardiff, v. 32, n. 2, p. 94-101, 1993.

SILBERBAUER-GOTTSBERGER, I.; GOTTSBERGER, G. A polinização de plantas do cerrado. Revista Brasileira Biologia, São Carlos, v. 48, n. 4, p. 651-663, 1988.

SILVA, R. M.B. Curso de apicultura. Nova Odessa. Instituto de Zootecnia. São Paulo, SP. 1985. 115p.

SILVEIRA, F.A. da. Abelhas silvestres (Hymenoptera: Apoidea) e suas fontes de alimento no cerrado da estação florestal de experimentação de Paraopeba - Minas Gerais. 1989. 50 p. Dissertação (Mestrado em Entomologia) - Universidade Federal de Viçosa, Viçosa, 1989.

SILVEIRA, F.A.; CAMPOS, M.J.O. A melissofauna de Corumbataí (SP) e Paraopeba (MG) e uma análise da biogeografia das abelhas do cerrado brasileiro (Hymenoptera, Apoidea). Revista Brasileira Entomologia, Curitiba, v. 39, n. 2, p. 371-401, 1995.

SILVEIRA, F.A.; ROCHA, L.B.; CURE, J.R.; OLIVEIRA, M.J.F. silvestres (Hymenoptera, Apoidea) da zona da mata de Minas Gerais. II. Diversidade, abundância e fontes de alimento em uma pastagem abandonada em Ponte Nova. Revista Brasileira Entomologia, Curitiba, v. 37, n. 3, p. 595-610, 1993.

SILVEIRA NETO, S.; NAKANO, O.; VILA NOVA, N.A. Manual de Ecologia dos Insetos. Piracicaba-SP: Ceres, 1976. 419p.

SIMAL, J.; HUIDOBRO, J. Parâmetros de calidde de la miel III. Acidez, (pH libre, lactónica \& total) e índice de formol. Offarm, Barcelona, v. 3, n. 9, p. 532, 1984. 
SMITH, F.G. Deterioration of the colour of honey. Journal of Apicultural Research, Cardiff, v. 6, n. 2, p. 95-98, 1967.

SODRÉ, G. S. Características físico-químicas e análises polínicas de amostras de méis de Apis mellifera L. 1758 (Hymenoptera: Apidae) da região litoral norte do estado da Bahia. 2000. 83 p. Dissertação (Mestrado em Entomologia) - Escola Superior de Agricultura "Luiz de Queiroz", Universidade de São Paulo, Piracicaba, 2000.

SODRÉ, G.S. Características físico-químicas, microbiológicas e polínicas de amostras de méis de Apis mellifera L., 1758 (Hymenoptera:

Apidae) dos estados do Ceará e Piauí. 2005. 127p. Tese (Doutorado em Entomologia) - Escola Superior de Agricultura "Luiz de Queiroz", Universidade de São Paulo, Piracicaba, 2005.

SODRÉ, G. da S. ; MARCHINI, L. C. ; ARRUDA, C. M. F. de ; LEVY, P. S. Viscosidade e umidade de amostras de méis de Apis mellifera provenientes de estados da região Nordeste do Brasil. In: SIMPÓSIO INTERNACIONAL DE INICIAÇÃO CIENTÍFICA DA UNIVERSIDADE DE SÃO PAULO, 10., 2002, Piracicaba. Anais... Piracicaba: Universidade de São Paulo, 2002. 1 CD Rbm.

SOFIA, S.H. As abelhas e suas visitas às flores em duas áreas urbanas. 1996. 236p. Tese (Doutorado em Zoologia) - Universidade Estadual de São Paulo "Júlio de Mesquita Filho", Rio Claro, 1996.

SOMMEIJER, M.J.; ROOY, G.A.; PUNT, W.; BRUIJN, L.L.M. A comparative study of foraging behaviour of pollen resources of various stingless bee (Hymenoptera, Meliponinae) and honeybees (Hymenoptera, Apinae) in Trindad, West-Indies. Apidologie, Les Ulis, v. 14, n. 3, p. 205 224, 1983.

SOUZA, V.C.; CORTOPASI-LAURINO, M.; SIMÃO-BIANCHINI, R.; PIRANI, J.R.; AZOUBEL, M.L.; GUIBU, L.S.; GIANNINI, T.C. Plantas apícolas de São Paulo e arredores. Instituto de Biociências. São Paulo. p. 143-178, 1993. ESALQ/USP.

SPETTOLI, P.; CECCHINI, A.; MATCOVICH, P. Indigene sulle caratteristiche fisico-chimiche di mieli del Frluli Orientale. Industrie Alimentari, Pinerolo, v.22, n. 210, p. 849-858, 1983.

STADELMEIER, M.; BERGNER, K.G. Proteine des Bienenhonigs. VII. Eigenschaften und Herkunft der Honigamylase. Zeitschrift für Lebensmittel-Untersuchung und Forschung, Berlin, v. 182, p. 196-199, 1986. 
TABIO, C.; ALVAREZ, J.D.; BERISIARTU, M. Preliminary characterization of some physicochemical and organoleptic characteristics of Citrus honeys from Jaguey Grande, Matanzas. Ciencia y Tecnica en la Agricultura - Apicultura, v.3., p.29-39, 1987./Resumo em CAB Abstracts on CD-ROM, V.3A, 1990-91/.

TAKENAKA, T.; ECHIGO, T. Changes in enzyme activity during the storage of Money. Bulletin of the Faculty of Agricultura, Tamagawa, n. 14, p. 19-25, 1974.

TAURA, H.M. A comunidade de abelhas silvestres (Apoidea) do Passeio Público, Curitiba, PR, sul do Brasil: uma abordagem comparativa. 1990. 144 p. Dissertação (Mestrado em Entomologia) - Universidade Federal do Paraná, Curitiba, 1990.

TEMIZ, A.I. Composition and characteristics of honeys from the Izmir region, and effects of different storage methods. Ege Bolge Zirai Arstirma Enstitusu Yayinlari, Berlin, v.31, n.11, p.113, 1983./Resumo em CAB Abstracts on CD-ROM, 1986-86.

TERRAB, A.; GONZALEZ, A.G.; DIEZ, M.J.; HEREDIA, F.J. Mineral content and electrical conductivity of the honeys produced in Northwest Morocco and their contribution to the caracterisation of unifloral honeys. Journal of the Science of Food and Agriculture, Hoboken, v. 83, n.7, p. 637-643, 2003.

THRASYVOULOU, A.T. The use of HMF and diastase as criteria of quality of greek honey. Journal of Apicultural Research, Cardiff, v. 25, n. 3, 186-195, 1986.

TOLEDO-FILHO, D.V. Composição florística e estrutura fitossociológica da vegetação de cerrado do município de Luis Antônio (SP). 1984. 173 p. Dissertação (Mestrado em Ecologia) - Instituto de Biociências, UNICAMP, Campinas, 1984.

TOOD, F.E.; MCGREGOR, S.E. The use of honey bees in the production of crops. Annual Review Entomology, Palo Alto, v. 5, p. 265-278, 1960.

TOSI, E.A.; RE, E.D.; CAZZOLI, A.F.; BALLERINI, G.; TAPIZ, L.M.; ORTEGA, M. Tipification and characterization of honeys from Santa Fe province (Argentina). Alimentaria, Catalunya, v.40, n. 341, p. 65-71, 2003.

UÑATES, M.A.; AGUILAR, A.B.; PIOLA, H.D.; STURNIOLO, H.L.; AGUILAR, G.; PEDERNERA, M.M. Estudio fisico-químico de mieles de la provincia de San Luis-República Argentina. Archivos Latinoamericanos de Nutrición, Acapulco, v. 49, n. 2, p. 193-196, 1999. 
VANSELL, G.H.; GRIGGS, W.H. Honeybees as agents of polination. Estados Unidos. Department of Agriculture. Insects: the yearbook of agriculture. Washington, D.C. 1952. p. 88-107.

VIDAL, R.; FREGOSI, E.V. Mel: características, análises físico-químicas, adulterações e transformações. Barretos: Instituto Tecnológico Científico "Roberto Rios", 1984. 95p.

VILLAMIEL, M.; DEL CASTILHO, M.D.; CORZO, N.; OLANO, A. Presence of furosine in honeys. Journal of the Science of Food and Agriculture, Hoboken, v. 81, n. 8, p. 790-793, 2001.

VIT, P.; PULCINI, P. Diastase and invertase activities in Meliponini and Trigonini honeys from Venezuela. Journal of Apicultural Research, Cardiff, v. 32, n. 2, p. 57-62, 1996.

WHITE JÚNIOR, J.W. A survey of American honeys. 7. Relation of color to composition. Bee Culture, Medina, v. 89, p. 292-293, 1961.

WHITE JÚNIOR, J.W. Honey. Advances in Food Research. Davis, v. 22. p. 287-374, 1978.

WHITE JÚNIOR, J.W. Honey. In: The hive and the honey bee. Hamilton: Dadant, 1984. p. 491-530.

WHITE JÚNIOR, J.W. Quality evaluation of honey: role of HMF and diastase assays. Part II. American Bee Journal, Hamilton, v. 132, n. 12, p. 792-794, 1992.

WIESE, H. Nova Apicultura. 5 ed. Porto Alegre: Agropecuária, 1984. 482p.

WIESE, H. Nova Apicultura. 6 ed. Porto Alegre: Agropecuária, 1985. 491p.

WILLE, A. Biology of stingless bees. Annual Review Entomology, Palo Alto, v. 28, p. 41-64, 1983.

WILLIAMS, N.M.; TEPEDINO, V.J. Consistent mixing of near and distant resources in foraging bouts by the solitary mason bee Osmia lignaria. Behavioral Ecology, Oxford, v. 14, n.1, p. 141149, 2003. 
WILSON, E.O. The insect societes. Cambridge, The Belkmap Press of Harward Univ. Press, 1972. 548p.

YEBOAH-GYAN, K.; MARFO, E.K. The colour and mineral composition of honeys produced in major vegetation áreas of Ghana. Journal of Apicultural Research, Cardiff, v. 37, n. 2, p. 79-84. 1998.

ZANNELA, F.C.V. Estrutura da comunidade de abelhas silvestres (Hymenoptera, Apoidea) da Ilha do Mel, planície litorânea paranaense, sul do Brasil. 1991. 88 p. Dissertação (Mestrado em Entomologia) - Universidade Federal do Paraná, Curitiba, 1991. 